\title{
Fundamental Research on Percussion Drilling: Improved rock mechanics analysis, advanced simulation technology, and full- scale laboratory investigations
}

\author{
DE-FC26-03NT41999 \\ Final Report $\left(2^{\text {nd }}\right.$ Version, Edited by DOE) \\ Period Start: Jan 01, 2004 \\ Period End: Dec 31, 2005
}

Prepared by:

Terralog Technologies Inc (USA)

332 E. Foothill Blvd., Suite B

Arcadia, CA 91006

Phone: (626) 305-8460

Fax: (626) 305-8462

Email:msbruno@terralog.com 


\section{DISCLAIMER}

This report was prepared as an account of work sponsored by an agency of the United States Government. Neither the United States Government nor any agency thereof, nor any of their employees, makes any warranty, express or implied, or assumes any legal liability or responsibility for the accuracy, completeness, or usefulness of any information, apparatus, product, or process disclosed, or represents that its use would not infringe privately owned rights. Reference herein to any specific commercial product, process, or service by trade name, trademark, manufacturer, or otherwise does not necessarily constitute or imply its endorsement, recommendation, or favoring by the United States Government or any agency thereof. The views and opinions of authors expressed herein do not necessarily state or reflect those of the United States Government or any agency thereof. 


\begin{abstract}
This report summarizes the research efforts on the DOE supported research project Percussion Drilling (DE-FC26-03NT41999), which is to significantly advance the fundamental understandings of the physical mechanisms involved in combined percussion and rotary drilling, and thereby facilitate more efficient and lower cost drilling and exploration of hard-rock reservoirs.

The project has been divided into multiple tasks: literature reviews, analytical and numerical modeling, full scale laboratory testing and model validation, and final report delivery. Literature reviews document the history, pros and cons, and rock failure physics of percussion drilling in oil and gas industries. Based on the current understandings, a conceptual drilling model is proposed for modeling efforts. Both analytical and numerical approaches are deployed to investigate drilling processes such as drillbit penetration with compression, rotation and percussion, rock response with stress propagation, damage accumulation and failure, and debris transportation inside the annulus after disintegrated from rock. For rock mechanics modeling, a dynamic numerical tool has been developed to describe rock damage and failure, including rock crushing by compressive bit load, rock fracturing by both shearing and tensile forces, and rock weakening by repetitive compression-tension loading. Besides multiple failure criteria, the tool also includes a damping algorithm to dissipate oscillation energy and a fatigue/damage algorithm to update rock properties during each impact. From the model, Rate of Penetration (ROP) and rock failure history can be estimated. For cuttings transport in annulus, a 3D numerical particle flowing model has been developed with aid of analytical approaches. The tool can simulate cuttings movement at particle scale under laminar or turbulent fluid flow conditions and evaluate the efficiency of cutting removal.

To calibrate the modeling efforts, a series of full-scale fluid hammer drilling tests, as well as single impact tests, have been designed and executed. Both Berea sandstone and Mancos shale samples are used. In single impact tests, three impacts are sequentially loaded at the same rock location to investigate rock response to repetitive loadings. The crater depth and width are measured as well as the displacement and force in the rod and the force in the rock. Various pressure differences across the rock-indentor interface (i.e. bore pressure minus pore pressure) are used to investigate the pressure effect on rock
\end{abstract}


penetration. For hammer drilling tests, an industrial fluid hammer is used to drill under both underbalanced and overbalanced conditions. Besides calibrating the modeling tool, the data and cuttings collected from the tests indicate several other important applications. For example, different rock penetrations during single impact tests may reveal why a fluid hammer behaves differently with diverse rock types and under various pressure conditions at the hole bottom. On the other hand, the shape of the cuttings from fluid hammer tests, comparing to those from traditional rotary drilling methods, may help to identify the dominant failure mechanism that percussion drilling relies on. If so, encouraging such a failure mechanism may improve hammer performance.

The project is summarized in this report. Instead of compiling the information contained in the previous quarterly or other technical reports, this report focuses on the descriptions of tasks, findings, and conclusions, as well as the efforts on promoting percussion drilling technologies to industries including site visits, presentations, and publications. As a part of the final deliveries, the 3D numerical model for rock mechanics is also attached. 


\section{Table of Contents}

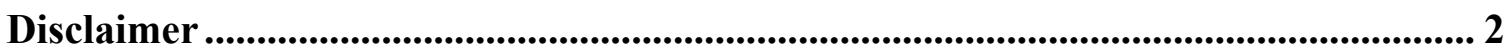

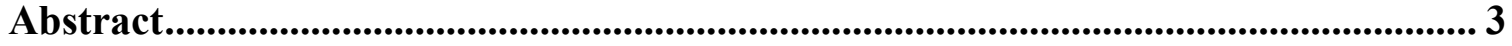

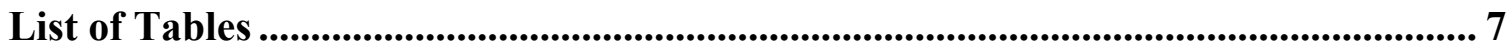

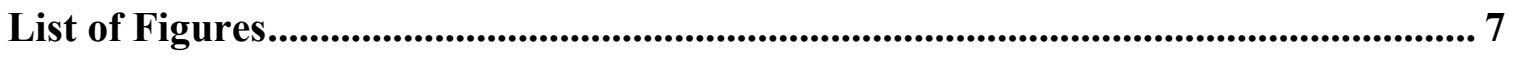

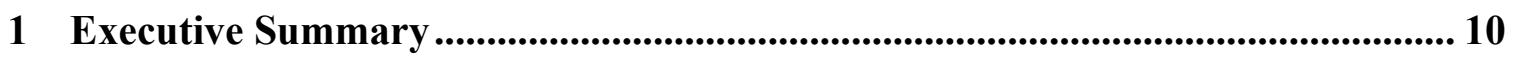

2 Project Outline .............................................................................................................. 13

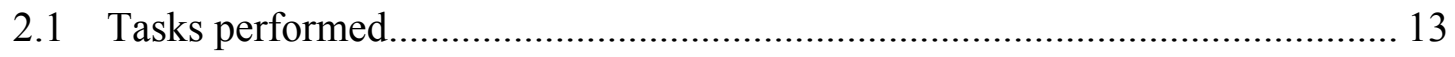

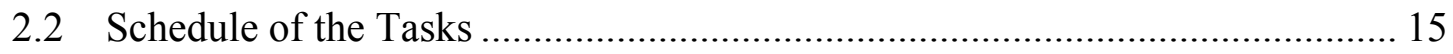

3 Literature Reviews................................................................................ 17

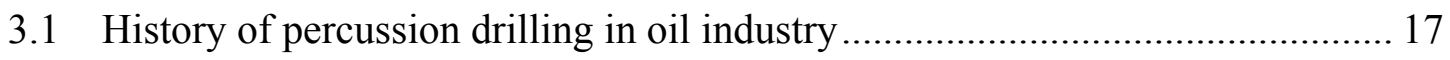

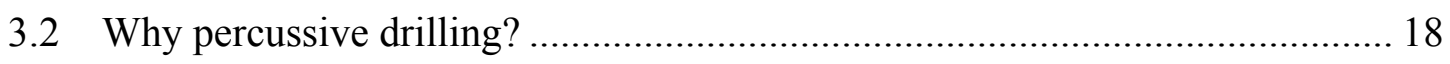

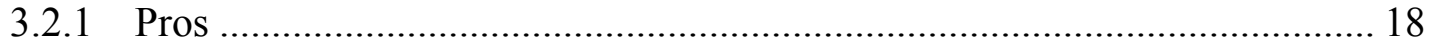

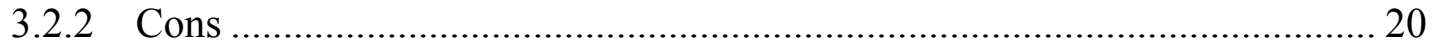

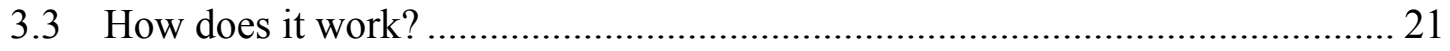

4 Modeling Efforts ......................................................................................................... 23

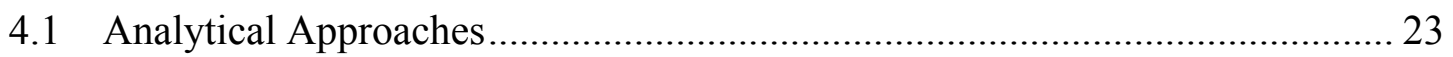

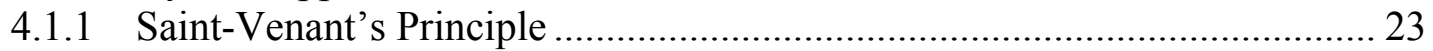

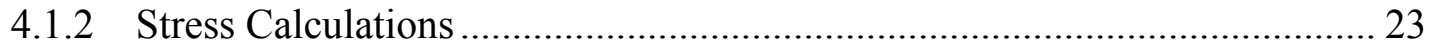

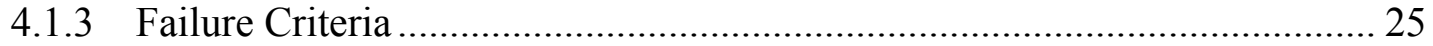

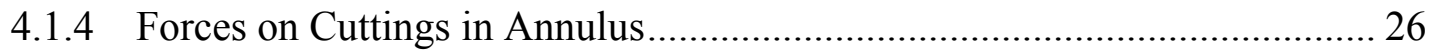

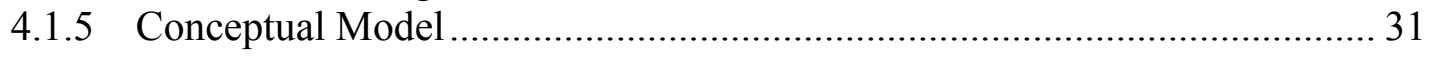

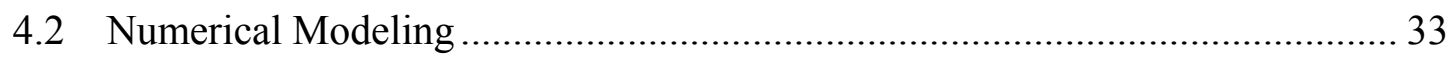

4.2.1 Selection and Confirmation of Numerical Tools ....................................... 34

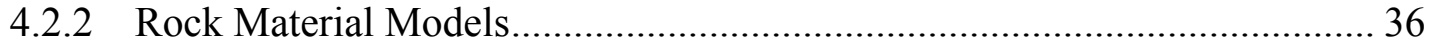

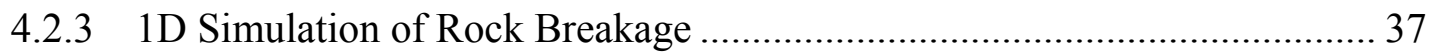

4.2.4 3D Dynamic Simulation of Rock Breakage............................................ 39

4.2.5 Numerical Simulation of Cuttings Transport............................................. 55

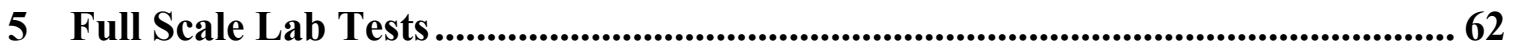

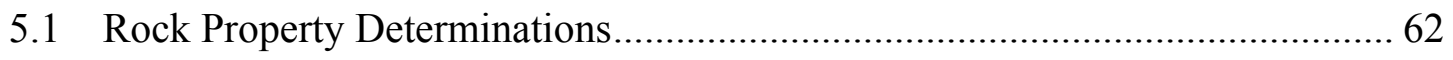

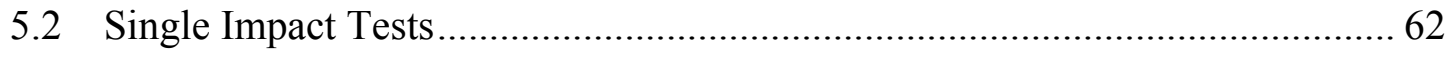

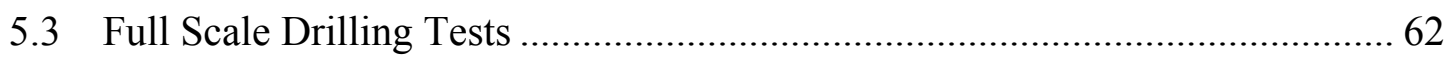

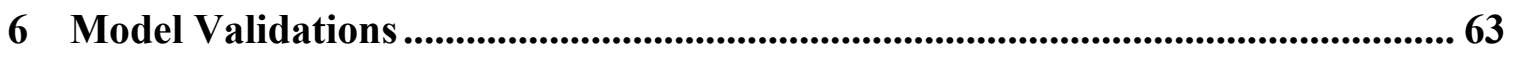

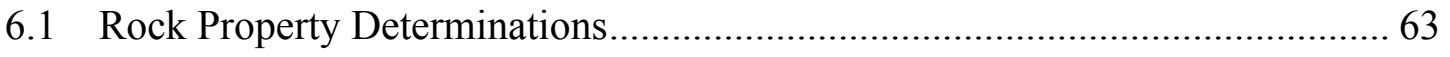

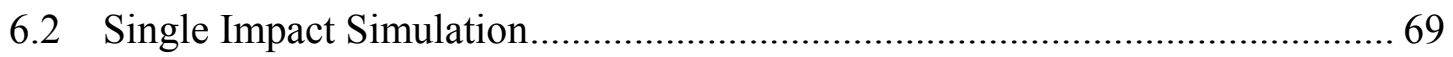




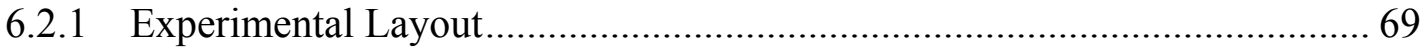

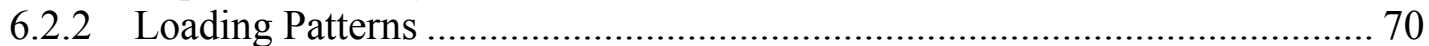

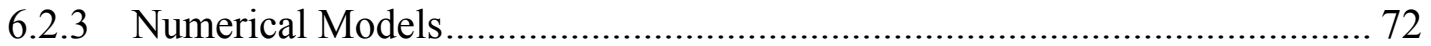

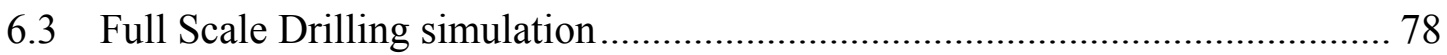

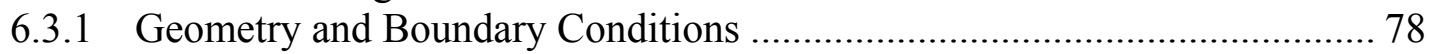

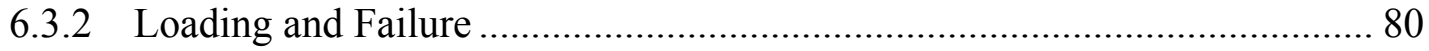

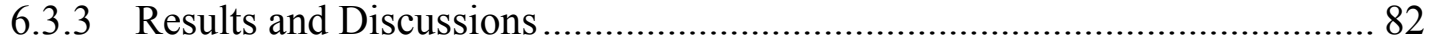

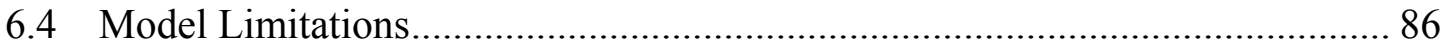

7 Summary of Findings and Deliveries .................................................................... 87

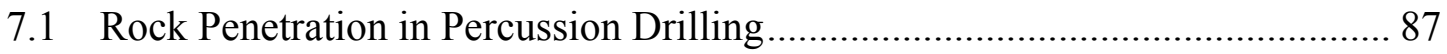

7.2 Cuttings Transport and Mud Circulation .................................................. 91

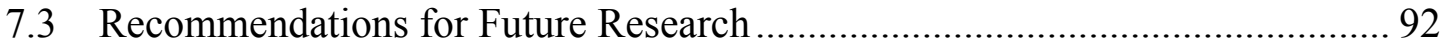

7.4 Site Visit, Presentations and Publications......................................................... 94

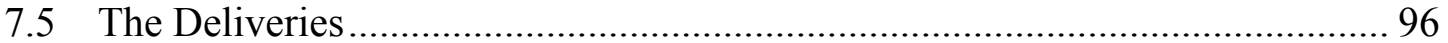

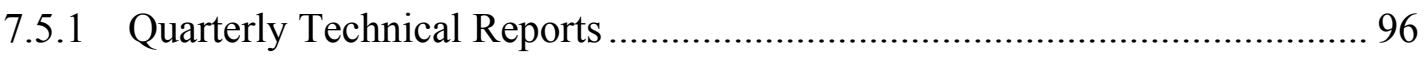

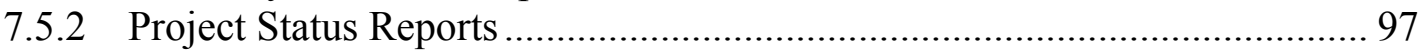

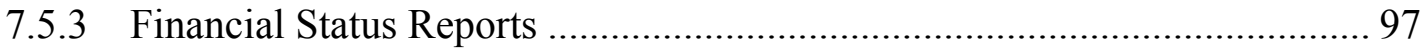

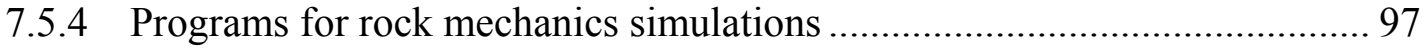

List of Acronyms and Abbreviations ...................................................................... 99

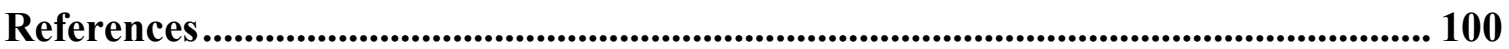

Appendix A: Numerical Program for Single Impact.............................................. 109

Appendix B: Numerical Program for Hammer Drilling............................................ 110 


\section{LIST OF TABLES}

Table 2-1. Schedule for Tasks Carried out for DOE Percussion Drilling ...................... 16

Table 4-1. Data for FLAC3D simulations of a surface load acting on a half-space

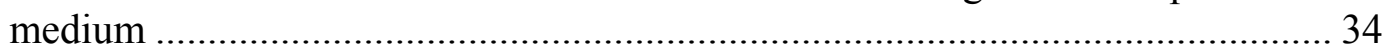

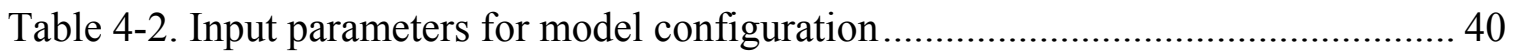

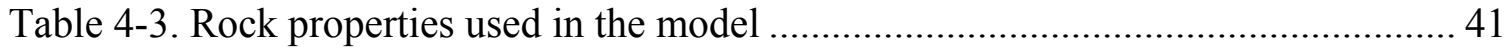

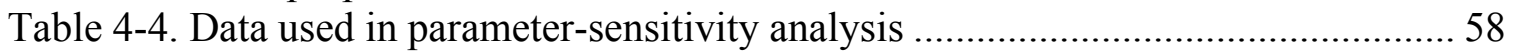

Table 4-5. Data for PFC3D simulations on cuttings transportation...............................59

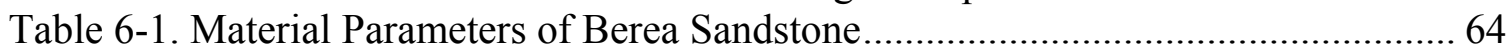

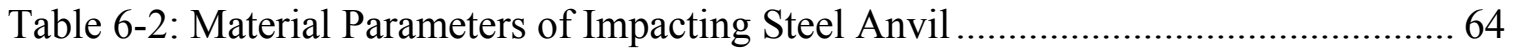

\section{LIST OF FIGURES}

Figure 3-1. Rock defragmentation in rotary and percussion drillings .......................... 21

Figure 3-2. Rock damage due to cyclic loadings (after Haimson, 1978) ....................... 22

Figure 4-1. Analytical solutions for point loading on a half-infinite elastic medium..... 24

Figure 4-2. Rock vertical displacement upon circular uniform loading ........................ 24

Figure 4-3. Contour plot of shear stress xz for point shearing.................................. 25

Figure 4-4. Drag coefficient with Reynolds number for a spherical particle ................. 27

Figure 4-5. Velocity profile of axial flow in annulus for Newtonian fluid flow ............. 29

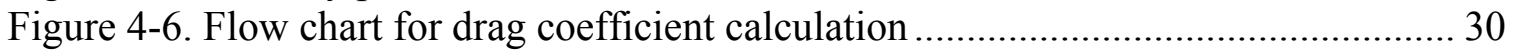

Figure 4-7. Conceptual model for percussion drilling ................................................ 33

Figure 4-8. Comparison of analytical and numerical stress solutions for point shear load

Figure 4-9. Comparison of analytical and numerical stress solutions for distributed shear

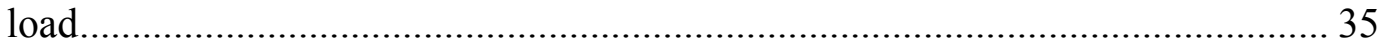

Figure 4-10. Rock Material Models: elastic, MC perfect plastic, MC strain softening... 36

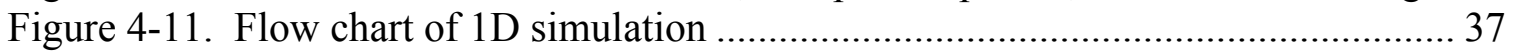

Figure 4-12. Dynamic modeling rock breakage for 1 column rock model...................... 38

Figure 4-13. Rock penetration for 1 column rock model........................................... 39

Figure 4-14. Configuration of 3D dynamic rock modeling ....................................... 40

Figure 4-15. Flowchart for 3D dynamic simulation .................................................. 43

Figure 4-16. Rock vertical velocity at the impact surface (large damping, $f_{c}=10000$,

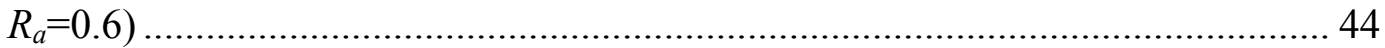

Figure 4-17. Rock vertical velocity at the impact surface (medium damping, $f_{c}=10000$,

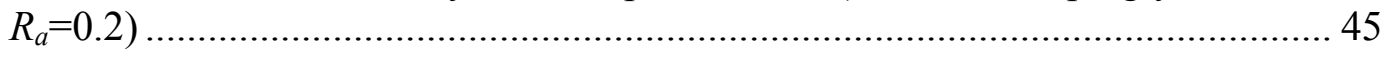

Figure 4-18 Rock vertical velocity at the impact surface (no damping)........................ 45

Figure 4-19. Development of damage during cyclic impacts .................................... 46

Figure 4-20. Rock vertical stress in the loading direction at the end of impact (unit: $\mathrm{Pa}$ ) 
Figure 4-21. Rock vertical stress $\left(\sigma_{\mathrm{zz}}\right)$ in the loading direction at the end of bit retreat

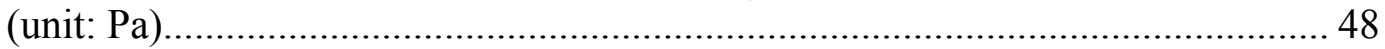

Figure 4-22. Rock shear stress $\left(\tau_{\mathrm{xz}}\right)$ at the end of impact (unit: Pa) .............................. 48

Figure 4-23. Velocity profile of the first impacted element without bit advancement (unit:

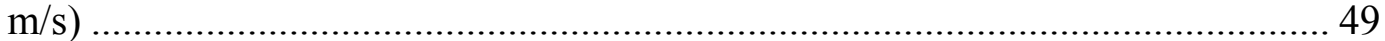

Figure 4-24. Number of damaged rock elements after the $1^{\text {st }}$ impact............................ 50

Figure 4-25. Number of damaged rock elements after the $2^{\text {nd }}$ impact............................ 50

Figure 4-26. Number of damaged rock elements after $3^{\text {rd }}$ impact ............................... 51

Figure 4-27. Number of damaged rock elements after $4^{\text {th }}$ impact ............................... 51

Figure 4-28. Number of damaged rock elements after $5^{\text {th }}$ impact ................................ 52

Figure 4-29. History for each fatigued/damaged element without bit advancement ....... 52

Figure 4-30. Rock velocities close to the impact surface with bit advancement and mud

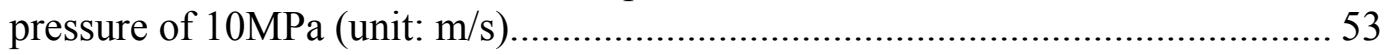

Figure 4-31. Distribution of rock vertical stress after bit advancement of $0.5 \mathrm{~m}$ (unit: $\mathrm{Pa}$ )

54

Figure 4-32. Bit advancement with and without bottom hole pressure ......................... 55

Figure 4-33. Drillpipe configuration in cuttings transportation .................................... 55

Figure 4-34. Different particles configurations in cuttings transport ........................... 56

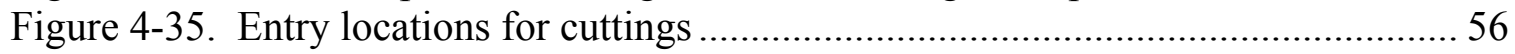

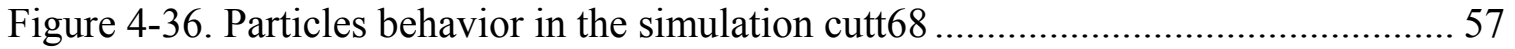

Figure 4-37. Modeling cuttings transport with PFC3D .............................................. 59

Figure 4-38. Cuttings transport in a vertical well with slow pipe rotation and mud

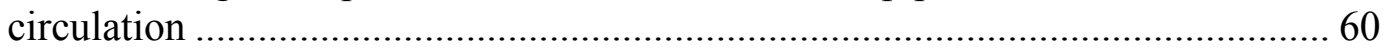

Figure 4-39. Cuttings transport in a vertical well with fast pipe rotation and mud

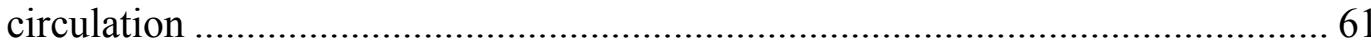

Figure 4-40. Inefficient cuttings transport due to slow mud circulation.......................... 61

Figure 6-1. Reflected and transmitted displacement waves in a layered elastic medium. 65

Figure 6-2. Reflected and transmitted stress waves in a layered elastic medium............ 66

Figure 6-3. Principal stress differences of Berea sandstone under different confinements.

Figure 6-4. Principal stress differences versus volume changes for three triaxial

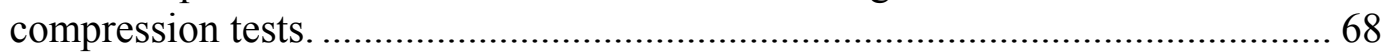

Figure 6-5. Tensile stress versus tensile strain for Berea sandstone.............................. 69

Figure 6-6. Top view of impacted Berea sandstone specimen .................................... 69

Figure 6-7. Schematic representation of test setup for impact on Berea sandstone ......... 70

Figure 6-8. Geometric layout of numerical model with symmetry taken into consideration

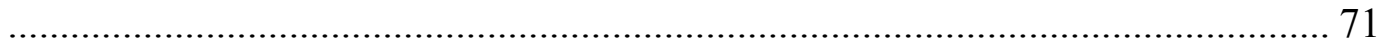

Figure 6-9. Compression and tensile waves applied to top surface of impacting rod ...... 72

Figure 6-10. Resultant applied load obtained from superposition of compressive and

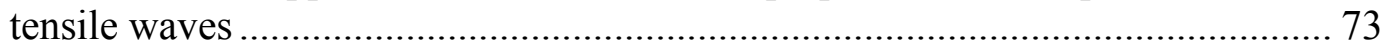

Figure 6-11. Geometric layout of reduced model .......................................................... 74

Figure 6-12. Comparison of experimental (red) and numerical values (blue) of axial

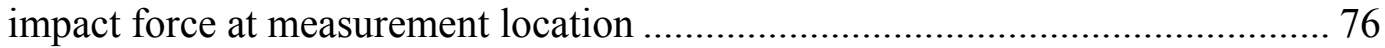

Figure 6-13. Time history of incoming force recorded at the bottom of the rock specimen 
Figure 6-14. Time history of the axial displacements of the anvil recorded at the top surface (red line) and at the strain gage location (blue line) ............................. 77

Figure 6-15. Axial displacement of top surface and at the strain gage location of the

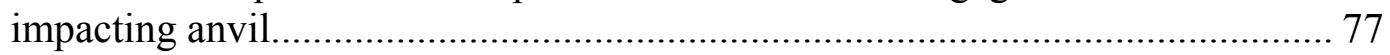

Figure 6-16. Contour plot of the plastic strain distribution in Berea sandstone ............... 78

Figure 6-17: Geometric layout, and initial vertical stress distribution of the 3-D drilling

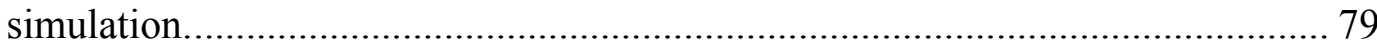

Figure 6-18: Detailed view of impact area and borehole............................................. 80

Figure 6-19: Applied load as a function of time applied to the bottom surface of the borehole, duration of impact and separation time............................................. 81

Figure 6-20: Change in cohesion $(\mathrm{Pa})$ below the borehole due to fatigue damage at 30.83

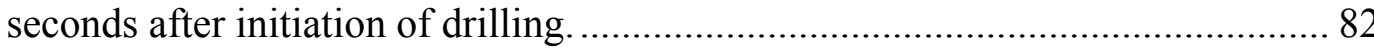

Figure 6-21: Change in the angle of friction below the borehole due to fatigue damage at 30.83 seconds after initiation of drilling.

Figure 6-22: Contour plot of plastic strain distribution below the borehole due to fatigue damage at 30.83 seconds after initiation of drilling. The limit of 5\% is reached in one element and the layer is about to fail.

Figure 6-23: Contour plot of plastic strain distribution below the borehole after removal of top three layers. Time is 30.87 seconds after initiation of drilling.

Figure 6-24: Contour plot of plastic strain distribution below the borehole after removal of additional three layers. Time is 54.88 seconds after initiation of drilling (1097 impacts).

Figure 6-25: Contour plot of plastic strain distribution below the borehole at 83.71 seconds after initiation of drilling (1674 impacts). A total of nine layers have been removed since start of drilling. 85

Figure 6-26: The increase of depth of the borehole as a function of time. The total time of the simulation is 83.71 seconds (1674 impacts). This corresponds to a ROP of $0.0026 \mathrm{~m} / \mathrm{sec}$. 86

Figure 7-1. Cuttings from drilling tests (Left: roller cone; Middle: hammer underbalance;

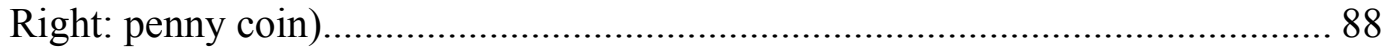

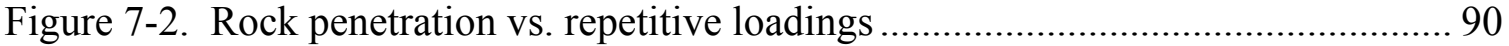

Figure 7-3. ROP data for a hammer drilling in Berea Sandstone and Mancos Shale, and for a baseline roller-cone Bit in Berea Sandstone 


\section{EXECUTIVE SUMMARY}

Under the DOE contract (DE-FC26-03NT41999), Terralog Technologies, Inc. (TTI) has carried out a research project, Fundamental Research on Percussion Drilling: Improved Rock Mechanics Analysis, Advanced Simulation Technology, and Full-Scale Laboratory Investigations. The objective of this research is to significantly advance the fundamental understandings of the physical mechanisms involved in combined percussion and rotary drilling, and thereby facilitate more efficient and lower cost drilling and exploration of hard-rock reservoirs. This final report summarizes TTI research achievements from Jan 1, 2004 to Dec 21, 2005.

The estimated yearly cost to drill hard rock in the US is $\$ 1,200$ million dollars (MM). Potential savings of $\$ 200 \mathrm{MM}$ to $\$ 600 \mathrm{MM}$ are possible if the penetration rate in hard rock is doubled with the assumption that bit life is reasonable (Tibbitts et al., 2002). It has been widely recognized that percussion drilling (even without rotary) has potential to provide faster penetration than conventional rotary drill or diamond drill, especially in some hard formations such as granite, sandstone, limestone, dolomite, etc. Besides a large increase of Penetration (ROP), percussion drilling improves hole geometry, reduces drillstring stresses, generates better and larger cuttings, and lowers the cost per foot substantially. On the other hand, negative factors such as inclusive overall results, risks in operation (such as mechanical failure), poor understanding and therefore control of drilling processes, and economical uncertainties greatly jeopardize the acceptance of percussion drilling technology into oil and gas industries. As a consequence, there is no such numerical, analytical, or empirical model available for drilling engineers as what exists in conventional rotary drilling.

First, intensive literature reviews have covered a wide range of topics such as rock drilling, rock excavation, rock fragmentation, rock quarrying, boring, and soil digging in multi-disciplines such as Petroleum Engineering, Rock Engineering, Tunnel Engineering, Mining Engineering, Mechanical Engineering, and Quarry Engineering. Different theories have been exploited including damage mechanics, failure mechanics, rock dynamics, fracture mechanics, penetration mechanics, etc. As a highlight of the review, a 
conceptual physical model for percussion drilling has been proposed. Three main processes involved in percussion drilling are summarized for modeling efforts, such as drillbit penetration with compression, rotation and percussion, rock response with stress propagation, damage accumulation and failure, and debris transportation inside the annulus after disintegrated from rock.

Based on the conceptual model, analytical efforts are laid out. Three failure mechanisms are proposed to account for rock damage and failure during bit-rock interactions, including rock crushing by compressive bit load, rock fracturing by both shearing and tensile forces, and rock fatigue by repetitive compression-tension type of loading. Possible theoretical candidates, including stress wave theory, damage mechanics, and elastoplastic continuum stress theory, are proposed for theoretical development of rock defragmentation, along with some empirical correlations. Using Saint-Venant's principle, a set of analytical solutions for vertical normal loading in the shapes of point, line, and circular, and shear loading on the surface of a semi-infinite elastic medium have been developed. The results are compared and confirmed with numerical solutions. With fluid dynamics coupled with particle mechanics, cuttings transport is investigated both at macroscopic and microscopic levels. Fluid dynamics is coupled with particle mechanics so that not only macroscopic fluid behavior but the effect of solid particles on mud flow at microscopic level can be described either as a Newtonian or non-Newtonian, laminar or turbulent flow.

As a result of these developments, numerical simulations of stresses in rock around bit and cuttings transport in annulus are carried out with numerical tools such as Finite Element Modeling code FLAC3D and Discrete Element Modeling code PFC3D, which were selected for this project after a review of available FEM and DEM codes. First, one column elements subjected to static and periodic vertical loadings with/without confining stress are simulated. Different material models are tested, including elastic model, MohrCoulomb model, and Strain Softening (SS) model. After comparing the results, a preference of SS model is selected for further development. Next, various failure criteria, such as strain-based failure criteria (critical strain and critical shear plastic strain criteria), 
and tensile criteria, are applied to determine when, where, and how rock fails after postyield state. A Rayleigh damping feature is used to dissipate excessive oscillation energy, while a fatigue/damage algorithm updates rock properties due to cyclic loading. Significant gains have been achieved in terms of stress wave propagation, rock damage and failure, and dynamic responses of rock with percussive loading patterns. For example, it has been found that compressive failure due to high impact force may cause dominant rock failure during bit-rock contact, while rock may fail in tension if there is not enough bottom hole pressure acting on the exposed rock surface. The latter may explain why hammer drilling performs better under underbalanced pressure condition.

For cuttings transport, the discrete particle models are developed. Cuttings are introduced as either spherical particles or particle clumps, and continuous cuttings generation is achieved. Both axial flow with and without pipe rotation, and cuttings generated from both inside drillbit slots and whole bit area are simulated. Parameters that affect carrying capacity of drilling fluid are investigated, such as pump rate (i.e. mud circulation rate), fluid viscosity and density, particle shape and mass, rotation per minute (RPM), and ROP. Their effects on fluid flow transport efficiency and particle behaviors are detailed. These accomplishments capture fundamental physics of cuttings transport in annulus, including interactions between cutting particles, fluid viscous drag force due to velocity difference between fluid and particles, cuttings settlement due to buoyancy force and gravity force, and a turbulent flow resulting from particle radial movement (i.e. from the center to the surface of pipe). With intensive visualization efforts, a set of interesting movies have been generated during each simulation.

To verify the theoretical models, a series of laboratory tests, including both full-scale fluid hammer tests and single impact tests, are executed. Both Berea sandstone and Mancos shale are used as samples. Their mechanical properties, including moduli, Poisson's ratio, cohesive strength, friction angle, tensile strength, etc., are first determined from confined triaxial tests and Brazilian tests. For each impact test, three impacts are sequentially loaded at the same rock location to investigate rock response to repetitive loadings. After each impact, crater depth and width are measured and rock 
debris is washed to leave a clean rock surface for the next impact. Meanwhile both the displacement and force in the rod and the force in the rock are recorded at high frequency levels of about $100 \mathrm{KHz}$. Various pressure differences across the rock-indentor interface (i.e. bore pressure minus pore pressure) are implemented to investigate the pressure effect on rock penetration. For hammer drilling tests, Smith International provided the use of their mud-hammer bit which was used to drill Berea sandstone and Mancos shale under both underbalanced and overbalanced conditions. Water-based mud of $1.2 \mathrm{~g} / \mathrm{cm}^{3}$ density circulates fast enough to clear failed rocks at the hole bottom. During the tests, Rate of Penetration is recorded continuously from one pressure condition to another. Cuttings are collected and analyzed after the tests. Besides calibrating the modeling tool, the data and cuttings collected from the tests indicate several other important applications. For example, different rock penetrations during single impact tests may reveal why a fluid hammer behaves differently with diverse rock types and under various pressure conditions at the hole bottom. On the other hand, the shape of the cuttings from fluid hammer tests, in comparison to those from traditional rotary drilling methods, may help to identify the dominant failure mechanism that percussion drilling relies on. If so, encouraging such a failure mechanism may improve hammer performance.

These achievements significantly advance the fundamental understandings of the physical mechanisms involved in percussive-rotary drilling, and thereby may facilitate more efficient and lower cost drilling and exploration of hard-rock reservoirs.

\section{PROJECT OUTLINE}

\subsection{Tasks performed}

Based on TASKS TO BE PERFORMED in the contract, a detailed outline of the project is listed below:

\section{Task 1 Technology Reviews}

Subtask 1.1 Review hammer drilling in petroleum industry 
Subtask 1.2 Review penetrating with vibrating in mining, boring, tunneling, cutting, excavating, and defragmenting applications and modeling efforts

Subtask 1.3 Review failure criterion and damage mechanics

Subtask 1.4 Review cuttings transport, especially in annulus

Task 2 Analytical Modeling of PD mechanisms

Subtask 2.1 Develop conceptual physical model and setup prototypes for rock, bit, and debris flow

About rock behavior:

Subtask 2.2 Determine physical processes involved in rock reactions to percussive-rotary drill, describe boundary and loading conditions

Subtask 2.3 Calculate stress/strain redistributions around borehole under rotary-percussive drilling conditions

Subtask 2.4 Develop criteria and algorithms for rock crushing, damage, and fracturing, as well as their effects on rock properties

About Cuttings transport:

Subtask 2.5 Develop constitutive models to describe cuttings transport as a Newtonian/non-Newtonian laminar flow

Subtask 2.6 Develop constitutive models for non-Newtonian turbulent flow in annulus

\section{Task 3 Numerical Modeling of PD processes}

Subtask 3.1 Evaluate state-of-art approaches such as FEM and DEM codes About rock behavior:

Subtask 3.2 Evaluate and test elastic stress wave with FLAC3D, investigate the possibility of describing moving boundary and damage accumulation in FLAC3D elements

Subtask 3.3 Calculate poroelastic and elastoplastic stress distributions around a static drilling wellbore, and describe damages and update rock properties with number of impacts 
Subtask 3.4 Investigate factors affecting ROP such as Weight on Bit (WOB), Uniaxial Compressive Strength (UCS), RPM, etc, and compare results with analytical solutions

\section{About Cuttings transport:}

Subtask 3.6 With PFC3D, analyze cuttings transport as a Newtonian/NonNewtonian fluid flowing laminarly with constant circulation rate and debris volume

Subtask 3.7 Analyze cuttings transport as a Non-Newtonian fluid flowing turbulently

Subtask 3.8 Investigate factors affecting mud circulation such as density, viscosity, velocity, drilling equip geometry, etc, and compare results with analytical solutions

Subtask 3.9 Couple drilling process and cuttings transport models

Task 4 Full-scale laboratory testing and model validation Task 5 Develop graphical display and deliver the final report

\subsection{Schedule of the Tasks}

The time schedule for the above tasks is laid out in Table 2-1. Most tasks are completed on schedule. Technology review has been finished within the first quarter of 2004, followed by the start of analytical modeling studies where the conceptual physical model has been developed. Based on an intensive review of current numerical tools and the conceptual model, numerical modeling efforts have been carried out with aid of FLAC3D. After nine months of development, the prototype of rock model and cuttings transport model has been completed. In order to validate the theoretical models, the lab tests have been scheduled at the beginning of 2005. However, a delay in experiment setup and problems in the pretests have postponed the tests to the second quarter of the year. Meanwhile, TerraTek has provided some previous single impact tests with Carthage Marble and Crab Orchard Sandstone so that we could start the model calibrations as early as possible. After simulating single impact and full scale laboratory tests, a final report has been submitted, as well as the drilling model developed. 


\begin{tabular}{|c|c|c|c|c|c|c|c|c|c|c|c|c|c|c|c|c|c|c|c|c|c|c|c|c|c|c|}
\hline \multirow[b]{3}{*}{ ID } & \multirow[b]{3}{*}{ Task Name } & \multicolumn{12}{|c|}{ Year of 2004} & \multicolumn{13}{|c|}{ Year of 2005} \\
\hline & & \multicolumn{3}{|c|}{ 1st Quarter } & \multicolumn{3}{|c|}{ 2nd Quarter } & \multicolumn{3}{|c|}{ 3rd Quarter } & \multicolumn{3}{|c|}{ 4th Quarter } & \multicolumn{3}{|c|}{ 1st Quarter } & \multicolumn{3}{|c|}{ 2nd Quarter } & \multicolumn{3}{|c|}{ 3rd Quarter } & \multicolumn{3}{|c|}{ 4th Quarter } & \multirow{2}{*}{\begin{tabular}{|l|} 
1st Q \\
Jan
\end{tabular}} \\
\hline & & Jan & Feb & Mar & Apr & May & Jun & Jul & Aug & Sep & Oct & Nov & Dec & Jan & Feb & Mar & Apr & May & Jun & Jul & Aug & Sep & Oct & Nov & Dec & \\
\hline 1 & Technolgoy Review & & & & & & & & & & & & & & & & & & & & & & & & & \\
\hline 2 & $\begin{array}{l}\text { Review hammer drilling in petroleum } \\
\text { industries }\end{array}$ & & & & & & & & & & & & & & & & & & & & & & & & & \\
\hline 3 & $\begin{array}{l}\text { Review hammer drilling in other } \\
\text { industries and modeling efforts }\end{array}$ & [ & & & & & & & & & & & & & & & & & & & & & & & & \\
\hline 4 & Review cuttings transport & & & & & & & & & & & & & & & & & & & & & & & & & \\
\hline 5 & $\begin{array}{l}\text { Review failure criterion and damage } \\
\text { mechanics }\end{array}$ & & - & & & & & & & & & & & & & & & & & & & & & & & \\
\hline 6 & Analytical Modeling Effort & & & & & & & & & & & & & & & & & & & & & & & & & \\
\hline 7 & $\begin{array}{l}\text { Develop a conceptual physical model } \\
\text { for rock, bit, and debris flow }\end{array}$ & & - & & & & & & & & & & & & & & & & & & & & & & & \\
\hline 8 & $\begin{array}{l}\text { Review and develop analytical } \\
\text { approach for cuttings transport }\end{array}$ & & & & & & & & & & & & & & & & & & & & & & & & & \\
\hline 9 & $\begin{array}{l}\text { Develop analytical model for rock } \\
\text { stress, failure and damage }\end{array}$ & & & & & & & & & & & & & & & & & & & & & & & & & \\
\hline 10 & Numerical Modeling Effort & & & & & & & & & & & & & & & & & & & & & & & & & \\
\hline 11 & $\begin{array}{l}\text { Investigate FLAC3D capacities, } \\
\text { analyze elastic w ave propagation }\end{array}$ & & & ᄃ & & & & & & & & & & & & & & & & & & & & & & \\
\hline 12 & $\begin{array}{l}\text { Analyze PFC3D capacities, describe } \\
\text { cuttings transport with constant mud } \\
\text { flow ing rate }\end{array}$ & & & L & & & & & & & & & & & & & & & & & & & & & & \\
\hline 13 & $\begin{array}{l}\text { Calculate elastoplastic stresses } \\
\text { around a drilling w ellbore, update rock } \\
\text { damages } w \text { ith drilling progress }\end{array}$ & & & & & & & & & & & & & & & & & & & & & & & & & \\
\hline 14 & $\begin{array}{l}\text { Study the sensitivity of cuttings } \\
\text { transport }\end{array}$ & & & & & & & & & & & & & & & & & & & & & & & & & \\
\hline 15 & Laboratory Tests and Model Verificatic & & & & & & & & & & & & & & & & & & & & & & & & & \\
\hline 16 & Single Impact Tests & & & & & & & & & & & & & & & & & & & & & & & & & \\
\hline 17 & Fluid Hammer Drilling Tests & & & & & & & & & & & & & & & & & & & & & & & & & \\
\hline 18 & Data Processing & & & & & & & & & & & & & & & & & & & & & & & & & \\
\hline 19 & Model Verifications & & & & & & & & & & & & & & & & & & & & & & & & & \\
\hline 20 & Final Report and Deliveries & & & & & & & & & & & & & & & & & & & & & & & & & \\
\hline
\end{tabular}

\section{Table 2-1. Schedule for Tasks Carried out for DOE Percussion Drilling}




\section{LITERATURE REVIEWS}

Hard rock regions in the US include, but are not limited to, the Rockies, Tuscaloosa trend, Anadarko basin, Cretaceous limestones, several areas in Texas, as well as deep Gulf of Mexico formations; worldwide interest include Bolivia, Colombia, Egypt, Argentina, Kazakhstan, South East Asia, and Oman. The estimated yearly cost to drill hard rock in the US is $\$ 1,200 \mathrm{MM}$. Potential savings of $\$ 200 \mathrm{MM}$ to $\$ 600 \mathrm{MM}$ are possible if the penetration rate in hard rock is doubled with the assumption that bit life is reasonable (Tibbitts et al., 2002).

\subsection{History of percussion drilling in oil industry}

Developed by the Chinese more than 4000 years ago, percussion drilling is basically the raising and dropping of heavy piercing tools to cut and loosen earth materials. The Chinese used a cutting head secured to bamboo rods, that were linked together to drill to depths of 3000 feet $(915 \mathrm{~m})$. The raising and dropping of the bamboo drill string allowed it to impact and fracture the less dense rock formations. It was reported to often take two to three generations of workers to complete large wells (Treadway, C., 1997).

In 1859 at Titusville, Pennsylvania, Colonel F. L. Drake completed the first oil well using a cable tool percussion-type machine. One of the earliest reports of percussion drilling technique occurred in 1949 (Harpst and Davis, 1949). Since then different terms have been used, such as downhole hammer, percussion hammer, Down-The-Hole hammer, percussive drill, percussive-rotary drill, etc.

Major developments and research in percussion drilling have been reported between the 1950s and 1960s (Wanamaker, 1951; Faihust and Lacabanne, 1956; Topanelian, 1958; Fish, 1961; Simon, 1964; Hartman, 1966; McGregor, 1967). Significant gains in understanding the percussive mechanism have been achieved in lab. Some single-well applications have been reported in oilfields for the purpose of demonstrating the effectiveness of percussion drilling (Smith and Kopczynksi, 1961; Bates, 1964). 
Mainly because of frequent mechanical failures, poor understanding with regard to the control of drilling operations, and economical uncertainties, a wide application of hammer drilling technology to oilfields was not reported until the 1980s. In 1987, Pratt reported that air hammers were tested on 27 wells in Alberta and British Columbia. Average time to total depth for recent air/mud drilled wells at Jumping Pound has been 80 days (best 66 days), compared to the record mud-drilled well which took 103 days. Whiteley and England (1986) also showed the field applications of air hammer in the Arkoma basin, which has significantly improved air drilling operations including a large increase in ROP, improved hole geometry, reduced drillstring stresses, and a substantial reduction in cost per foot.

Since the 1990s, oil wells have been drilled deeper and deeper, and consequently, with increasing depth, the rocks become harder and harder. An hydraulic hammer or water hammer has been developed to accommodate these new challenges and efficient mechanical designs have been achieved (Kong et al, 1996; Giles et al, 2001; Tibbitts et al, 2002). These designs, however, are still in pre-field stage.

Throughout its history, theoretical development of percussion drilling technology has relatively lagged behind, compared to its improvement in mechanical designs. This phenomenon is not uncommon in the drilling industry as the integrated process of rock drilling involves so many disciplines and complicated physics that modeling it rigorously faces prohibitive theoretical challenges.

\subsection{Why percussive drilling?}

\subsubsection{Pros}

It has been widely recognized that percussion drilling (even without rotary) can result in penetration faster than conventional means such as rotary drill or diamond drill, especially in hard formations such as siliceous granite, sandstone, limestone, dolomite, etc (Whiteley and England, 1986; Pratt, 1987). With the same rotation and WOB the percussive-rotary method is 7.3 times faster than the conventional rotary method in a 
medium-hard granite, while at the best operational conditions for both methods, percussive-rotary has a 2.3 times advantage in ROP over the rotary (Melamed, 2000).

This advantage is mainly due to the effects of frequent blows and high impact loads through bit teeth, as well as chipping of rock from a clean surface with the bit rotation. Other advantages of percussion drilling are:

- Static and lower WOB. For example, ROP of $3.3 \mathrm{~m} / \mathrm{h}$ was achieved with the $8^{3 / 4}$ inch bit when WOB is 4.5 tons. While in rotary drilling mode, 18.5 tons of WOB is needed to achieve the same ROP (Melamed, 2000);

- Less contact time with rock, only one or two percent of total operational drilling time (Bates, 1965; Melamed et al, 2000), which leads to less abrasion of the bit and therefore a longer bit life;

- Hammering force reduces the use of other bottomhole assembly;

- Less hole deviation and easier control of deviation problems for straight hole drilling, because the fracturing pattern of the bit tooth is arranged in a conical shape directed downward in line with the striking force; and,

- Larger cuttings may be generated, giving a better representation for geological study. Meanwhile large-sized chips may lead to hole cleaning problems in the fast-drilled larger holes (Pratt, 1987).

Some potential applications of percussion drilling have been proposed, such as:

- The impact of the hammer also provides a steady seismic signal at the bottom of the hole by means of mechanical impact waves transmitted to the rock through the drill bit, and also by means of hydraulic pressure fluctuations in the borehole (Figure 5). Particular vibrational energy can be seen in the 10 to $20 \mathrm{kHz}$ range, which has been found useful for acoustic wireline and logging while drilling tools. Such tools have been used to estimate porosity, elastic moduli of the rock, and synthetic seismograms for comparison with surface seismic data (Minear et al., 1996);

- Hammer may be used as a steerable drilling device that provides down-hole rotation (Bui 1995); and, 
- Impact energy may be exploited for down-hole electricity generation, down-hole high-pressure jet intensification, etc.

Because of these attractions, it has been predicted that “...The combination of rotary and percussion-type drilling could make a frontal attack into the drilling technology and open a new era of drilling." (Samuel, 1996)

\subsubsection{Cons}

On the other hand, inclusive overall results, risks in operation (such as mechanical failure), and economical uncertainties greatly jeopardize the acceptance of percussion drilling technology by operators, even though it has been a hot topic for both oil and gas drilling for a long time. There are many unclear but critical issues yet to be solved, such as:

- Unreliable estimation of optimized values for hammer type, number of blows, energy per blow (which is directly related to length of the stroke, area of piston, supplied pressure), etc. The best ROP with acceptable economics lies more on the basis of field experience rather than a convincing theory;

- Hammer bits (cutters) may get balled and lose the ability to drill ahead;

- Wellbore stability issues associated with excessive hammer energy, such as cavity creation in shale, wellbore collapse due to reaming or vibration;

- Poor performance in shale and other soft rocks;

- Severe vibration to the drill string and the rig structure;

- Little field evidence of continuous operations of percussion hammers in oil industries; and,

- No evidence of the performance in either directional, horizontal wells, slim hole drilling, or coiled tubing drilling.

Therefore a wide acceptance of percussion drilling may not come until these critical issues have been addressed so that more confidence can be gained. 


\subsection{How does it work?}

In rotary drilling, bit rotation produces both impact and shearing forces, which may result in two types of rock failures (see Figure 3-1): crushing because of an axial thrust from the weight on bit (WOB), and fracturing because of shear cutting force.

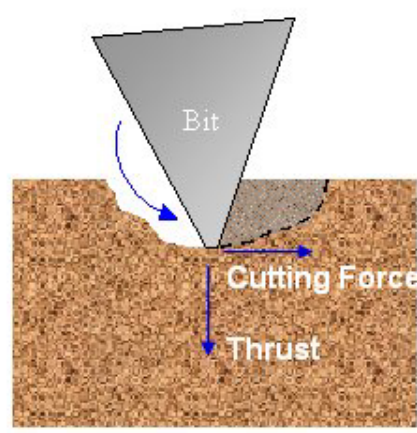

Rotary Drilling Process

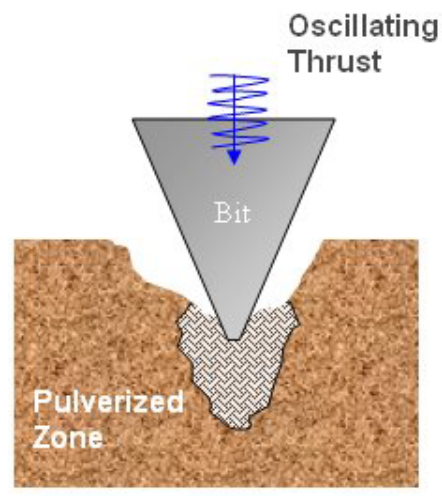

Percussion Drilling Process

Figure 3-1. Rock defragmentation in rotary and percussion drillings

Without bit rotation, rock damages after bit-rock impact in percussive drilling are carried out in several stages (White, 1969). At first, the force developed between the bit inserts and the rock builds slowly, and gradually the surface irregularities are crushed and compacted. Then a rapid increase of the force starts, and subsurface cracks develop in the rock radiating out from the lines of stress concentration at the outer boundaries of the bit inserts. Two main cracks form along a narrow wedge in the rock, which is then crushed and compacted, and the force rises less rapidly. The crushed zone may extend to a depth several times greater than the actual depth of bit penetration (Faihust and Lacabanne, 1956). Finally, large fragments are suddenly fractured out along a curved trajectory up to the surface adjacent to the crushed zone (i.e. in the form of flat conchoidal flakes). As the side walls for the crushed wedge are removed, the force drops. A new rock surface is now available. The process is repeated if failed rock is cleared efficiently from the impact surface.

Because hammer blows can be delivered at a rate of 1500 to 3000 per minute while the longitudinal wave velocity in drill-steel is around $5200 \mathrm{~m} / \mathrm{s}$ (Roberts, 1981), loading force 
on the rock oscillates dramatically, generated by the stress waves from both the initial blow and the reflected pulses along the drilling rod. This leads to another possible important mechanism for rock failure during this type of drilling: rock fatigue due to cyclic loading.

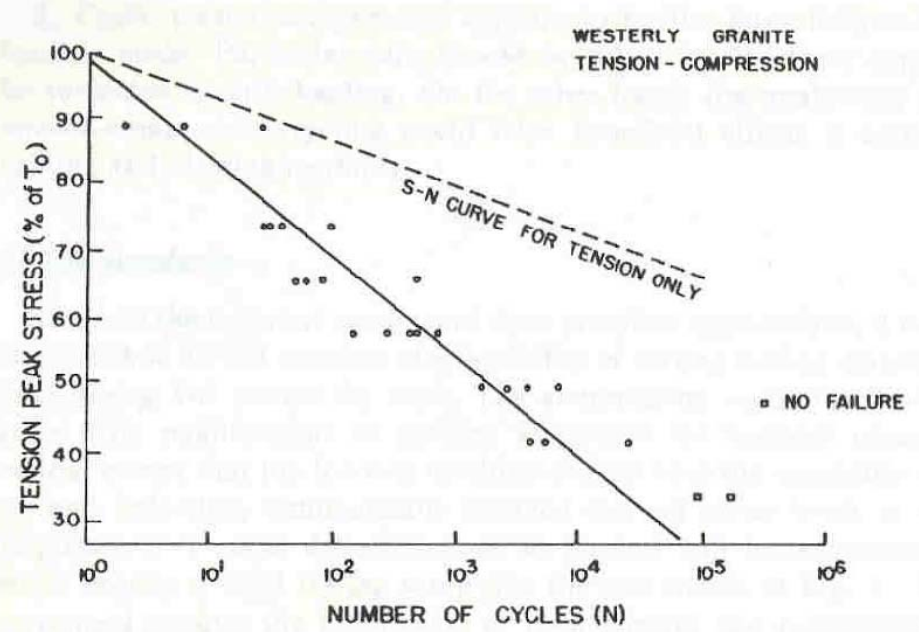

Figure 3-2. Rock damage due to cyclic loadings (after Haimson, 1978)

In general, it is clear for various rocks such as marble, limestone, sandstone, and granite that repetitive loading of any type can weaken rock strength and results in premature rock failure (e.g. Haimson, 1978). In the uniaxial tension-compression loading, which is likely to be the case in percussion drilling during bit-rock interactions, the strength lost due to accumulated damage can be as high as 75 percent of uniaxial compressive strength (UCS). This type of rock damage has not been systematically studied until the late 1970s, when percussive drilling lost its attractions to the oil industry due to its high risks and uncertainties. We believe, however, this is one of the fundamental mechanisms for rock damage during percussion drilling, and may explain why this type of drilling is much faster than traditional rotary drilling and that the rock to be drilled has already been weakened and more easily fractured due to the development of microfractures. One goal of lab tests is to confirm this damage theory and verify the theoretical damage model developed in this project. 


\section{MODELING EFFORTS}

\subsection{Analytical Approaches}

In order to model the sophisticated percussion drilling, significant simplifications and assumptions have been made. Justifying such simplifications involves not only experimental confirmations, but also the introduction of some famous principles such as Saint-Venant's principle.

\subsubsection{Saint-Venant's Principle}

The principle of Saint-Venant allows us to simplify the solution of drilling dynamics by altering the boundary conditions while keeping the systems of applied forces statically equivalent. If a system of forces, acting on a small portion of the surface of an elastic body, is replaced by another statically equivalent system of forces acting on the same portion of the surface, the redistribution of loading produces substantial changes in the stresses only in the immediate neighborhood of the loading. The stresses are essentially the same in the part of the body which are at large distances in comparison with the linear dimension of the surface on which the forces are changed (Saada, 1974).

\subsubsection{Stress Calculations}

To lay down bases of analytical efforts to describe rock stresses under different loading conditions, i.e. both vertical periodic circular loading from axial hammer movement and shearing torsion from hammer rotation are considered, four types of loadings on a semiinfinite isotropic elastic medium have been solved analytically:

1) A point normal force acting on the surface of a semi-infinite solid;

2) A uniform normal line loading on a part of surface of a semi-infinite solid;

3) A uniform circular loading on the surface of a semi-infinite solid; and,

4) A tangential point loading on the surface of a semi-infinite solid.

The analytical equations developed for stress profile for each above case are listed in the report 41999R04.doc. The summaries are plotted in the following figures. 

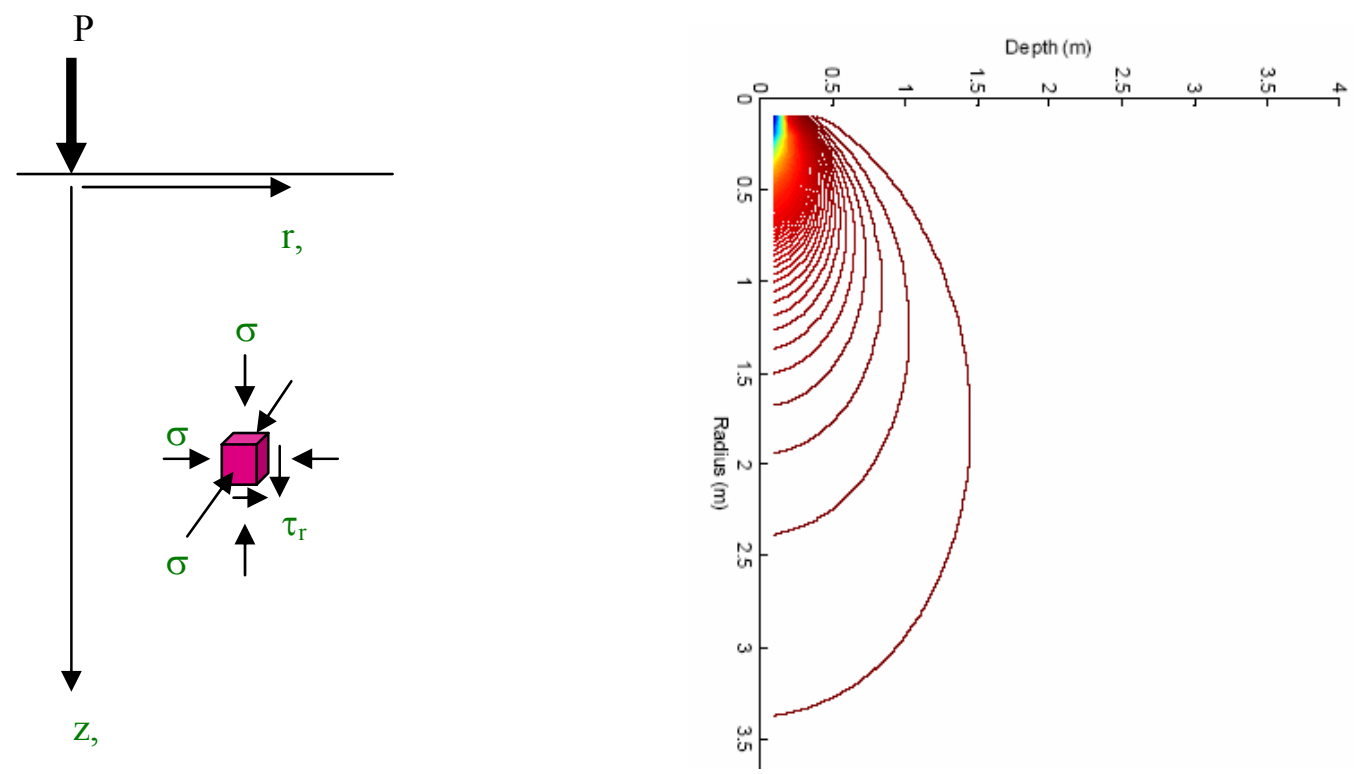

Figure 4-1. Analytical solutions for point loading on a half-infinite elastic medium
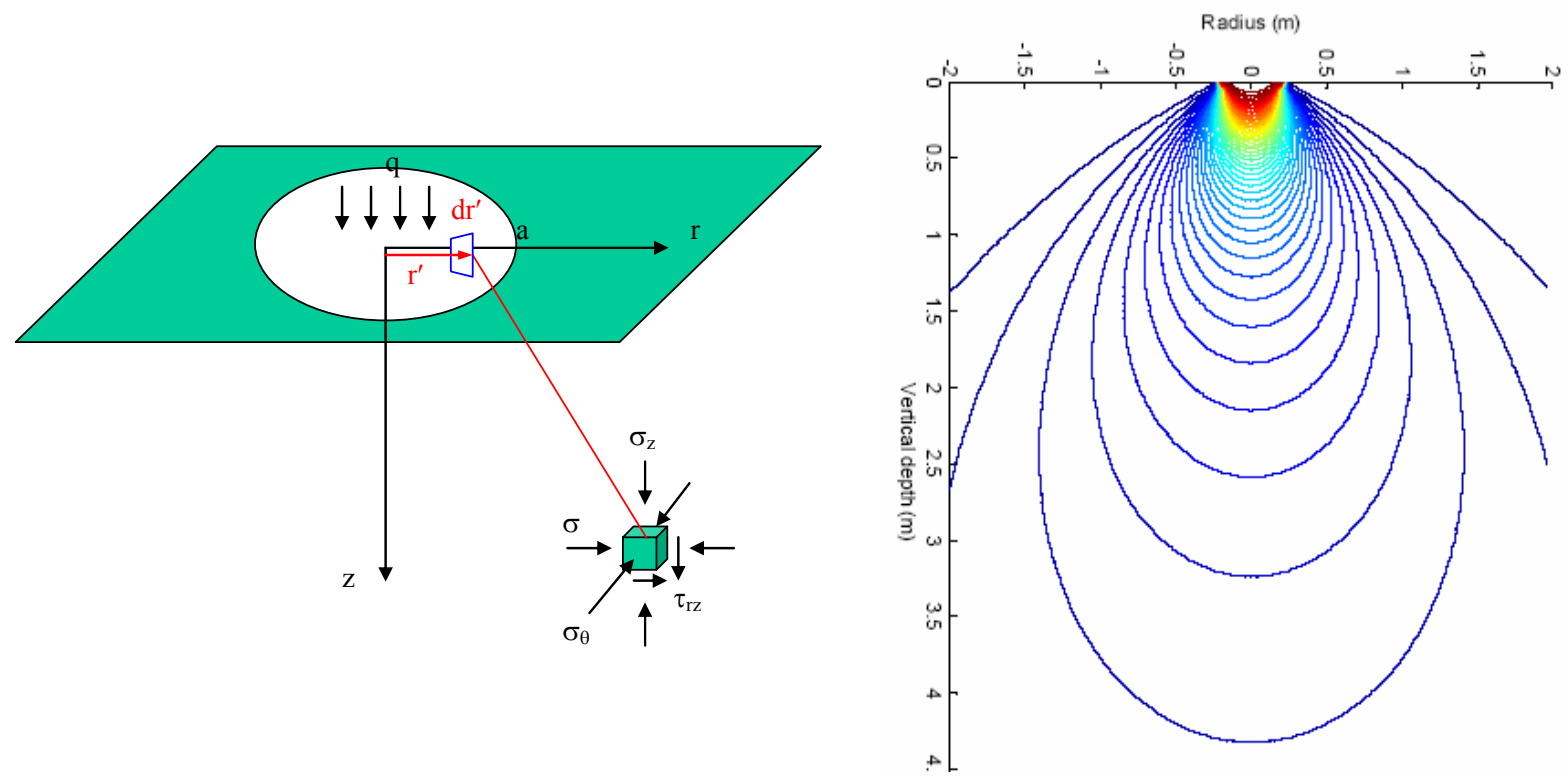

Figure 4-2. Rock vertical displacement upon circular uniform loading 

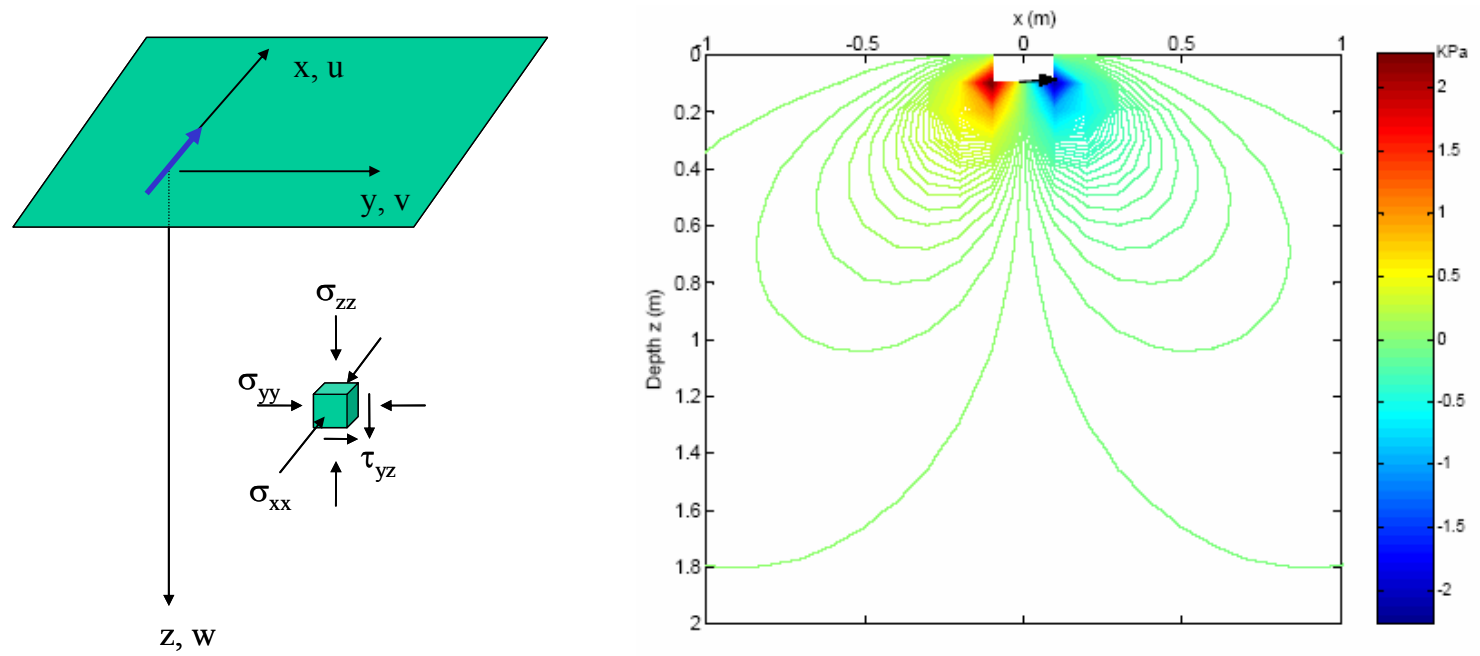

Figure 4-3. Contour plot of shear stress $x z$ for point shearing

\subsubsection{Failure Criteria}

Three rock failure criteria are applied. Failure can occur due to 1) excessive compressive strain; 2) excessive plastic shear strain; 3) excessive tensile stress. The rock is assumed to completely lose its ability to support further loading after failure.

\section{Compressive failure}

A critical compressive strain is proposed to describe when rock fails due to excessive compressional strain in loading direction:

$$
\varepsilon_{z z}>\bar{\varepsilon}_{z}
$$

where $\varepsilon_{z z}$ is calculated compressional strain in loading direction, and $\bar{\varepsilon}_{z}$ is the critical strain value determined from lab testing.

\section{Shear failure}

For plastic shear strain failure,

$$
\varepsilon^{p s}>\bar{\varepsilon}_{p s}
$$

where $\varepsilon_{\mathrm{ps}}$ is calculated plastic shear strain and $\bar{\varepsilon}_{p s}$ is determined from lab testing. 


\section{$\underline{\text { Tensile failure }}$}

For tensile failure,

$$
\sigma_{1}>\sigma_{T}
$$

where $\sigma_{1}$ is the maximum principal stress and $\sigma_{\mathrm{T}}$ is the critical tensile strength determined from lab testing or suitable correlations. This type of failure most likely occurs during bit retreat when the compressive stress wave is reflected in tension, a significant case if there is not enough Bottom Hole Pressure (BHP), such as in drilling with an air hammer.

\section{Fatigue/Damage model}

At the end of each loading/unloading cycle, both rock cohesive strength and tensile strength will be updated based on applied rock damage model, providing the peak loading stress reaches 75 percent of rock peak strength. The algorithm is derived from the work Ewy et al. has developed (Ewy et al., 2004):

$$
y=a x^{b}
$$

where $\mathrm{x}$ is number of cycles, and $\mathrm{y}$ is the ratio of rock peak strength to initial strength. It should be noted that the two coefficients determined by lab tests vary from different types of rocks.

\subsubsection{Forces on Cuttings in Annulus}

Extensive attentions have been paid on mud flow in annulus because it is crucial to effectively clean drilled debris and continue the drilling processes. Due to the complexity of mud flow and mud properties, however, most approaches are within continuum scope, i.e. they are assuming mud is a continuous fluid in which solid particles have no impact on its flow behavior and there is no interaction among these solid particles. The unique aspect of this research is coupling fluid dynamics with

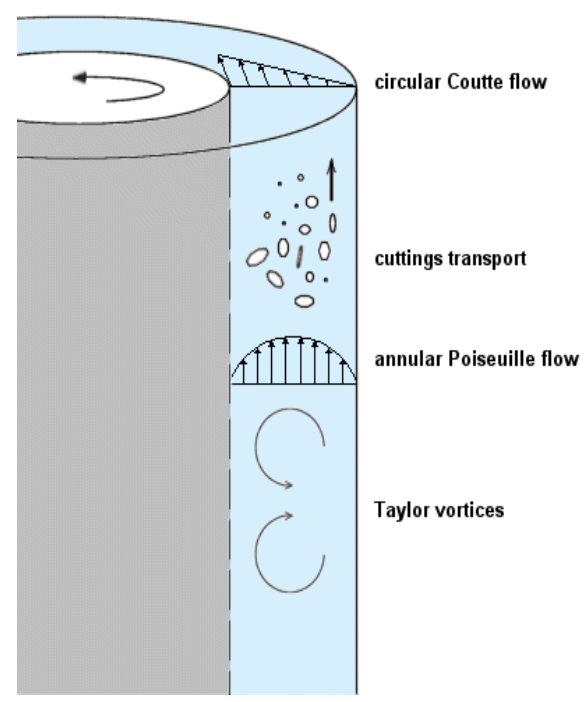


particle mechanics so that not only macroscopic fluid behavior, but the effect of solid particles on mud flow at microscopic levels, can be described (either as Newtonian, NonNewtonian, laminar or turbulent flow).

A particle suspended in a fluid is subjected to a number of hydrodynamic forces, such as drag force induced by fluid viscosity and pressure difference, buoyancy force, Basset force, etc.

\section{Drag force}

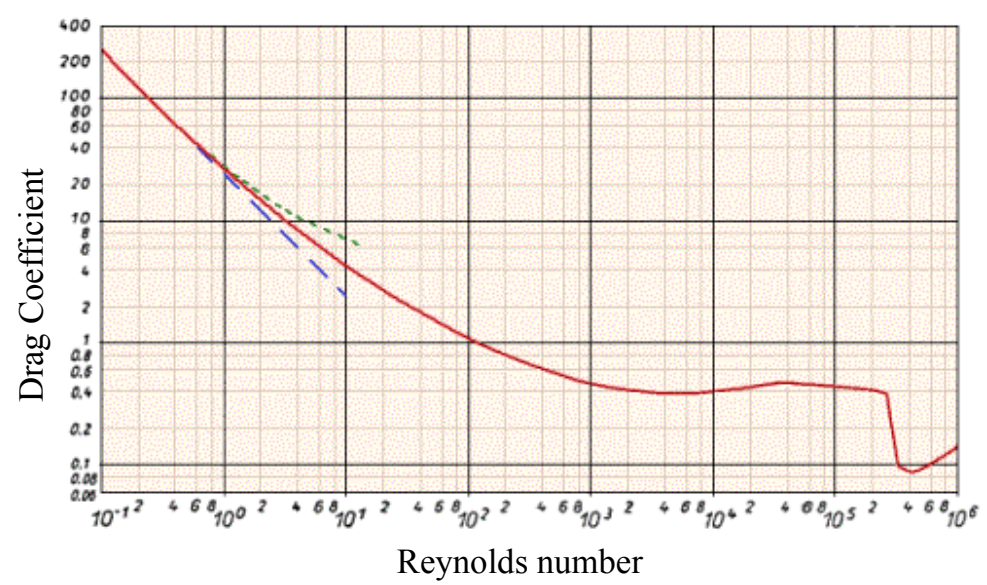

Figure 4-4. Drag coefficient with Reynolds number for a spherical particle

The general drag force equation reads:

$$
F_{D}=\frac{1}{2} C_{D} \rho A\left(\bar{v}_{z}-v_{p}\right)^{2}
$$

where $\rho$ is mud density, A is the cross section of cutting particles in the flow direction, and $C_{D}$ is drag coefficient that represents a part of the kinetic energy to overcome the drag force. It can be calculated analytically if particle Reynolds number, defined as $\operatorname{Re}_{p}=\frac{\rho d_{p}\left(\bar{v}_{z}-v_{p}\right)}{\mu}$, is less than 1 :

$$
C_{D} \approx \frac{24}{\operatorname{Re}_{p}}
$$


where $d_{p}$ is particle diameter. For the cases such as turbulent flow and non-spherical particle shapes, empirical estimates for the drag coefficient can be obtained (Chien, 1992). Relationship between drag coefficient and Reynolds number for a spherical particle in a Newtonian fluid is plotted in Figure 26. When flow is very slow, the force is also known as Stoke's force, calculated by

$$
F_{D}=6 \pi \mu r\left(\bar{v}_{z}-v_{p}\right)
$$

Buoyancy force

With consideration of gravity force, the buoyancy force on a spherical particle that results from submerged particle volume in fluid can be

$$
F_{n e t}=\frac{\pi}{6}\left(\rho_{P}-\rho_{f l}\right) g R_{p}^{3}
$$

Traditionally, due to the limitation of continuum theory, an average particle radius is taken for calculation. With aid of particle mechanics, each particle or cluster of particles can have its own properties such as diameter, shape, density, etc., which results in different force magnitudes (and therefore particle behaviors).

\section{Basset force}

Basset force is an unsteady force on a particle due to the velocity difference between particle and fluid. The instantaneous fluid velocity field, and therefore the shear stress acting on the particle, depends on the "history" leading to the current situation. It is especially important for the initial stage of particle movement when particles are accelerated from stationary state. However, the numerical complexity involved to derive the force is so prohibitive that usually it is neglected for most biphasic flow models. In this research it is neglected as it is less important compared to other forces.

There are some other forces resulting from interactions between fluid and particles, such as Saffman lift force that is due to the velocity shear between adjacent fluid layers or the wall effect, and Magnus force that is due to particle rotation. Because of their smaller magnitude comparing to the drag force discussed above, e.g. Saffman life force is about 
an order of magnitude smaller than the drag force when the particles are more than one to two particle diameters from the wall. These are not considered in this project.

In the above calculations, fluid velocity needs to be determined depending on fluid type (Newtonian or Non-Newtonian) and flow regime (laminar or turbulent). For laminar Newtonian flow, it can be calculated as follows:

- Axial flow along the cuttings transport direction (Wilson, 2001)

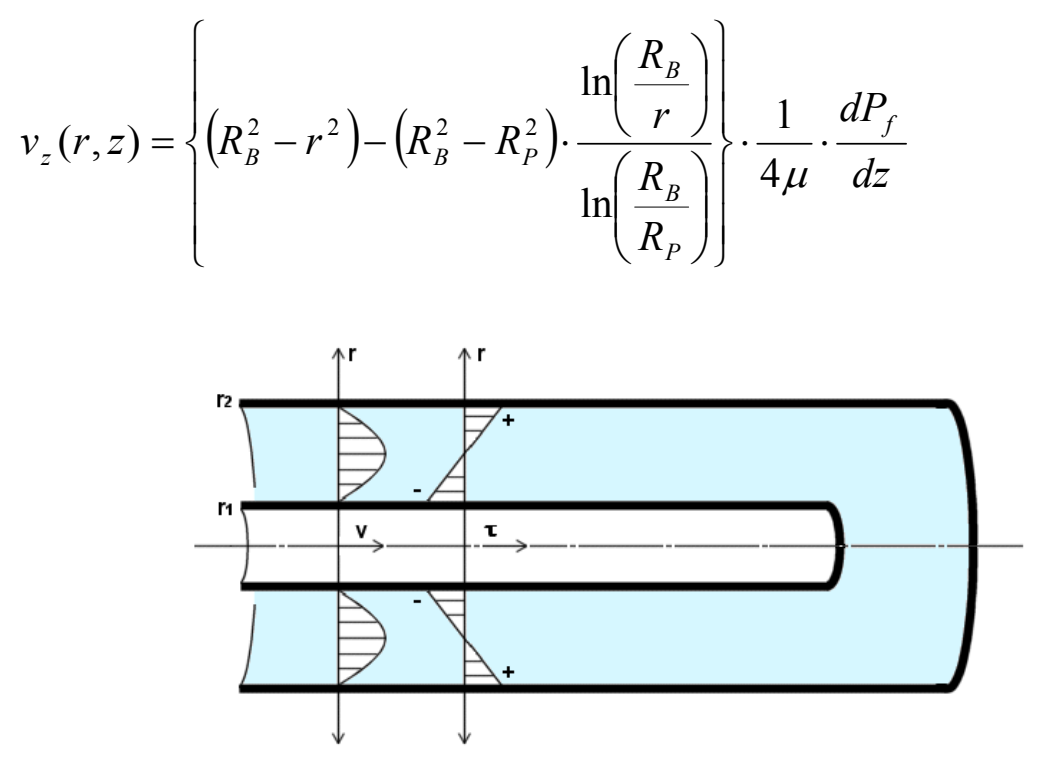

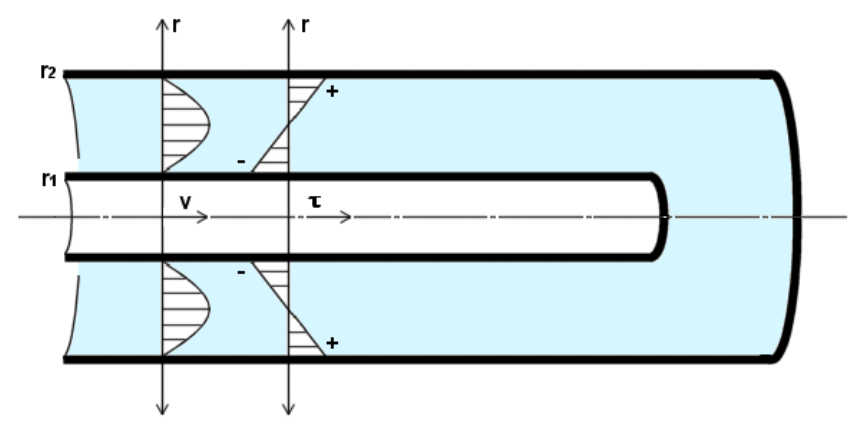

Figure 4-5. Velocity profile of axial flow in annulus for Newtonian fluid flow

- Circumferential flow perpendicular to the transport direction

$$
v_{\theta}(r)=\omega \cdot R_{P} \cdot \frac{\left(\frac{R_{B}}{r}-\frac{r}{R_{B}}\right)}{\left(\frac{R_{B}}{R_{P}}-\frac{R_{P}}{R_{B}}\right)}
$$

where $R_{B}$ is radius of wellbore, $R_{P}$ is radius of drillpipe, $r$ is the radial distance of particle from center axis, $\mu$ is mud dynamic viscosity, $\omega$ is angular rotation speed of drillpipe, and $\mathrm{dP}_{\mathrm{f}} / \mathrm{dz}$ is axial frictional pressure gradient. Based on HagenPoiseuille law, the frictional pressure drop along the annulus for a Newtonian laminar flow can be obtained 


$$
\frac{d P_{f}}{d z}=\frac{8 \mu \bar{v}_{z}}{\left(R_{B}^{2}+R_{P}^{2}-\frac{R_{B}^{2}-R_{P}^{2}}{\ln R_{B} / R_{P}}\right)}
$$

where $\bar{v}_{z}$ is mean axial flow rate.

The axial and circumferential velocity fields can be obtained independently of each other despite the nonlinearity of the Navier-Stokes equations. This decoupling occurs because the non-linear convective terms in the original momentum equations identically vanish due to the assumption of laminar Newtonian flow. Thus, changes in rotation rate will not affect properties in axial direction. Figure 4-7 summarizes the flow chart to calculate drag coefficient.

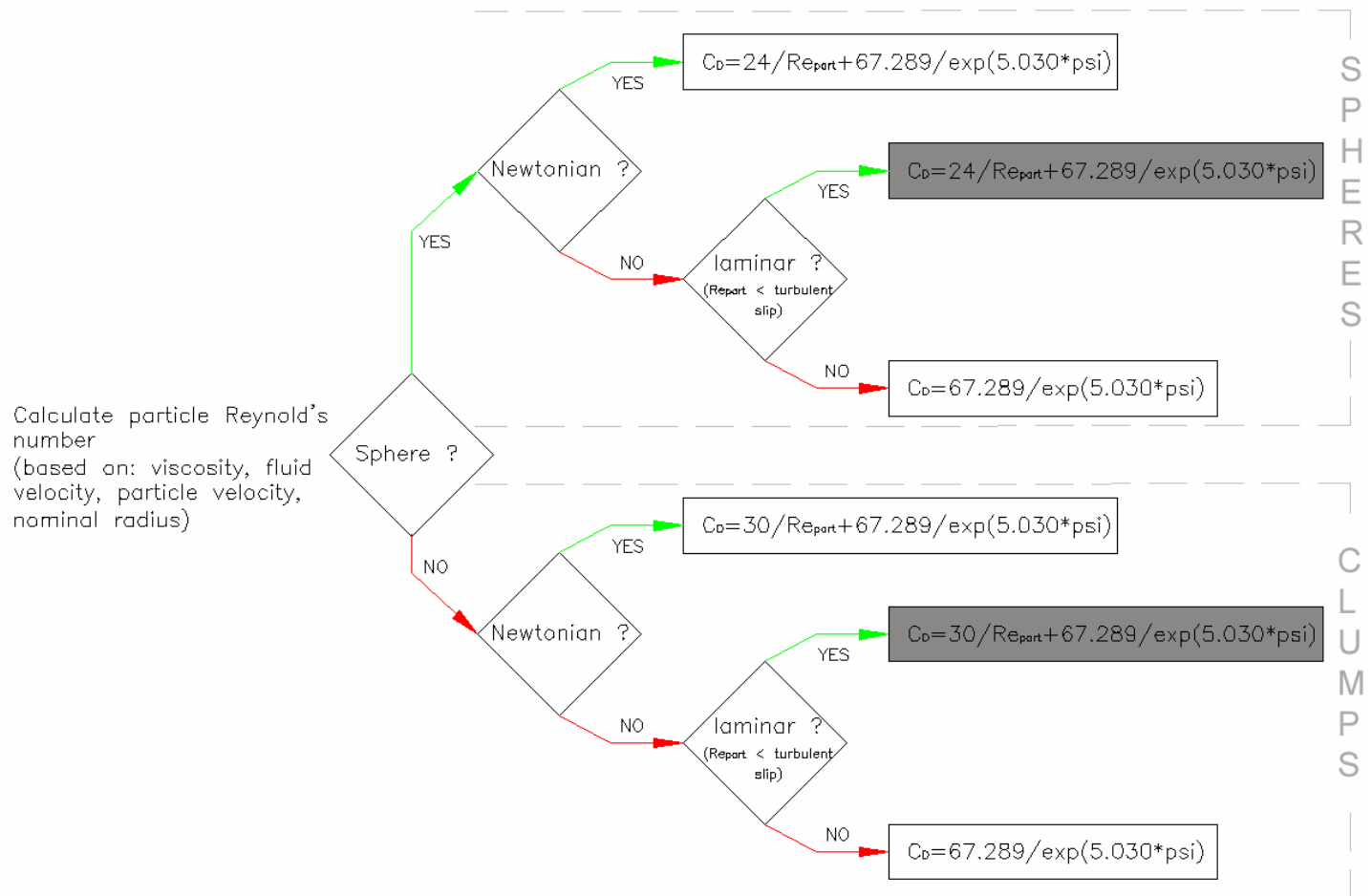

Figure 4-6. Flow chart for drag coefficient calculation 


\subsubsection{Conceptual Model}

As a highlight of the analytical modeling efforts, a conceptual model is developed to serve as a basis for further numerical investigations (see Figure 4-7). In order to simplify the complicated drilling processes, a list of simplifications are made.

1) The studied areas are 10 times the bit diameter (e.g. $D_{b}=0.216 \mathrm{~m}$, or $\left.8.5^{\prime \prime}\right)$ up along the wellbore for cuttings transport and elastic wave propagation $2.16 \times 2.16 \mathrm{~m}^{2}$ or $\left.85^{\prime \prime} \times 85^{\prime \prime}\right)$ below the drilling bit for rock damage; the diameter of drilled hole equals that of the drillbit.

2) During percussion drilling, three main processes are involved:

a) Drillbit penetration with compression, rotation and percussion

b) Rock response with stress propagation and damage accumulation

c) Debris transportation inside the annulus after disintegrated from rock Three damage/failure mechanisms are focused:

a) Rock crushing by compressive bit load

b) Rock fracturing by both shearing and tensile forces

c) Rock fatigue by repetitive compression-tension type of loading

3) Drillpipe is in vertical straight hole with depth up to $3048 \mathrm{~m}(10,000 \mathrm{ft})$

4) For drillbit

a) Drilling bit head is flat, and contacts consistently with the rock while rotating, compressing, and oscillating

b) No cutter wear is considered (i.e. assume the cutter properties are not changed with drilling progress)

c) Magnitude of bit thrust, frequency of bit oscillation, and WOB are all known variables from manufacturer

5) For drilling fluid

a) Mud is a plastic fluid (or non-Newtonian such as Bingham fluid) that becomes less viscous when it flows inside the annulus and sheared by drilling pipe rotation. Both laminar and turbulent flow patterns are to be investigated, based on Reynolds number $(<2000)$ 
b) The volume of debris, mud flowing rate and viscosity are known even though the size and shape may vary

c) Most debris are non-spherical, irregular and of various size while some flakes have different ratios of thickness to diameter

d) Debris concentration in the mud is $\leq$ five percent

e) Mud is strong enough to hold and carry the specified amount of cuttings in the annulus in both flowing and static conditions, and transport efficiency $\geq$ 50 percent

f) No mud cake is formed; mud has no communication with formation water

6) Borehole stability and fatigue of drilling equipment are not considered 


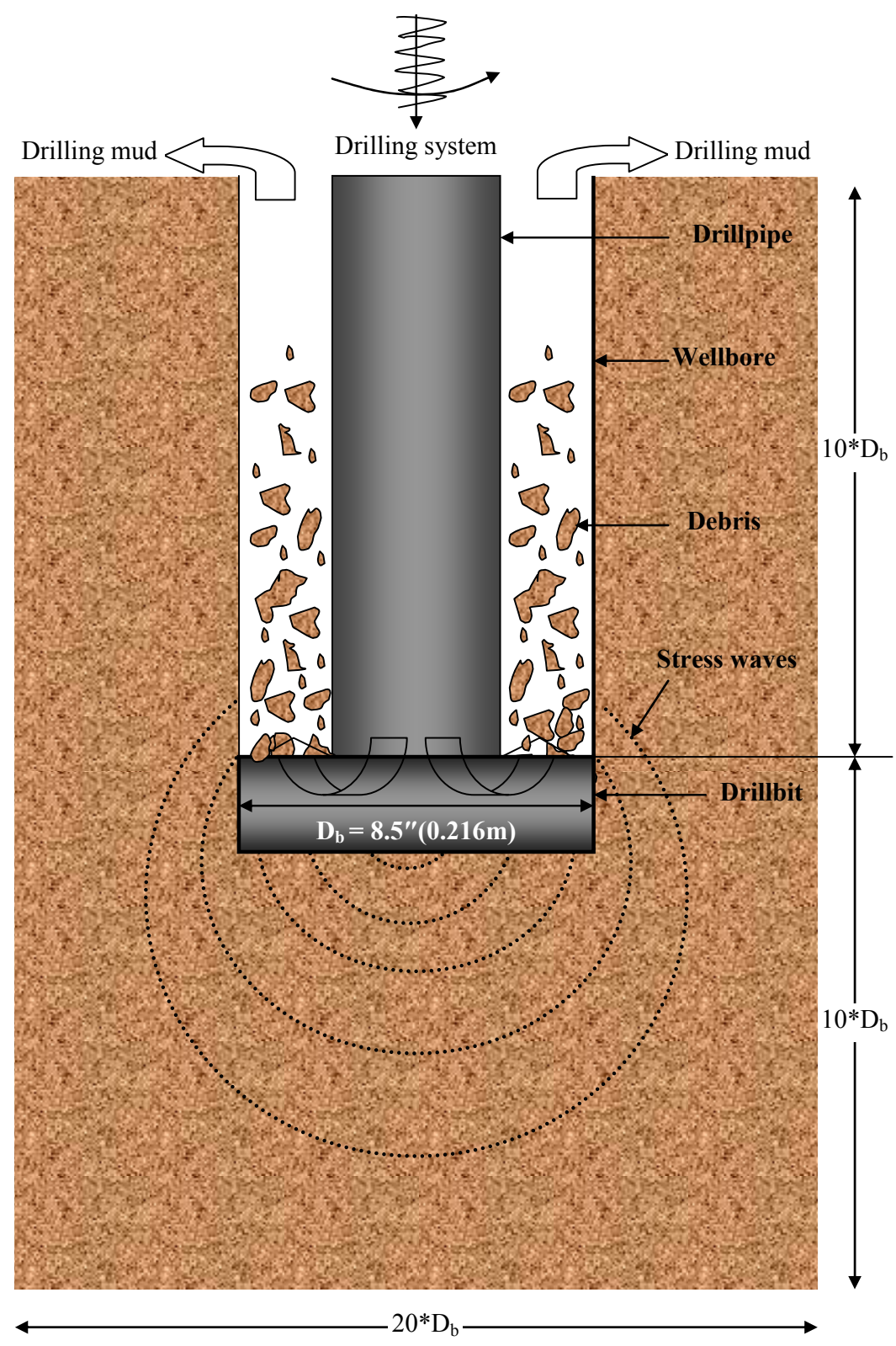

Figure 4-7. Conceptual model for percussion drilling

\subsection{Numerical Modeling}

To numerically investigate the drilling processes, three steps have been taken. First is to select and confirm the best numerical candidates, applying them to study simple cases. For rock model, 1D simulation of a column of rock elements is developed to study the effects of material models, loading patterns, boundary conditions, and dynamic features on rock breakage. The second step involves cuttings transport where the laminar 
Newtonian flow with uniform spherical particles is investigated in the annulus. Finally, develop a sophisticated 3D dynamic simulation for a rock model and turbulent flow with non-spherical, non-uniform particles for cuttings transport.

\subsubsection{Selection and Confirmation of Numerical Tools}

We have evaluated different FEM software, such as ABAQUS and FLAC3D for rock model, and particle flowing codes PFC3D, FLUENT, HUBS for cuttings transport. After reviews, FLAC3D and PFC3D are selected for this project. Two sets of comparisons are carried out to compare the numerical results by FLAC3D with the analytical solutions discussed in Section 4.1.2.

Point shear traction on the surface of a semi-infinite half-space

A horizontal shear load of $10 \mathrm{~N}$ is applied at the center point on top of a cubic model.

Cylindrical or cubical types of elements are used. For the cubical model with 71424 zones, the analytical results agree with the numerical results very well

Figure 4-8).

\begin{tabular}{|c|c|c|c|c|c|c|c|c|}
\hline & \multicolumn{4}{|c|}{ Cylindrical model } & \multicolumn{4}{|c|}{ Cubical model } \\
\hline & \multicolumn{2}{|l|}{ SI units } & \multicolumn{2}{|c|}{ field units } & \multicolumn{2}{|c|}{ SI units } & \multicolumn{2}{|c|}{ field units } \\
\hline \multicolumn{9}{|l|}{ Geometry } \\
\hline Height & 2,00 & $\mathrm{~m}$ & 6,56 & $\mathrm{ft}$ & 5,00 & $\mathrm{~m}$ & 16,40 & $\mathrm{ft}$ \\
\hline Length & 4,00 & $\mathrm{~m}$ & 13,12 & $\mathrm{ft}$ & 20,00 & $\mathrm{~m}$ & 65,62 & $\mathrm{ft}$ \\
\hline \multicolumn{9}{|l|}{ FLAC3D properties } \\
\hline zone command & brick & & & & brick & & & \\
\hline \# of zones & 16000 & & & & 71424 & & & \\
\hline volume of one zone & 0,001 & $\mathrm{~m}^{3}$ & 0,04 & $\mathrm{ft}^{3}$ & 0,037 & $\mathrm{~m}^{3}$ & 1,31 & $\mathrm{ft}^{3}$ \\
\hline boundary conditions & bottom $\mathrm{z}$ fixed & & & & bottom $\mathrm{x}, \mathrm{y}, \mathrm{z}$ fixed & & & \\
\hline Model & elastic & & & & elastic & & & \\
\hline bulk modulus & 20 & Gpa & $2,90 \mathrm{E}+06$ & PSI & 20 & Gpa & $2,90 \mathrm{E}+06$ & PSI \\
\hline shear modulus & 12 & Gpa & $1,70 \mathrm{E}+06$ & PSI & 12 & Gpa & $1,70 \mathrm{E}+06$ & PSI \\
\hline shear point load & 10 & $\mathrm{~N}$ & 2,2 & $\mathrm{lbf}$ & 10 & $\mathrm{~N}$ & 2,2 & $\mathrm{lbf}$ \\
\hline
\end{tabular}

Table 4-1. Data for FLAC3D simulations of a surface load acting on a half-space medium 


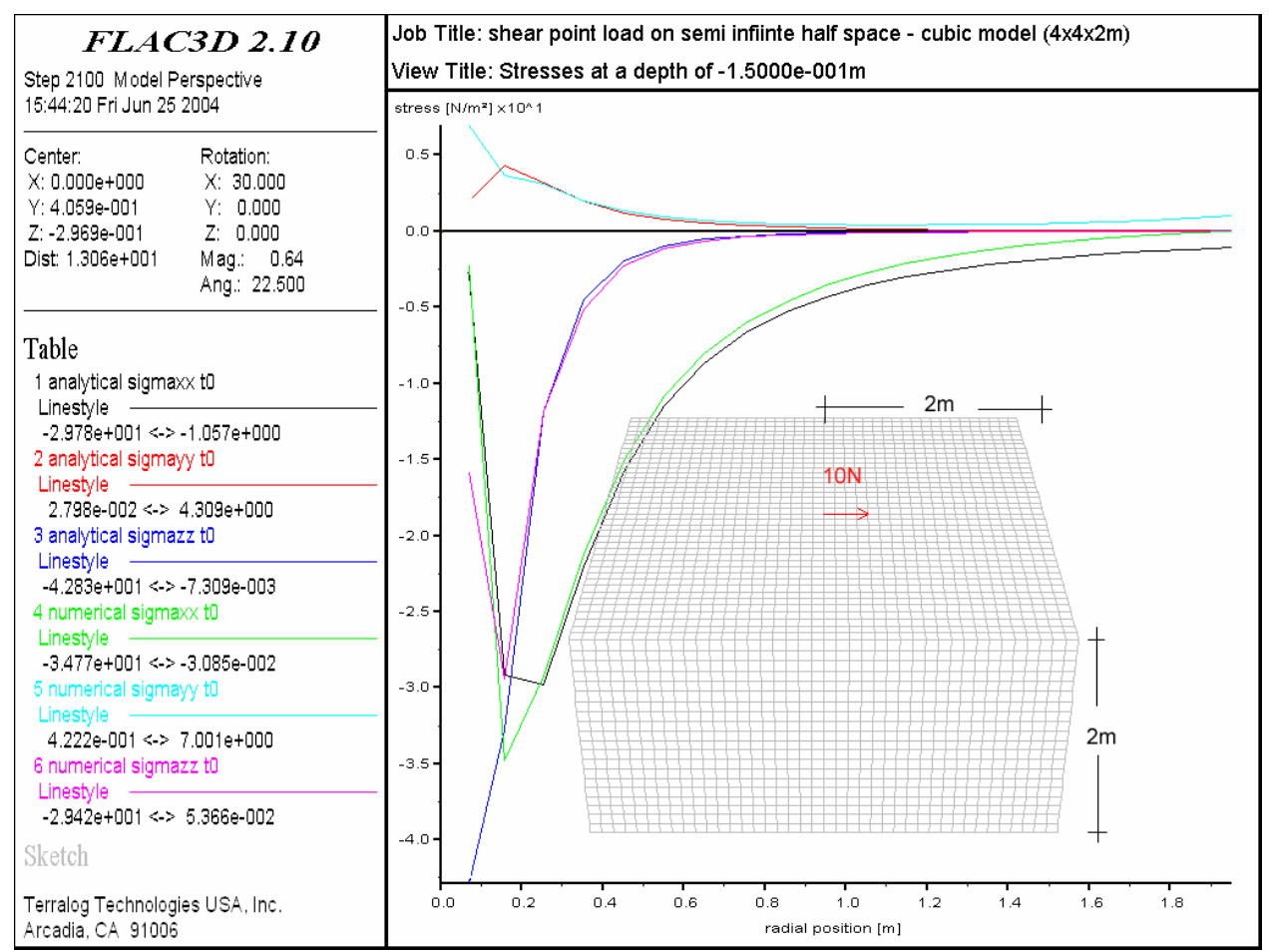

Figure 4-8. Comparison of analytical and numerical stress solutions for point shear load

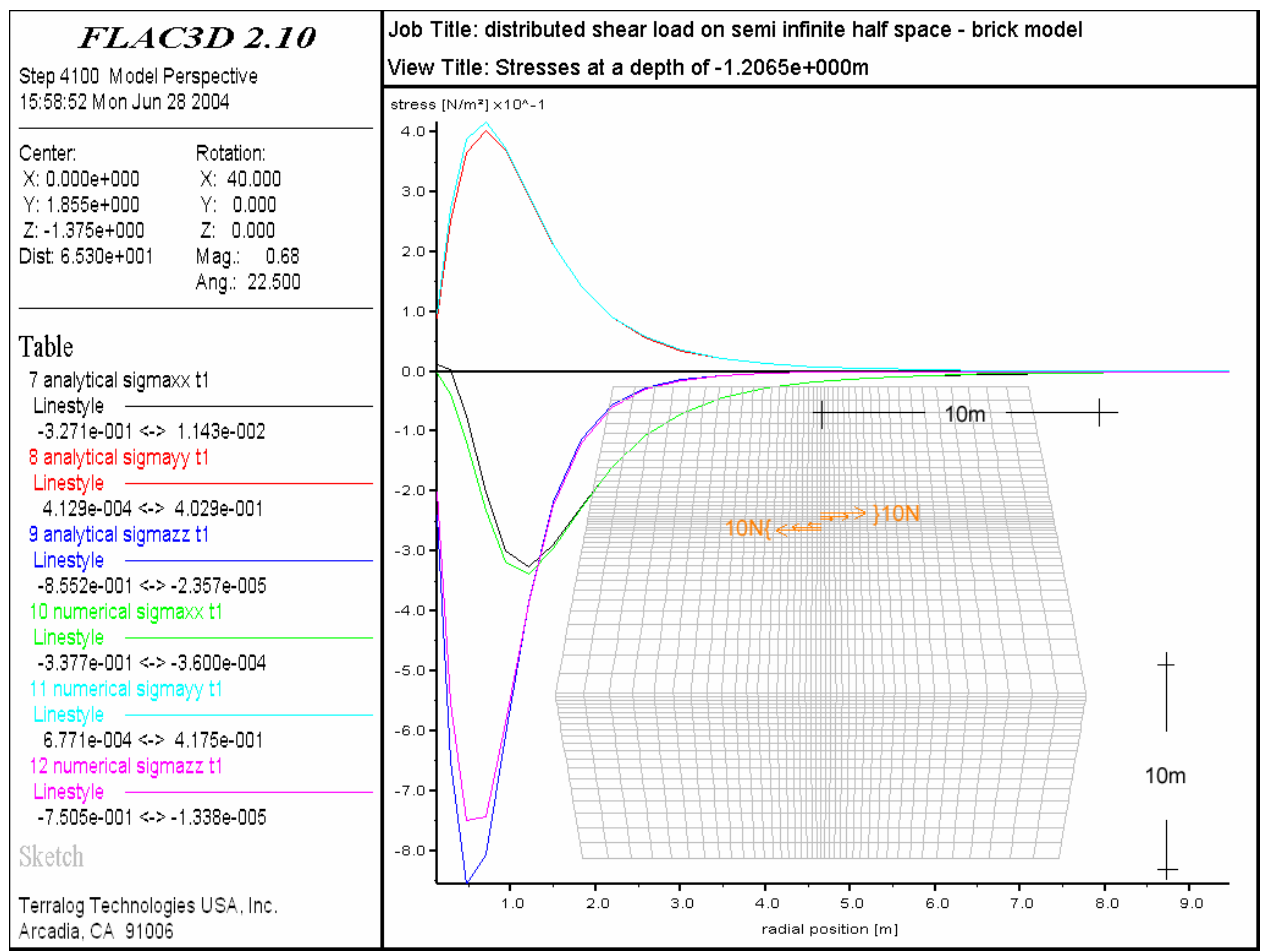

Figure 4-9. Comparison of analytical and numerical stress solutions for distributed shear load 


\section{Distributed shear traction (torsion) over a circular area}

Shear load is linearly distributed in $\mathrm{x}, \mathrm{y}, \mathrm{z}$ directions. A good match between the analytical and numerical solutions can be seen in Figure 4-9, where the measured stresses in $\mathrm{x}-, \mathrm{y}$ - and $\mathrm{z}$-directions are plotted against the analytical solution.

After confidence is gained through the comparison between the analytical and the numerical solutions, we have simulated the rock breakage for one column of rock and 3D wellbore situation.

\subsubsection{Rock Material Models}

Three types of material models are tested, including Elastic model, Mohr-Coulomb model, and the Strain Softening model. The results are plotted in Figure 4-10. Both the Elastic model and the Mohr-Coulomb (MC) perfect plastic model underestimate rock deformation after loading stress reaches rock peak strength. This leads to overestimation of a failed element number when strain-based failure criteria are applied. Therefore, the Strain Softening model is used in this research because of its closer approximation to reality.

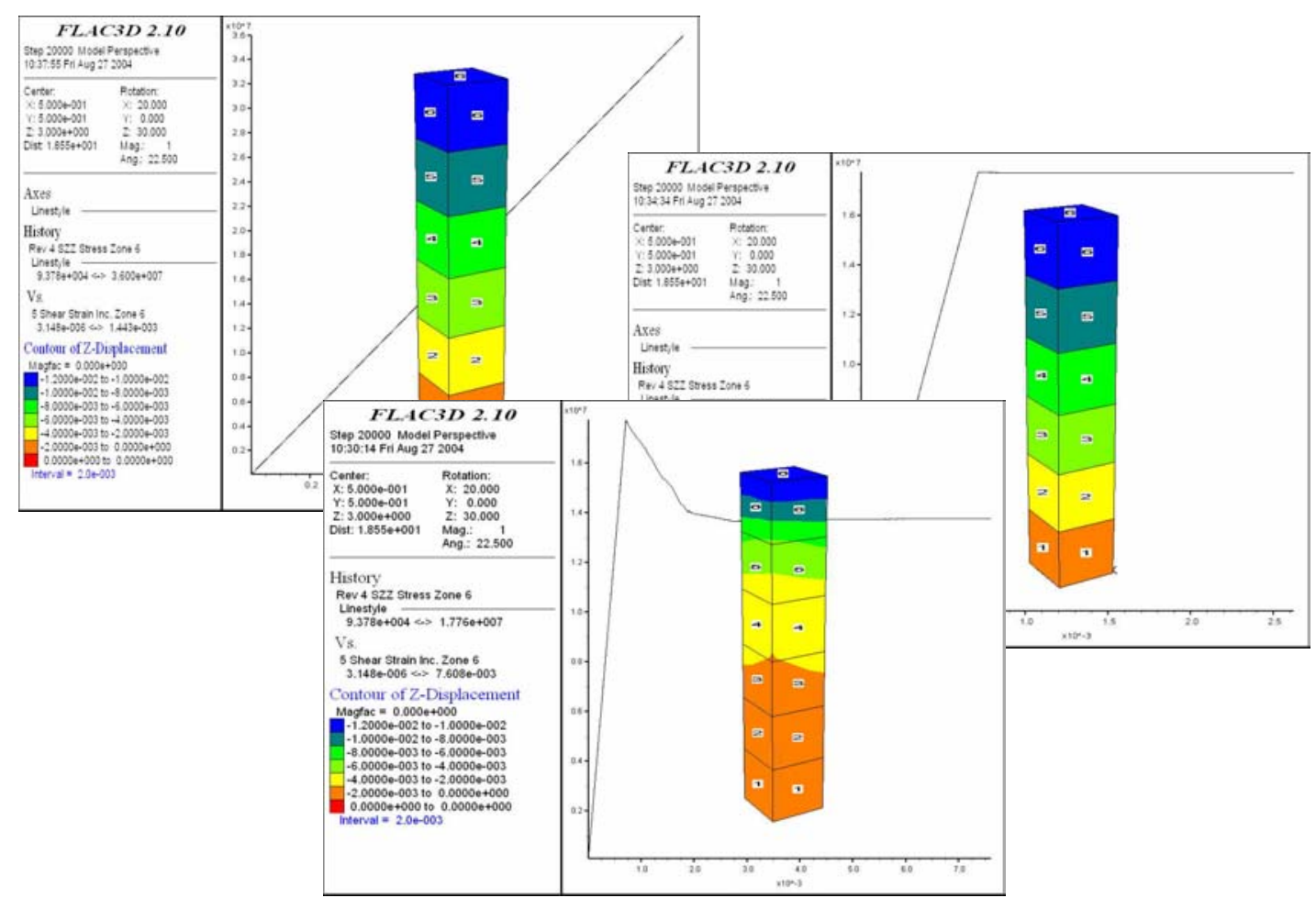

Figure 4-10. Rock Material Models: elastic, MC perfect plastic, MC strain softening 


\subsubsection{D Simulation of Rock Breakage}

The flow chart of simulation is described in Figure 4-11. Starting from mesh

construction and selection of a material model, boundary conditions are applied: bottom of the model is fixed, the laterals are set as either free or confined, and vertical load applied directly on the top. After $\mathrm{n}$ timesteps, failure tests are carried out for each element. If any failed zones exist, they will be deleted and loading stress will move to the element on top of rock column. Otherwise, further $n$ timesteps are executed. The program stops when the bottom of rock is reached or the total timesteps set at the beginning are met.

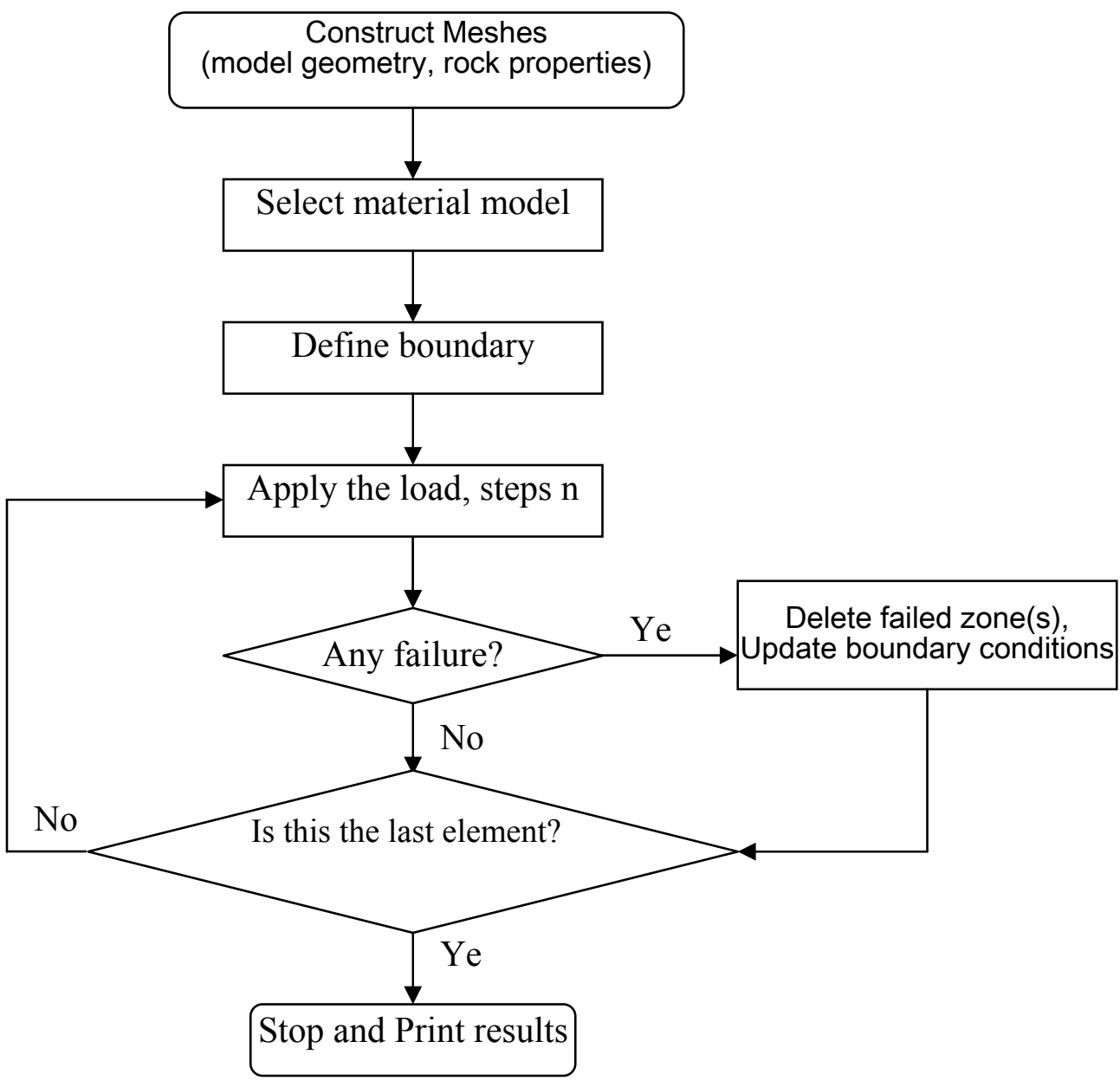

Figure 4-11. Flow chart of 1D simulation 
Figure 4-12 illustrates how the bit advances during six percussive impacts. The number of timesteps at which the model checks and updates the failed element(s) is shown to be critical. Less timesteps lead to larger unbalanced force and therefore longer runtime, while bigger ones result in exaggerated failure judgment, and consequently the speed of failure progress may vary. Appropriate value for timesteps should minimize unbalanced force while maximizing running speed. Another interesting phenomenon is that, despite the compressional nature of loading stress at the top, there are some zones that underwent tensile failure during simulation This is mainly because of the lateral expansion (i.e. extension) when longitudinal loading direction is under compression. Nevertheless, when simulation is carried out with confining stress in lateral directions (as little as less than $1 \mathrm{MPa}$ ), there is no more tensile failure. Figure 4-13 plots the displacement of each element after each impact. Discontinuity in the displacement curves and a jump in the ROP curve indicate the failure of the element and its subsequent removal.

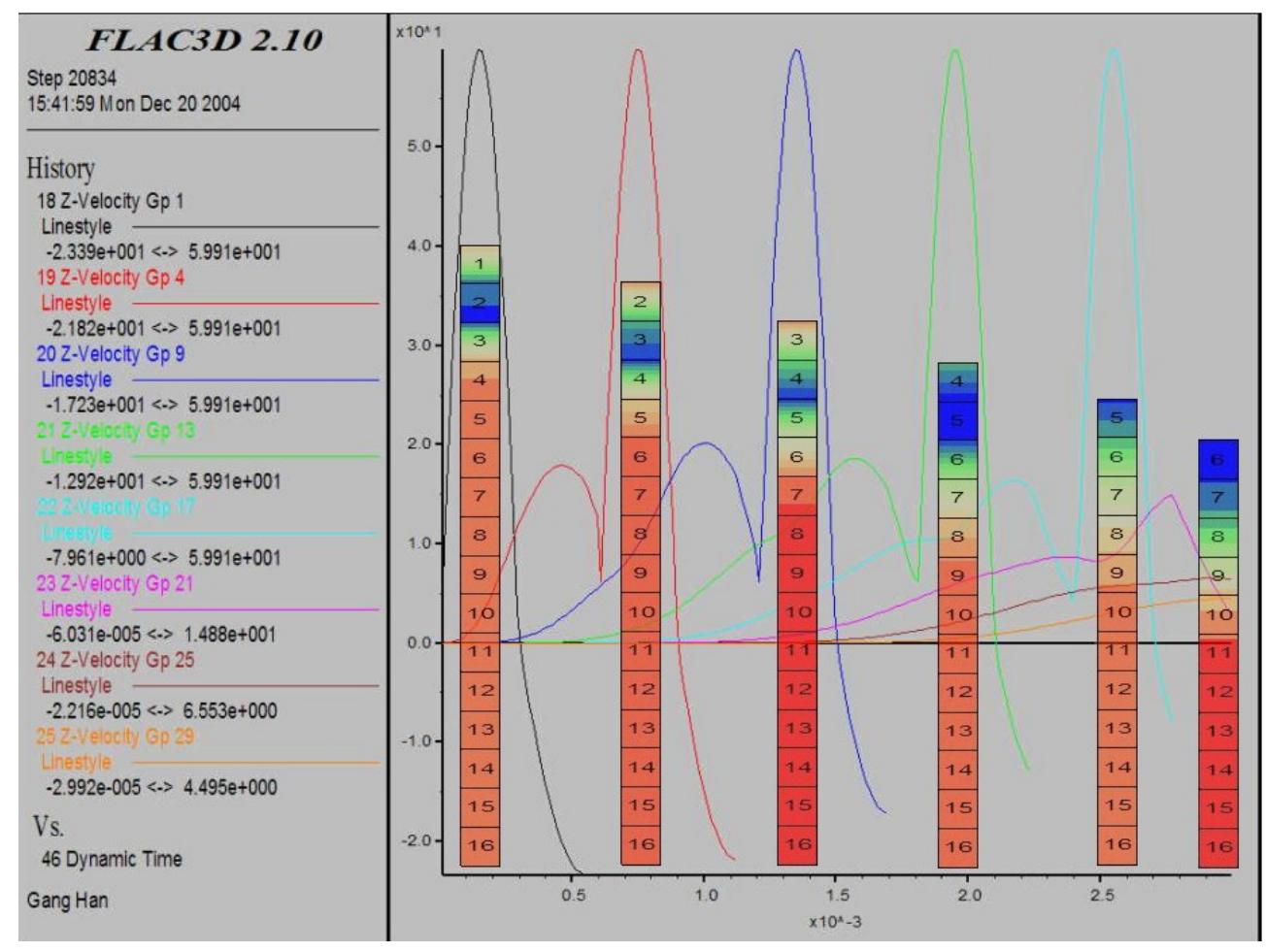

Figure 4-12. Dynamic modeling rock breakage for 1column rock model 


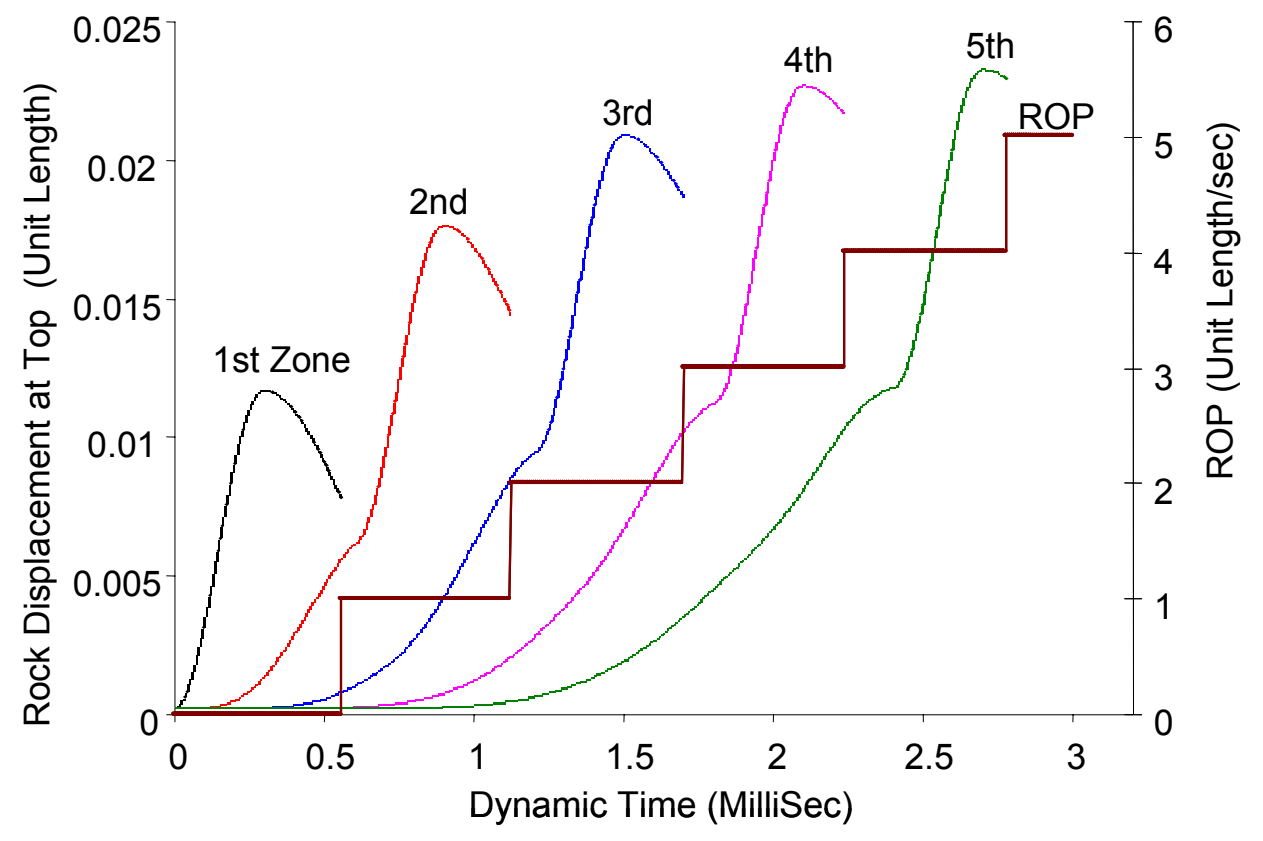

Figure 4-13. Rock penetration for 1column rock model

\subsubsection{D Dynamic Simulation of Rock Breakage}

To investigate rock deformation and failure during percussion drilling, a 3D rock mechanics model has been developed with aid of FLAC3D. The implementation includes a Mohr-Coulomb type material model with strain-softening behavior, a Rayleigh damping feature to dissipate excessive oscillation energy, three failure models to describe when and how rock experiences failure, and a fatigue/damage algorithm to update rock properties (e.g. cohesive strength and tensile strength) due to cyclic loading.

\section{Configuration}

As shown in Figure 4-14, the dimension of the 3D model is $1.5 \mathrm{~m}$ (length) $\times 1.5 \mathrm{~m}$ (width) $\times 3.0 \mathrm{~m}$ (height). There is a $0.5 \mathrm{~m}$ deep drilled borehole with diameter of $17.8 \mathrm{~cm}$. The boundary conditions for the rock block include a confining stress of $12.5 \mathrm{MPa}$, an overburden stress of 15MPa, and a fixed bottom condition. Table 4-2 lists the details of these inputs. 


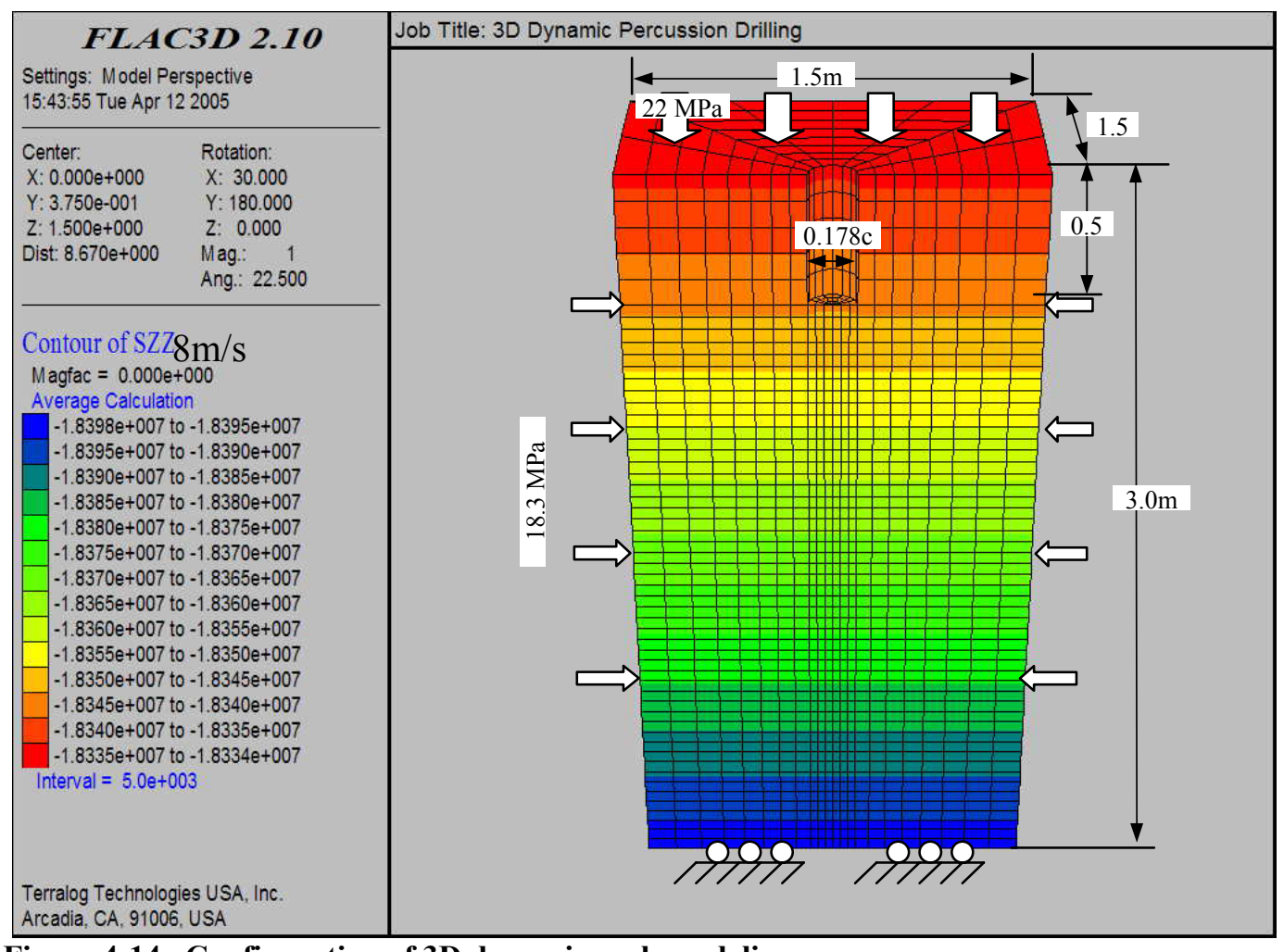

Figure 4-14. Configuration of 3D dynamic rock modeling

\begin{tabular}{|l|l|l|l|l|l|l|l|l|}
\hline $\begin{array}{l}\text { Model size } \\
(\mathrm{X} \times \mathrm{Y} \times \mathrm{Z})\end{array}$ & $\begin{array}{l}\text { Wellbore } \\
\text { diameter }\end{array}$ & $\begin{array}{l}\text { Confining } \\
\text { stress }\end{array}$ & $\begin{array}{l}\text { Overburden } \\
\text { Pressure }\end{array}$ & $\begin{array}{l}\text { Formation } \\
\text { Depth }\end{array}$ & $\begin{array}{l}\text { Mud } \\
\text { Density }\end{array}$ & $\begin{array}{l}\text { Peak } \\
\text { Impact } \\
\text { Velocity }\end{array}$ & $\begin{array}{l}\text { Impact } \\
\text { span }\end{array}$ & $\begin{array}{l}\text { Number } \\
\text { of } \\
\text { Impacts }\end{array}$ \\
\cline { 1 - 6 } $1.5 \mathrm{~m} \times 1.5 \mathrm{~m} \times 3.0 \mathrm{~m}$ & $0.178 \mathrm{~m}$ & $18.3 \mathrm{MPa}$ & $22 \mathrm{MPa}$ & $1000 \mathrm{~m}$ & $1.25 \mathrm{~g} / \mathrm{cm}^{3}$ & $8 \mathrm{~m} / \mathrm{s}$ & $\begin{array}{l}3 \times 10^{-} \\
4^{4}\end{array}$ & \\
\cline { 1 - 5 } & $4.9 \mathrm{ft} \times 4.9 \mathrm{ft} \times 9.8 \mathrm{ft}$ & $7^{\prime \prime}$ & $2654 \mathrm{psi}$ & $3190 \mathrm{psi}$ & $3280 \mathrm{ft}$ & $10.4 \mathrm{lb} / \mathrm{gal}$ & $26.2 \mathrm{ft} / \mathrm{s}$ & \\
\hline
\end{tabular}

Table 4-2. Input parameters for model configuration 


\section{$\underline{\text { Rock Material Model }}$}

A Cascade sandstone with cohesive strength of $10.41 \mathrm{MPa}(1510 \mathrm{psi})$ and friction angle of 30 degrees is selected for initial 3D simulations. The rock is modeled as a Mohr-Coulomb type with strain-softening behavior. Under confining stress of $18.3 \mathrm{MPa}$ (2654psi) at the depth of $1000 \mathrm{~m}$, the rock has $7.66 \mathrm{GPa}$ and $5.75 \mathrm{GPa}$ in bulk and shear moduli, respectively. Other rock properties are described in Table 4-3. Those parameters are derived from a series of stress-strain curve matches.

\begin{tabular}{|c|c|c|c|c|c|c|c|c|c|c|}
\hline \multirow[t]{2}{*}{$\begin{array}{l}\text { Rock } \\
\text { Density }\end{array}$} & \multirow[t]{2}{*}{$\begin{array}{l}\text { Bulk } \\
\text { modulus }\end{array}$} & \multirow[t]{2}{*}{$\begin{array}{l}\text { Shear } \\
\text { modulus }\end{array}$} & \multirow[t]{2}{*}{$\begin{array}{l}\text { Cohesive } \\
\text { Strength }\end{array}$} & \multirow[t]{2}{*}{$\begin{array}{l}\text { Friction } \\
\text { Angle }\end{array}$} & \multirow[t]{2}{*}{$\begin{array}{l}\text { Tensile } \\
\text { Strength }\end{array}$} & \multirow[t]{2}{*}{$\begin{array}{l}\text { Critical } \\
\text { Strain }\end{array}$} & \multirow{2}{*}{$\begin{array}{l}\text { Critical } \\
\text { Plastic } \\
\text { Shear } \\
\text { Strain }\end{array}$} & \multirow{2}{*}{$\begin{array}{l}\text { Critical } \\
\text { tensile } \\
\text { strain }\end{array}$} & \multicolumn{2}{|c|}{$\begin{array}{c}\text { Fatigue } \\
\text { Coefficients }\end{array}$} \\
\hline & & & & & & & & & $\mathrm{a}$ & $\mathrm{b}$ \\
\hline $2.2 \mathrm{~g} / \mathrm{cm}^{3}$ & $7.66 \mathrm{GPa}$ & $5.75 \mathrm{GPa}$ & $10.41 \mathrm{MPa}$ & 30 & $1.9 \mathrm{MPa}$ & 0.12 & 0.06 & 0.0005 & 0.9987 & -0.0313 \\
\hline $137 \mathrm{lb} / \mathrm{ft}^{3}$ & 1.17Mpsi & $0.70 \mathrm{Mpsi}$ & $1510 \mathrm{psi}$ & & $275 \mathrm{psi}$ & & & & & \\
\hline
\end{tabular}

Table 4-3. Rock properties used in the model

Flowchart

The flowchart of 3D numerical simulation is described in Figure 4-15. There are five steps before calculation of stress wave propagation in the rock: define grid meshes, choose material model, describe boundary conditions, input stress waves, and test and determine rock damping properties.

Stress wave input is defined as a sine wave with a peak value of impact velocity and an impact span (or frequency of impact). After impact, the bit will retreat and velocity input is removed. The impact surface will oscillate after that. 
After the model reaches mechanical equilibrium, with input of rock properties and boundary conditions, the stress wave starts to impose on the impact surface, i.e. the rock elements adjacent to the hole bottom. After a few steps of loading, the program will determine whether any rock failure occurs based on the applied failure criteria. If there is no rock failure, and the loaded element is not the last one (i.e. at the bottom of the rock model), a few more steps of loading will be executed. However, if there is any failure, possibly due to excessive compression, shear, or tension, the element(s) will be deleted, as well as the other elements at the same depth. Meanwhile, if the element(s) have failed during impact, the loading stress wave will immediately impose on the next level of stable elements adjacent to the failed ones; if the element(s) have failed during bit retreat (mainly because of excessive tensile deformation), there is no change of boundary conditions.

After a cycle of impact, including bit-rock contact and bit retreat, the program will update the remaining stable rock elements based on fatigue/damage algorithm applied. Basically both cohesive and tensile strengths will decrease with number of cycles (Fig. 8). Unless it is the end of a series of impacts, the loading of the next wave cycle will continue.

The program stops for two reasons: when all elements are drilled out, and when all cycles of loading waves have been applied. For each case, four outputs will be generated: a ROP value, a plot of bit advancement, a history of rock failure, and a history of rock fatigue/damage. The rock failure history describes when and how many rock elements (or grid units) have failed, and what type of failure they have experienced while rock fatigue/damage history demonstrates when and how many rock elements have been damaged during which impact. 


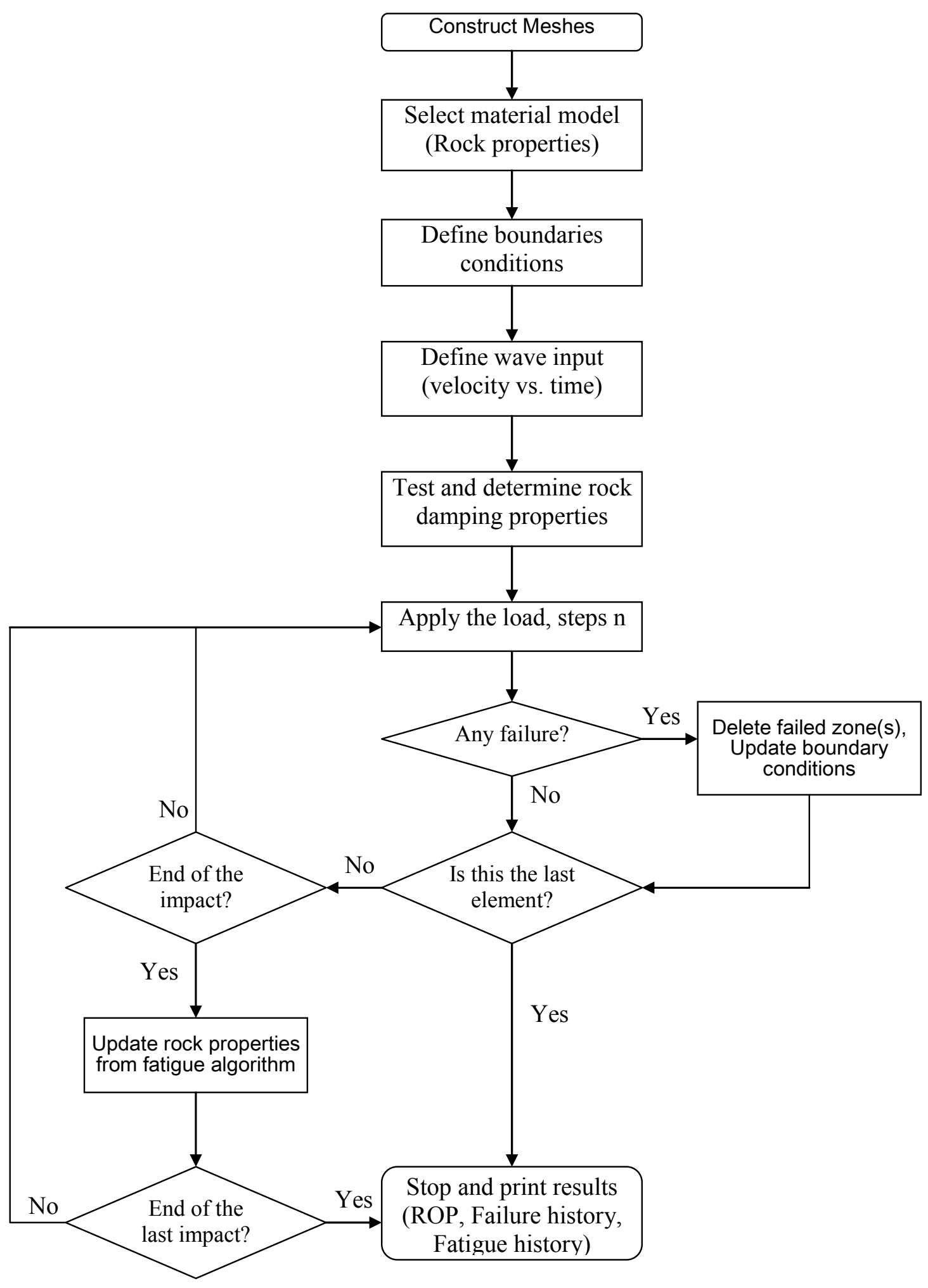

Figure 4-15. Flowchart for 3D dynamic simulation 


\section{Dynamic Damping}

A Reyleigh damping feature is applied. As indicated in FLAC3D menu (Optional

Features), the two parameters required for this algorithm are a critical wave frequency defining how fast rock responds to wave disturbance, and a damping ratio describing how much range of the frequency can be efficiently damped. Because the critical frequency is determined by rock mass $(\mathrm{M})$ and modulus (K), i.e. $f \propto \sqrt{K / M}$, each model used in the simulation needs to run some tests to determine the values of the frequency $\left(f_{c}\right)$ and the ratio $\left(R_{a}\right)$.

Figure 4-16, Figure 4-17, and Figure 4-18 describe the selections of damping magnitude on stress wave propagation. With decrease of damping (from 60 percent of $f_{c}, 20$ percent of $f_{c}$, to no damping), the reflected waves after the first impact are quite different. The less damping applied the larger amount of the wave energy reflected.

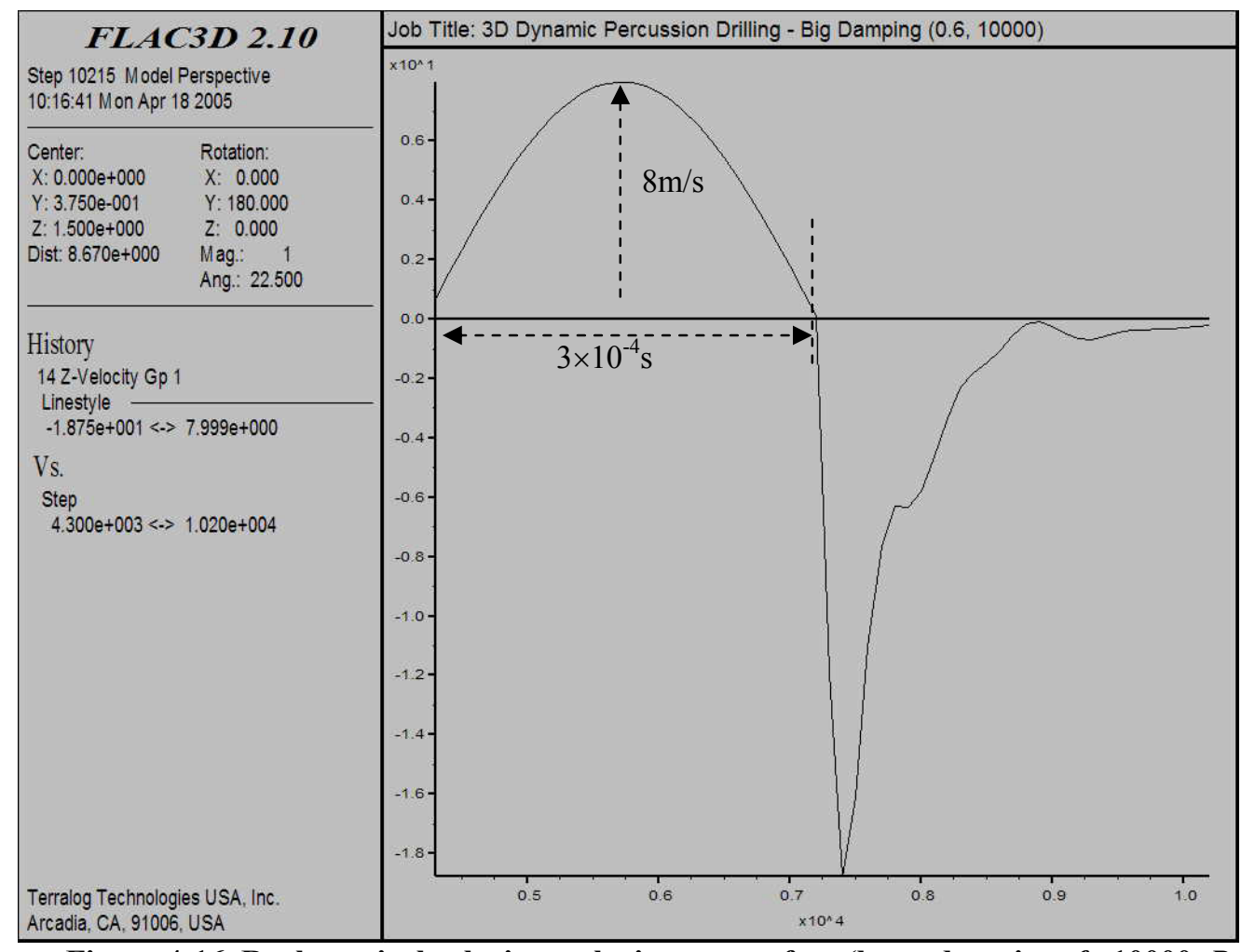

Figure 4-16. Rock vertical velocity at the impact surface (large damping, $\left.f_{c}=10000, R_{a}=0.6\right)$ 


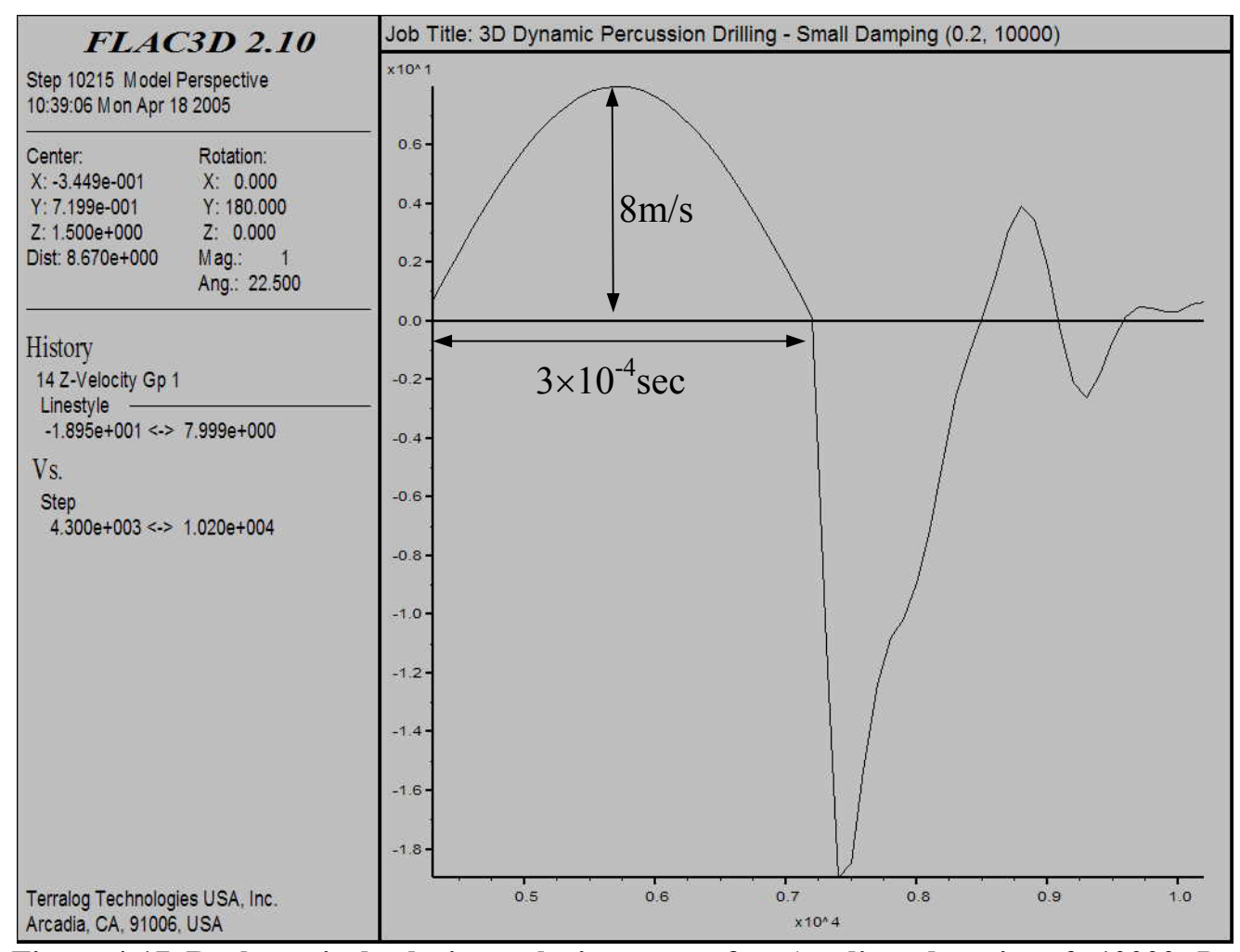

Figure 4-17. Rock vertical velocity at the impact surface (medium damping, $f_{c}=10000, R_{a}=0.2$ )

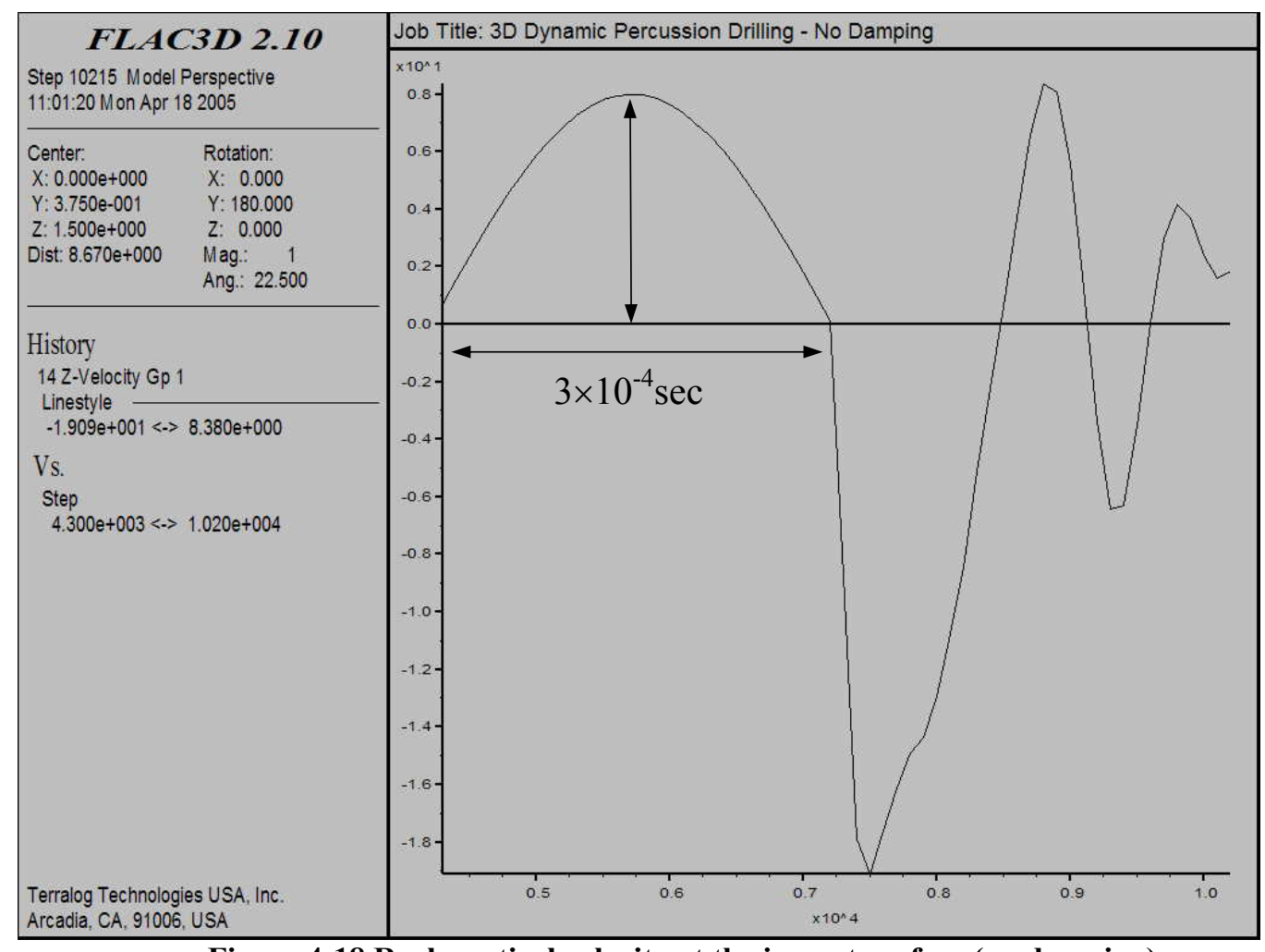

Figure 4-18 Rock vertical velocity at the impact surface (no damping) 


\section{Fatigue/Damage Model}

The plot of rock damage under the bit vs. cycles is shown in Figure 4-19. In general, rock damage, in terms of strength reduction, evolves with number of cycles. There is a significant damage development during the first cycle. This attributes to a strainweakening phenomenon where rock experiences plastic deformation leading to the development of microfractures. Even though cyclic fatigue contributes partly to rock defragmentation during percussion drilling, strain-weakening deformation may play a more important role in terms of strength reduction.

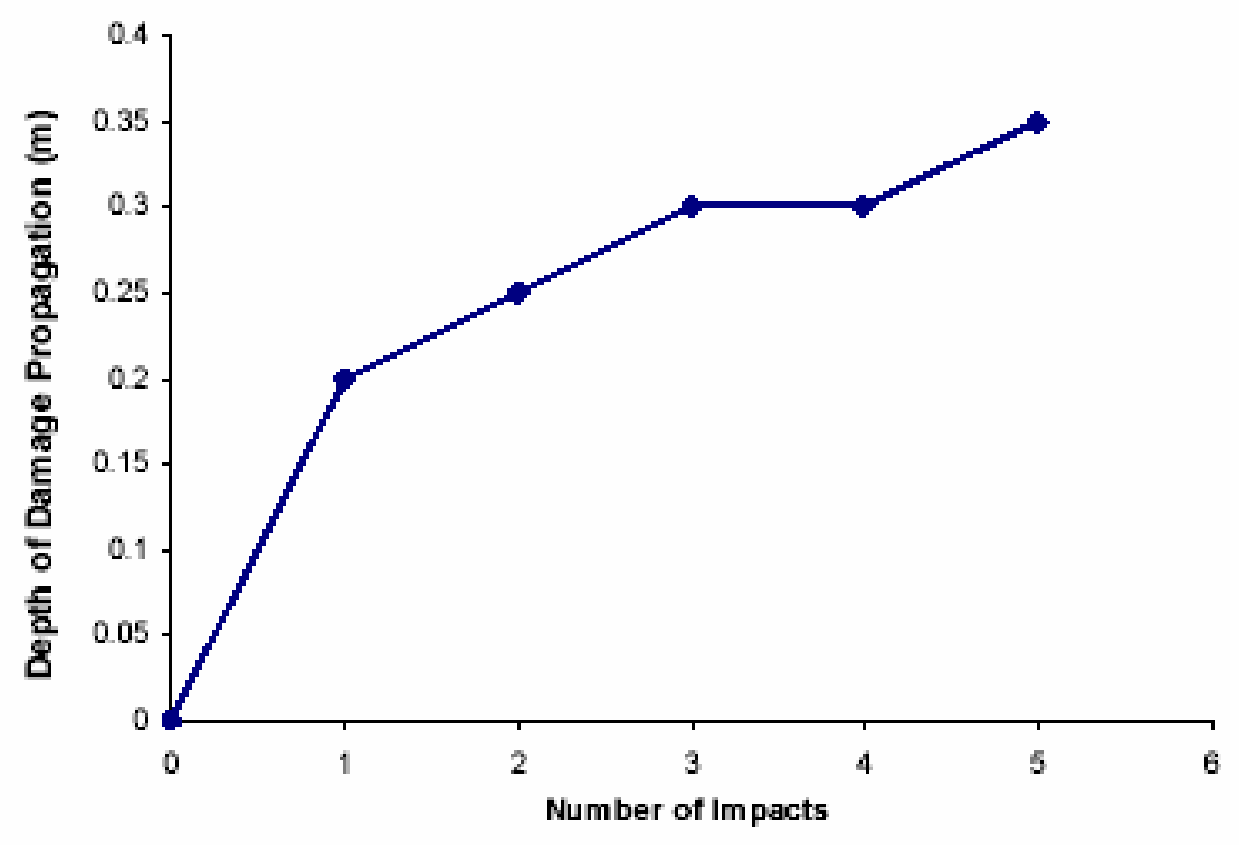

Figure 4-19. Development of damage during cyclic impacts

\section{Dynamic Stress Propagation in the Rock}

Figure 4-20 and Figure 4-21 show how rock vertical stresses in the loading direction evolve. Initially the rock is under $18.3 \mathrm{MPa}$ confining stress and $22 \mathrm{MPa}$ overburden stress. Mud pressure at the wellbore bottom is around 10Mpa, which is lower than in-situ stresses. At the end of bit-rock impact, the rock compressive stress $\left(\sigma_{\mathrm{zz}}\right)$ reaches the maximum of about 100MPa (Figure 4-20). During the loading, there are two layers of elements (total $0.1 \mathrm{~m}$ ) that have failed and therefore been deleted from the simulation, which results in two abrupt changes in rock velocity profiles (the black and red lines in 
Figure 4-21). After each elimination, the impact is immediately passed to the next available rock element adjacent to the failed ones. As soon as bit starts retreat, stress disturbation created by hammer impact starts to disappear gradually (Figure 4-21).

The changes of rock shear stresses $\left(\tau_{\mathrm{xz}}\right)$ are more complicated than those of compressive stress $\left(\sigma_{z z}\right)$. Initial shear stress, in the magnitude of $3 \mathrm{MPa}$, is concentrated around the corner of the wellbore bottom, in a clockwise direction. If the impact continues, the direction of $\tau_{\mathrm{xz}}$ completely changes to counter-clockwise and increases to $16.7 \mathrm{MPa}$ (Figure 4-22). After bit starts to retreat, the direction of $\tau_{\mathrm{xz}}$ recovers back and decreases to around 14.4MPa. The direction-change cycle tends to twist the rock and may damage it to some extent.

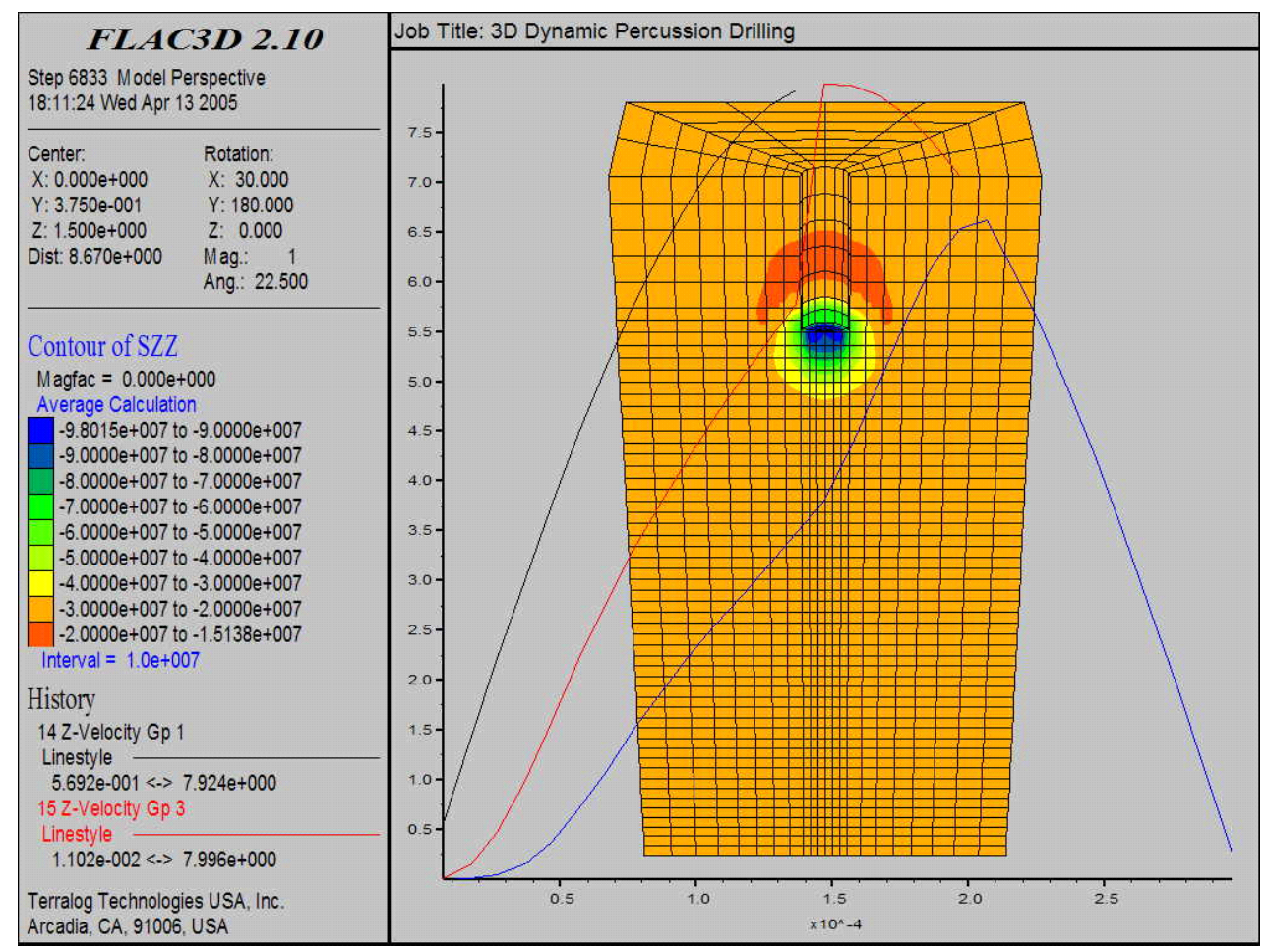

Figure 4-20. Rock vertical stress in the loading direction at the end of impact (unit: Pa) 


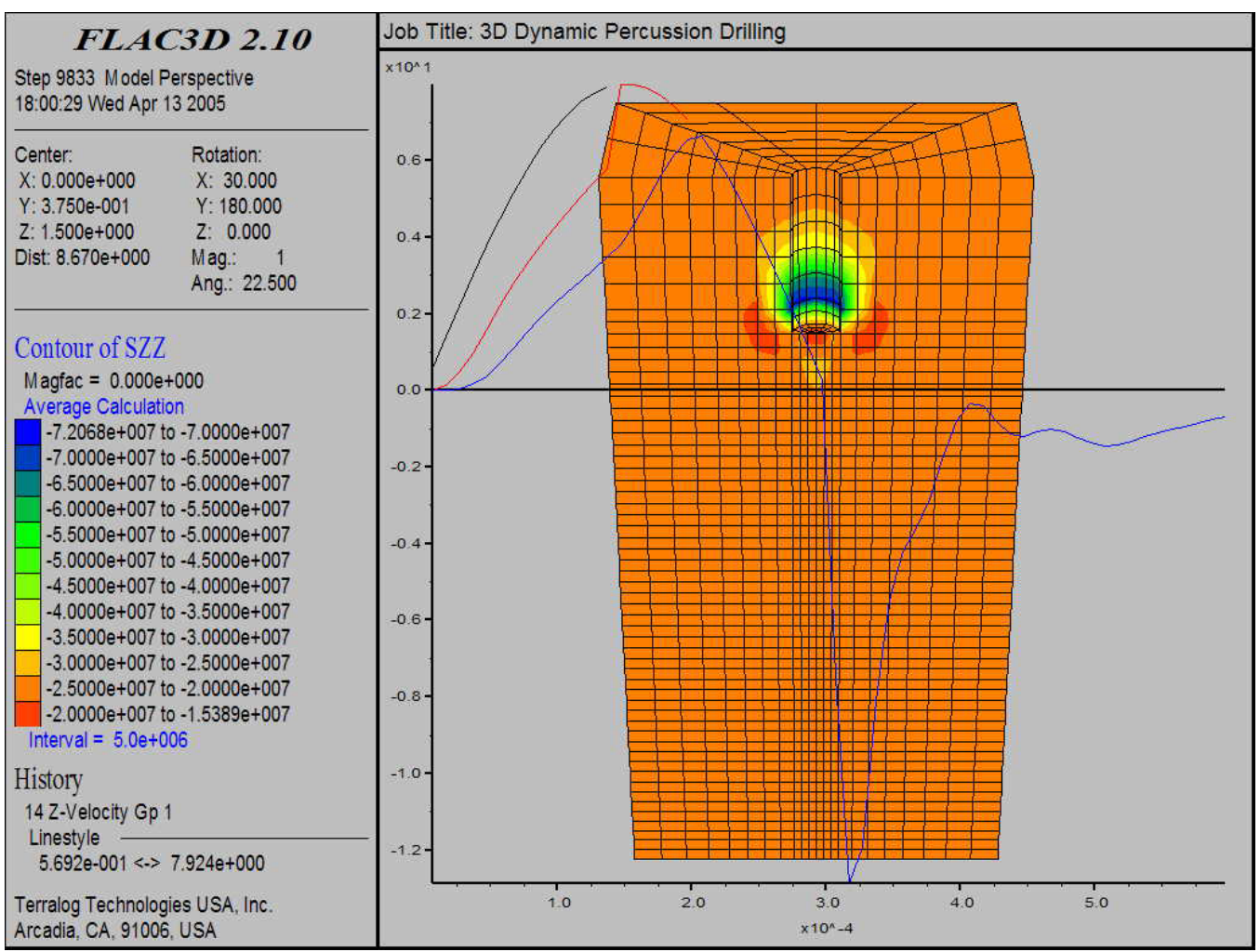

Figure 4-21. Rock vertical stress $\left(\sigma_{\mathrm{zz}}\right)$ in the loading direction at the end of bit retreat (unit: Pa)

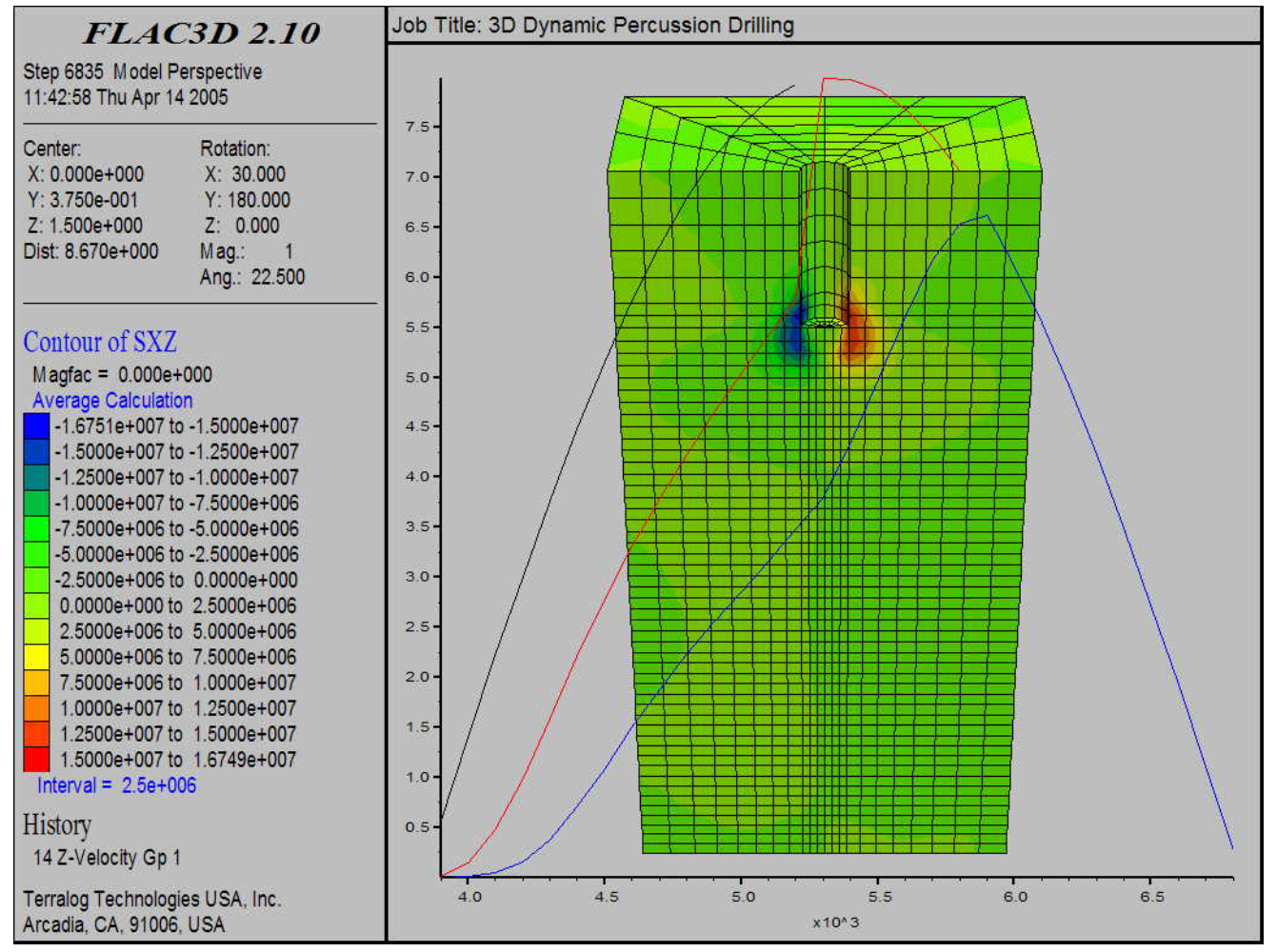

Figure 4-22. Rock shear stress $\left(\tau_{\mathrm{xz}}\right)$ at the end of impact (unit: Pa) 


\section{Damage Development in the Rock with Cyclic Loading}

Five cycles are imposed to investigate the initiation and accumulation of rock damage.

The velocity profile of at the rock at the hole bottom is plotted in Figure 4-23.

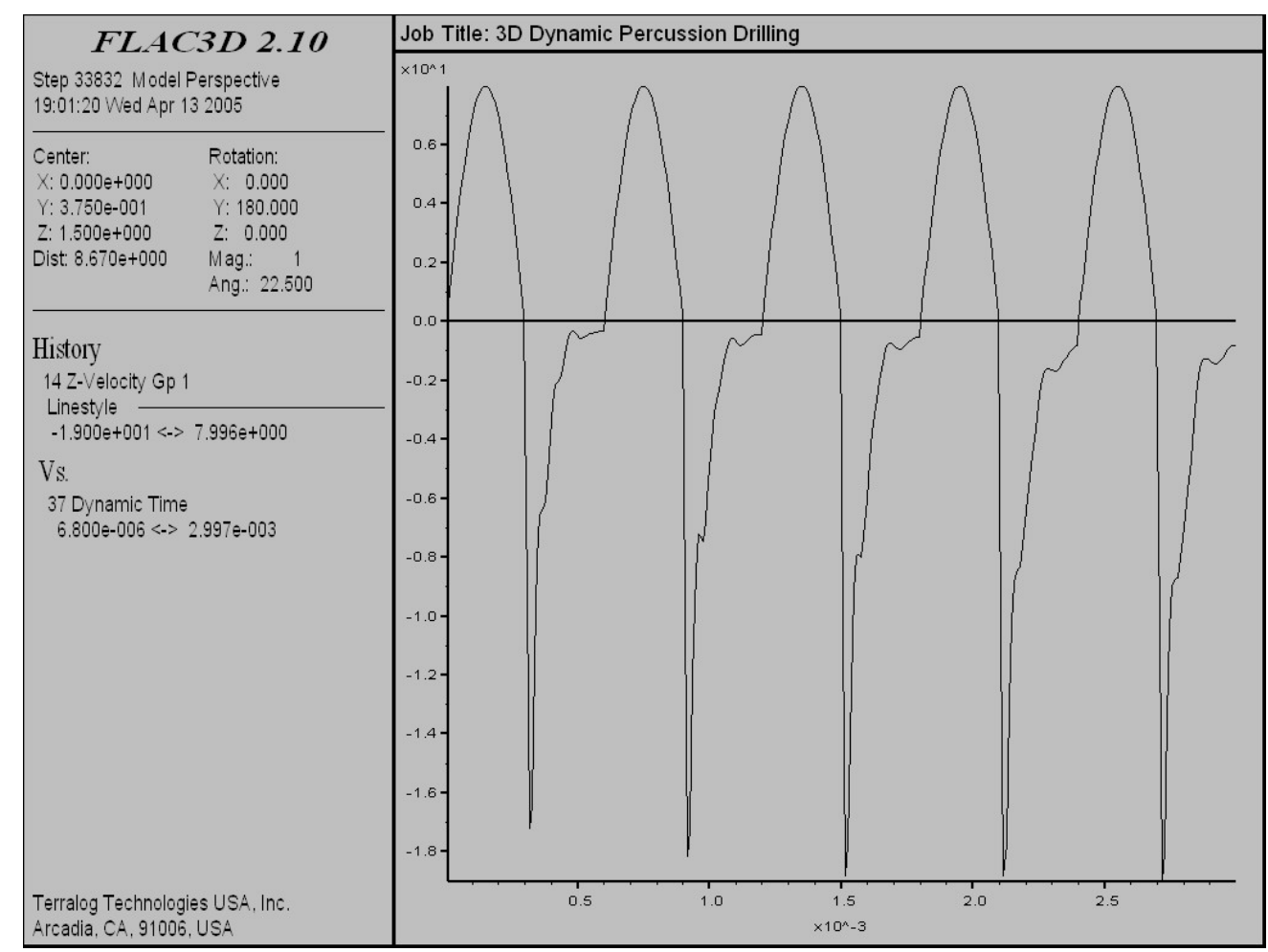

Figure 4-23. Velocity profile of the first impacted element without bit advancement (unit: $\mathrm{m} / \mathrm{s}$ )

The numerical program developed in this research can describe propagation of rock damage and fatigue with number of cycles in both graphs (Figure 4-24 to Figure 4-28) and text document (Figure 4-29). As shown from Figure 4-24 to Figure 4-28, the damage has clearly propagated into deeper rock elements with more impact cycles. The text document describes which element has experienced or experiences how many fatigue cycles, and the remaining strength after these cycles. For example, zone \#6, which is directly below the impact, has experienced five effective cycles. i.e., for five times, rock compressive stress $\left(\sigma_{\mathrm{zz}}\right)$ has exceeded 75 percent of rock compressive strength at the current level of confining stress (18.3MPa). Even though various elements have experienced the same number of fatigue cycles, e.g. zone \#6 and zone \#7, their cohesive strengths may be different, as they may also be in different stages of strain-weakening. Figure 4-29 summarizes the damage propagation in terms of number of elements and 
their depth. Both of them follow the same trend, which means the damage progresses vertically and smoothly. For the rock model studied, the elements as deep as $0.35 \mathrm{~m}$ below the impact surface are damaged to some extent after five impacts.

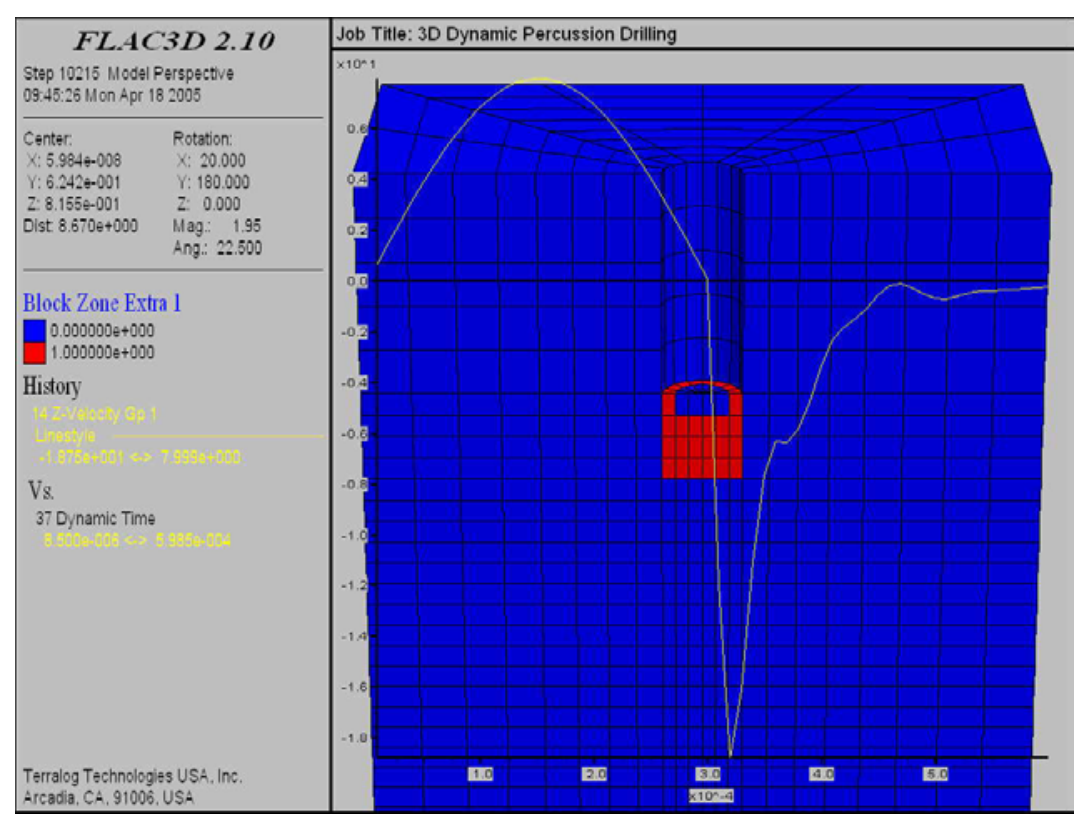

Figure 4-24. Number of damaged rock elements after the $1^{\text {st }}$ impact

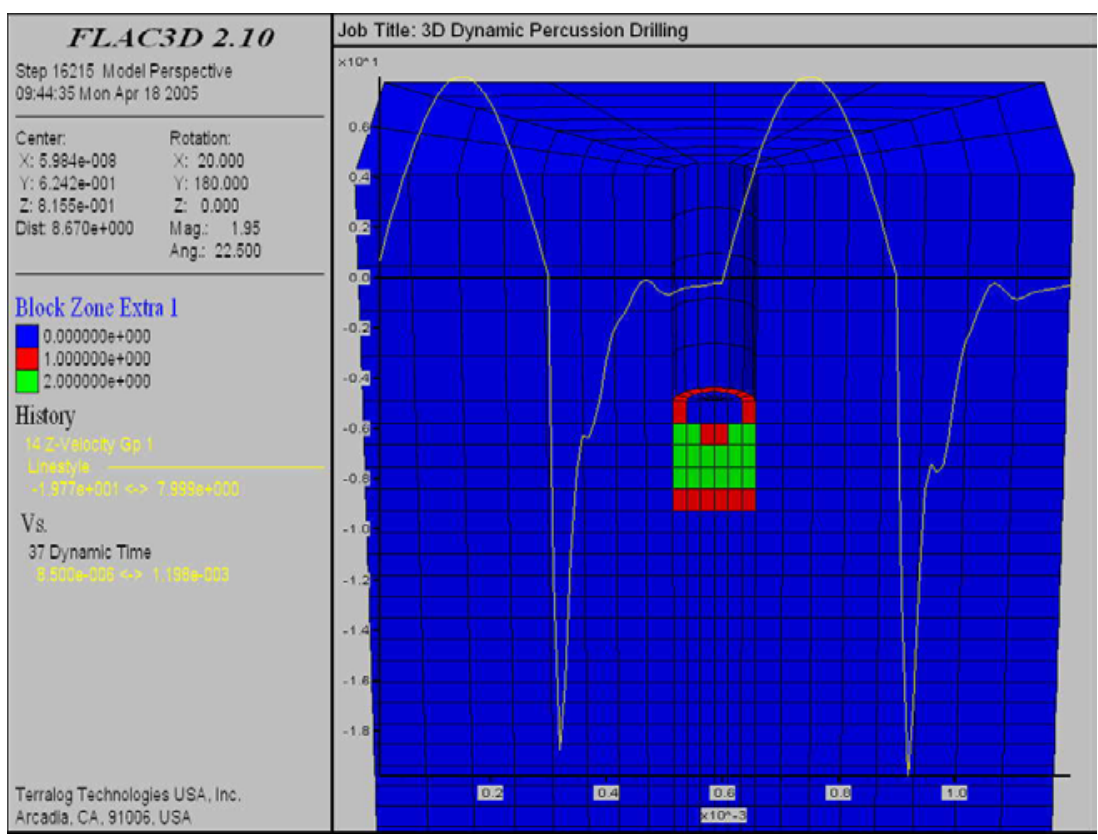

Figure 4-25. Number of damaged rock elements after the $2^{\text {nd }}$ impact 


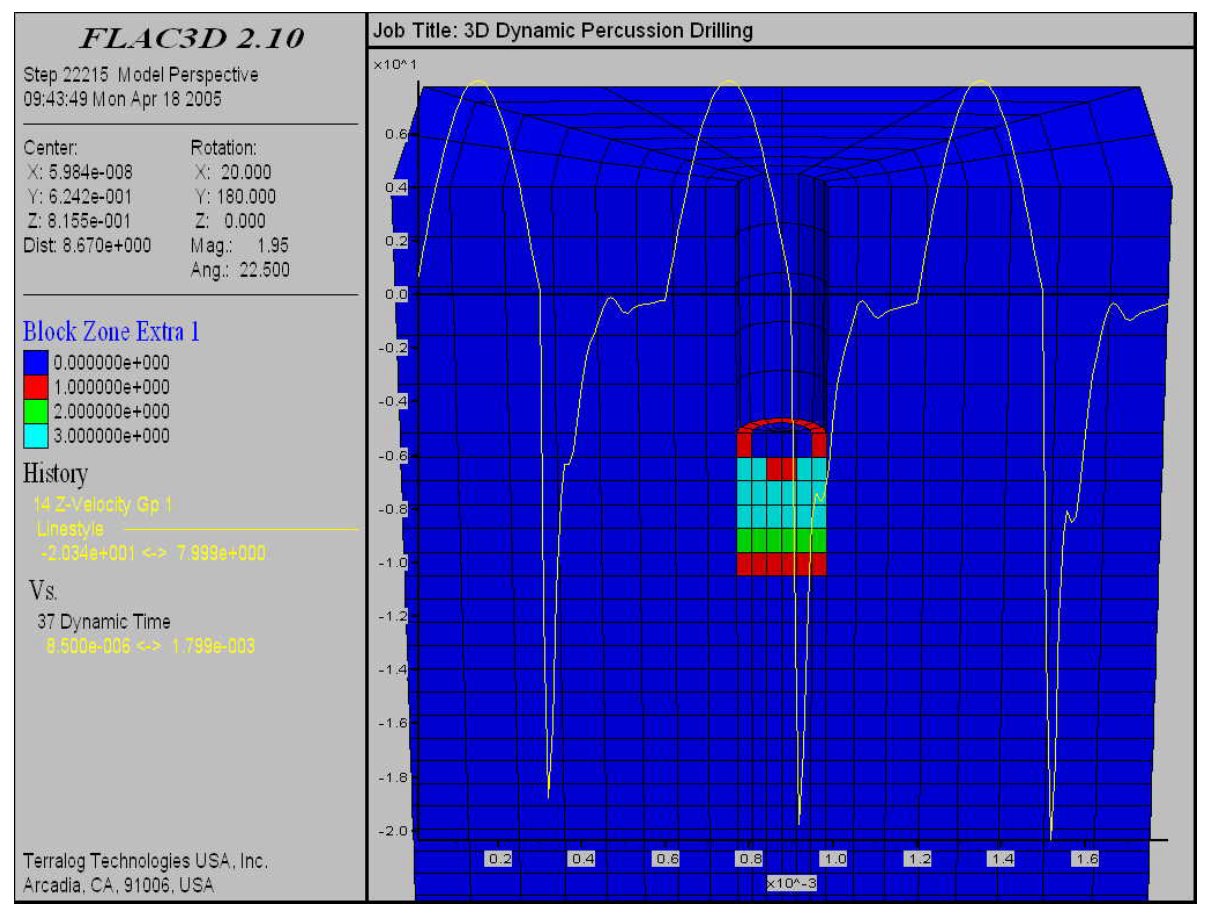

Figure 4-26. Number of damaged rock elements after $3^{\text {rd }}$ impact

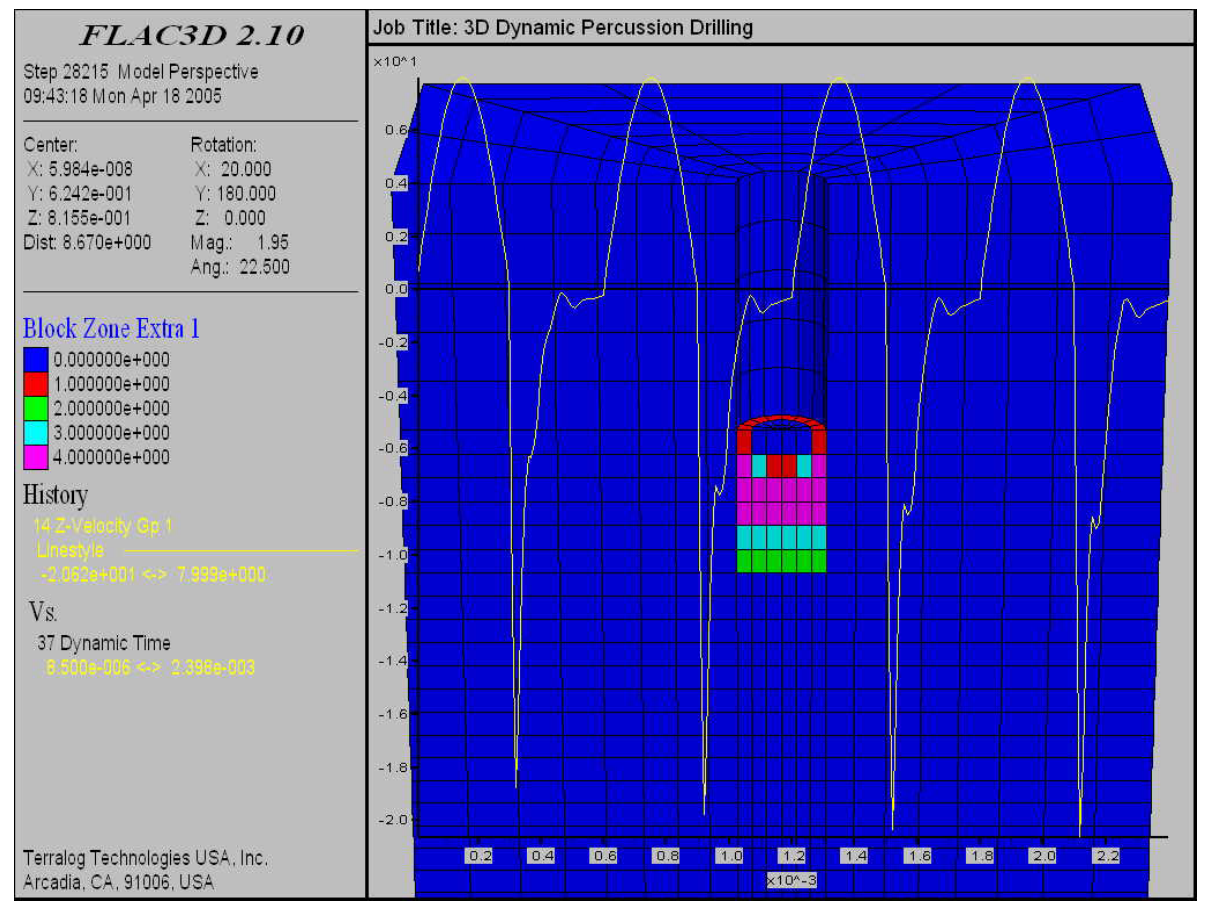

Figure 4-27. Number of damaged rock elements after $4^{\text {th }}$ impact 


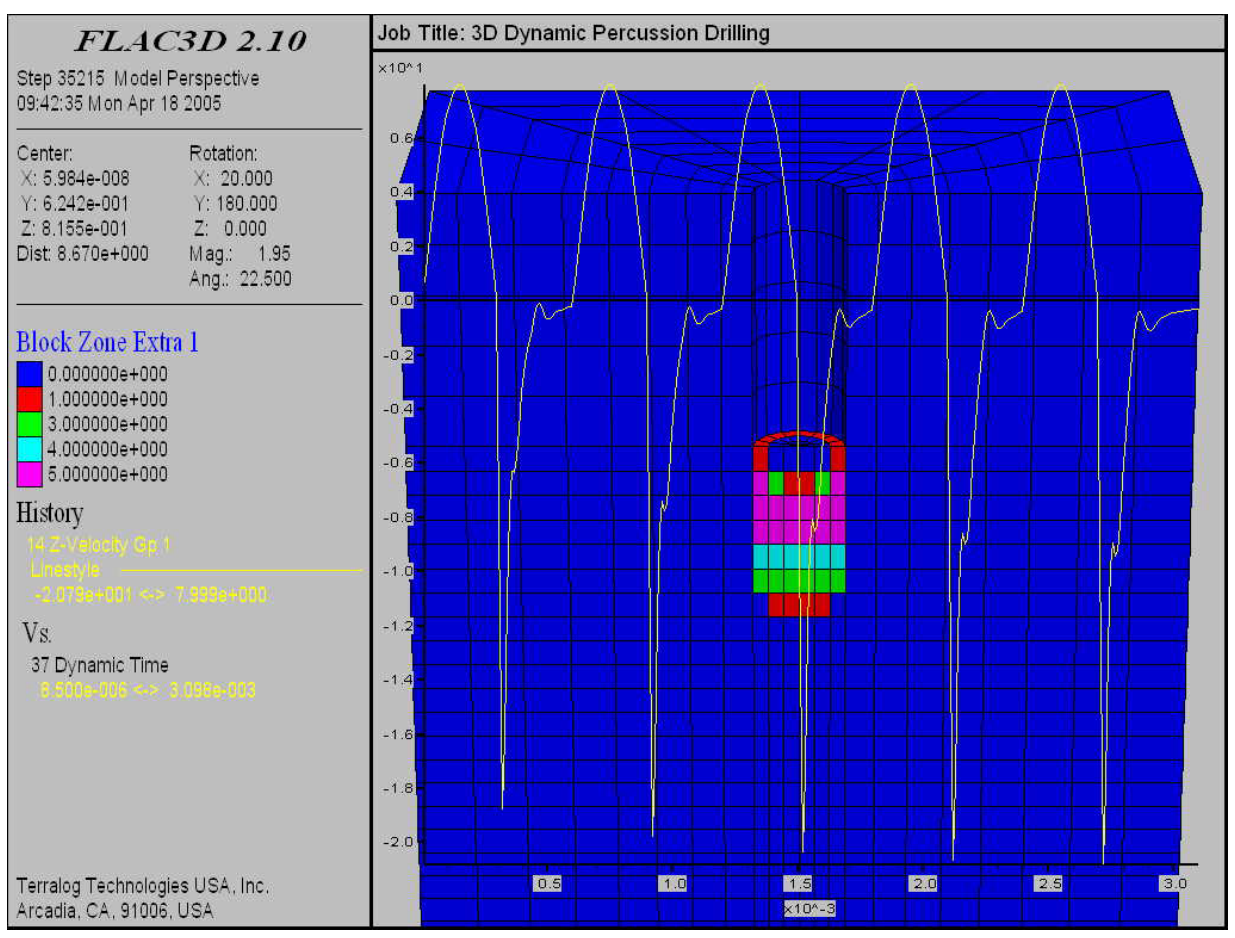

Figure 4-28. Number of damaged rock elements after $5^{\text {th }}$ impact

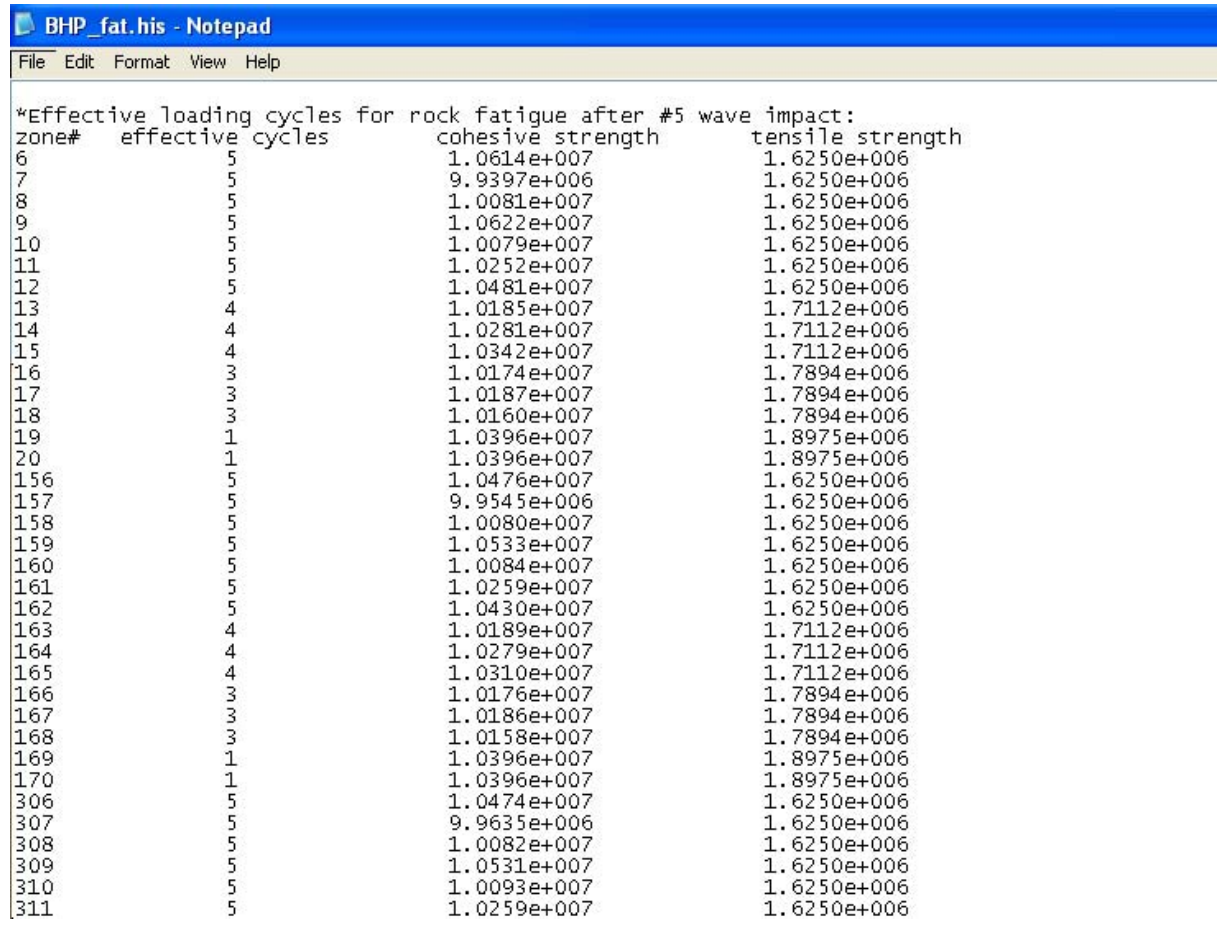

Figure 4-29. History for each fatigued/damaged element without bit advancement 


\section{Bit Penetration and Pore Pressure}

With rock failure being removed from the model, the velocity profile of elements close to the impact surface is plotted in Figure 4-30. The discontinuity of curves is due to a lack of available data after the removal of the failed elements. The sudden jump of the velocity profiles accounts for the effect that after the failed element is removed, the hammer velocity immediately is imposed on the next adjacent element since the cuttings removal from the failed surface is assumed instantaneously. The distribution of vertical stress $\left(\sigma_{z z}\right)$ at the end of simulation is pictured in Figure 4-31.

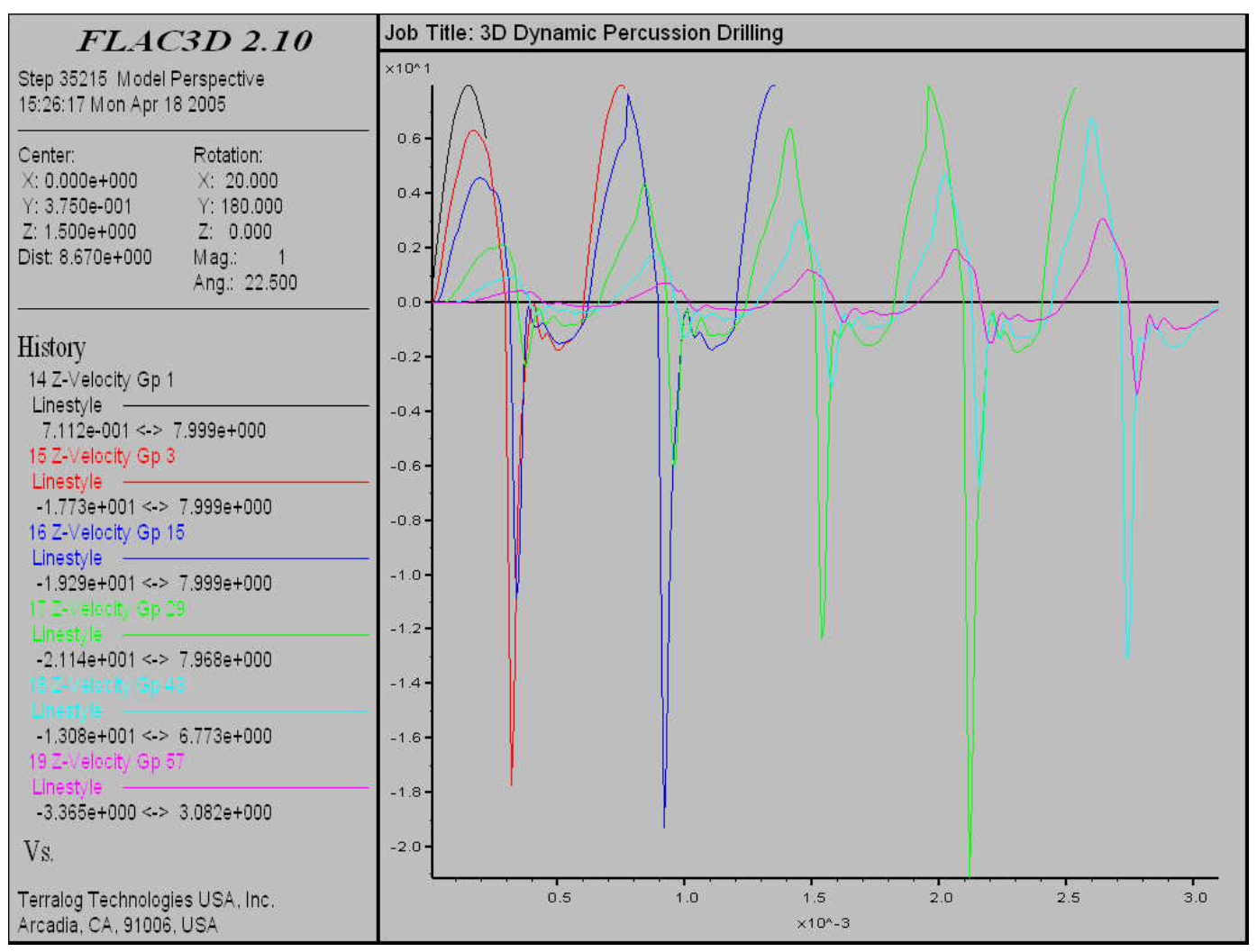

Figure 4-30. Rock velocities close to the impact surface with bit advancement and mud pressure of 10MPa (unit: $\mathrm{m} / \mathrm{s}$ ) 


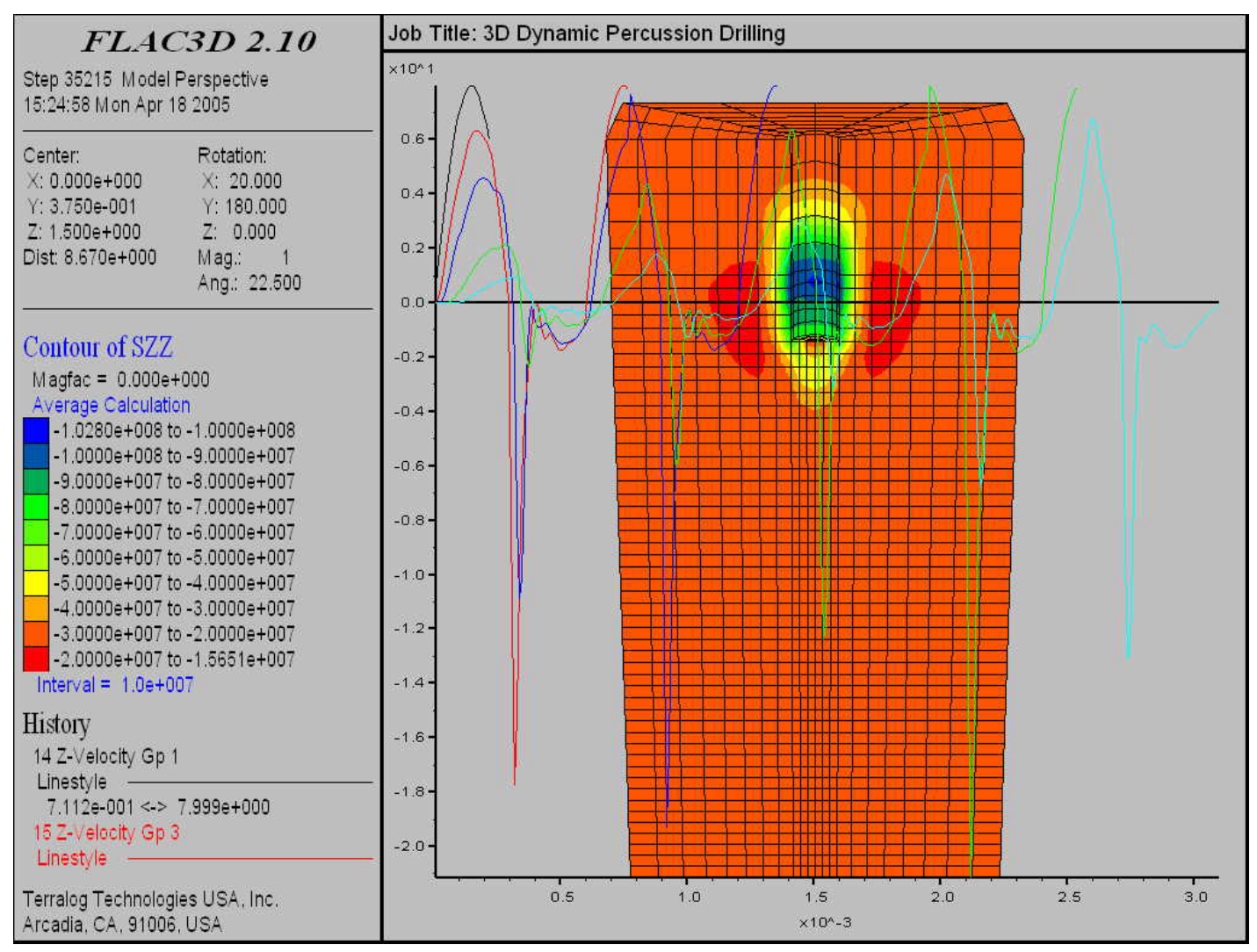

Figure 4-31. Distribution of rock vertical stress after bit advancement of 0.5m (unit: Pa)

Effect of Bottom Hole Pressure (BHP) on Rate of Penetration is also investigated and plotted in Figure 4-32. Comparing to the blue line, where BHP is assumed to be as high as $10 \mathrm{MPa}$, the pink line, which represents zero BHP (e.g. in the case of air hammer drilling), indicates a significant increase in bit advancement. This agrees with experiment and field observations. There are several speculations on the mechanisms behind this increase of ROP, such as effect loading stress is decreased as a result in the increase of BHP, higher confining stress around the rock results in higher rock compressive strength, or no compressing stress from drilling fluid allows rock to more easily deform in tension with bit retreat. Usually rock tensile strength is much smaller (1/5 to $1 / 10$ of rock compressive strength). The failure histories for both drilling with BHP (i.e. 10MPa) and without BHP (i.e. air drilling) clearly reveal a significant amount of elements have failed in tension when bit retreats (after $3.0 \times 10^{-4} \mathrm{sec}$ ) during the first wave impact. 


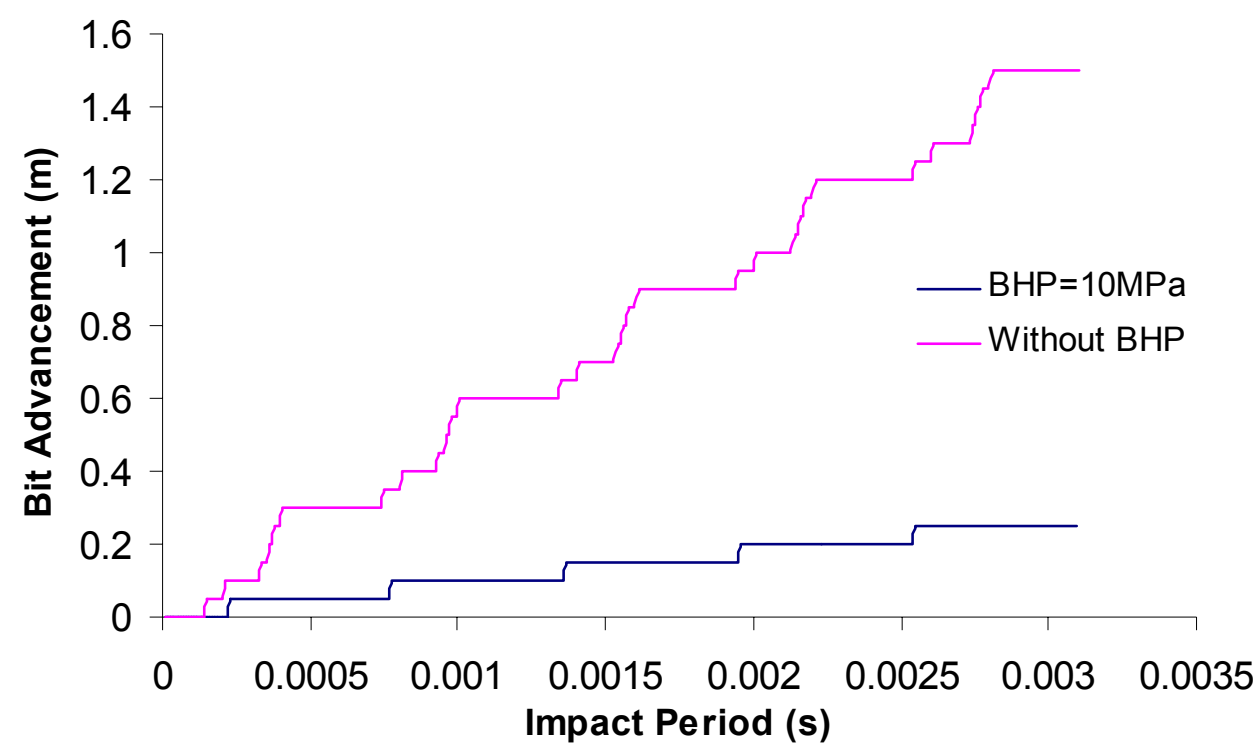

Figure 4-32. Bit advancement with and without bottom hole pressure

\subsubsection{Numerical Simulation of Cuttings Transport}

\section{Model Geometry}

Figure 4-33 demonstrates the generated model for drillpipe and annulus (transparent).

Note that the cylindrical and spiral walls are plotted as wire frames consisting of multiple flat plates, while the geometry of the walls are formulated analytically in the PFC3D kernel, and are continuously curved.

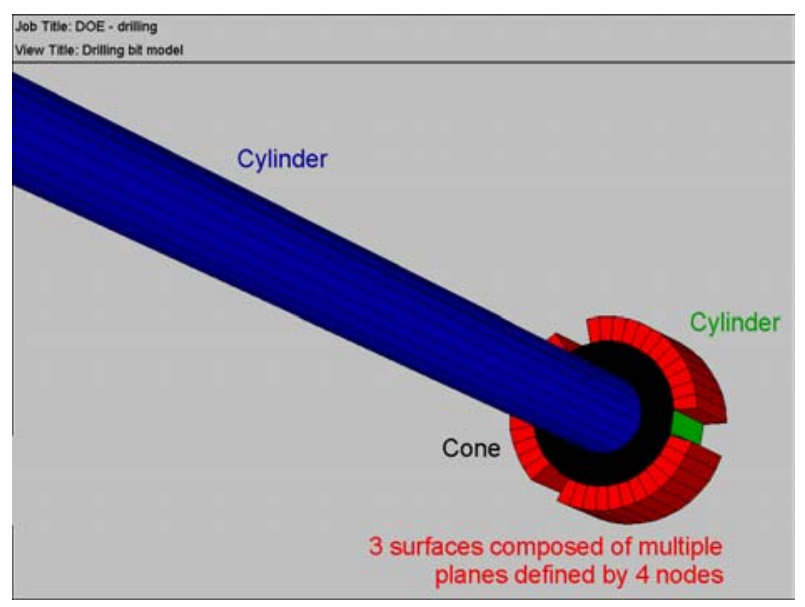

Figure 4-33. Drillpipe configuration in cuttings transportation 


\section{Cuttings Generation}

Particles are generated at the bottom of the wellbore in the three slots. Different shapes of cuttings are generated, including spheres (1, 2, 4, 7 particles), plate (8 particles), cluster, clumps, or random shape. They are summarized in Figure 4-34. Each of them can be created randomly within one of the three slots (Figure 4-35).

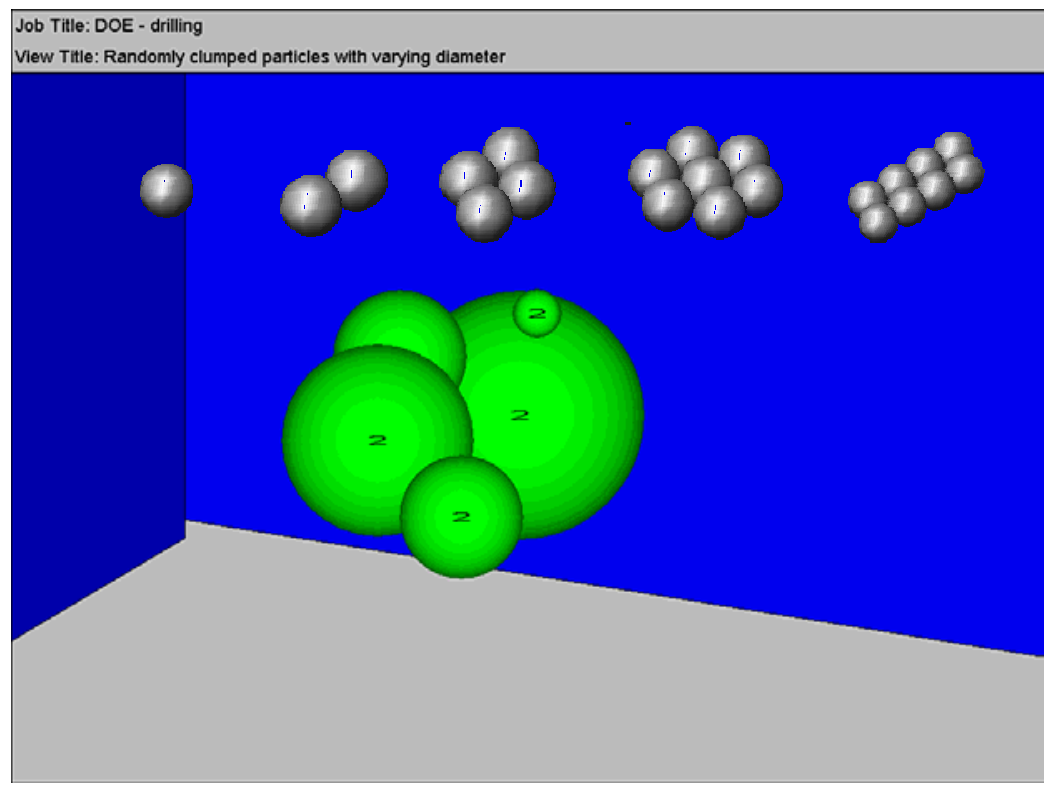

Figure 4-34. Different particles configurations in cuttings transport

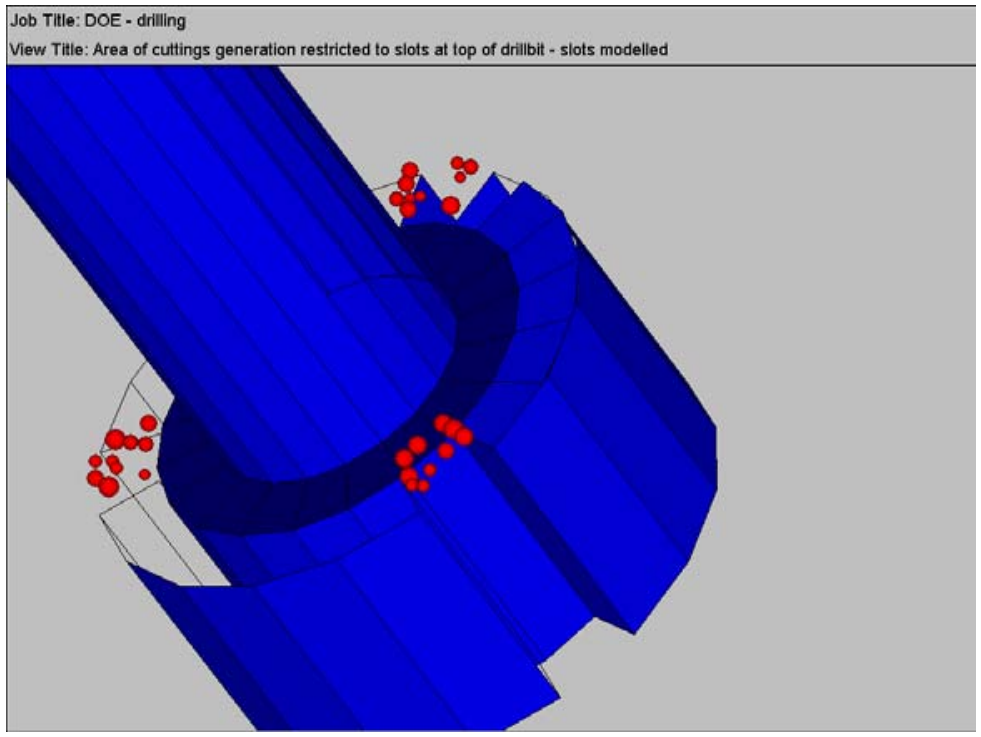

Figure 4-35. Entry locations for cuttings 


\section{$\underline{\text { Parameter Sensitivity Studies }}$}

There are numerous factors related to cuttings transport such as pump rate, fluid viscosity (currently Newtonian theology active), density, particle shape and mass, rotation rate, penetration rate, type of flow regime, etc. We have studied the influence of pump rate and viscosity (cutt \#68 and cutt \#71) in this research. The details of these two simulations are listed in Table 4-4. In cutt 68, almost no ability for cuttings transportation since a very low pump rate of $0.00063 \mathrm{~m}^{3} / \mathrm{s}(0.1673 \mathrm{gal} / \mathrm{s})$ and low viscosity of 0.004 Pas $(4 \mathrm{cp})$ was used. The cuttings transport efficiency has been improved in simulation cutt 71, where fluid viscosity and pump rate are increased to 0.04 Pas $(40 \mathrm{cp})$ and $0.006 \mathrm{~m}^{3} / \mathrm{s}$ (1.585 gal/s), respectively. Different cutting colors, blue, red, and yellow, represent different entry slots (Figure 4-36).
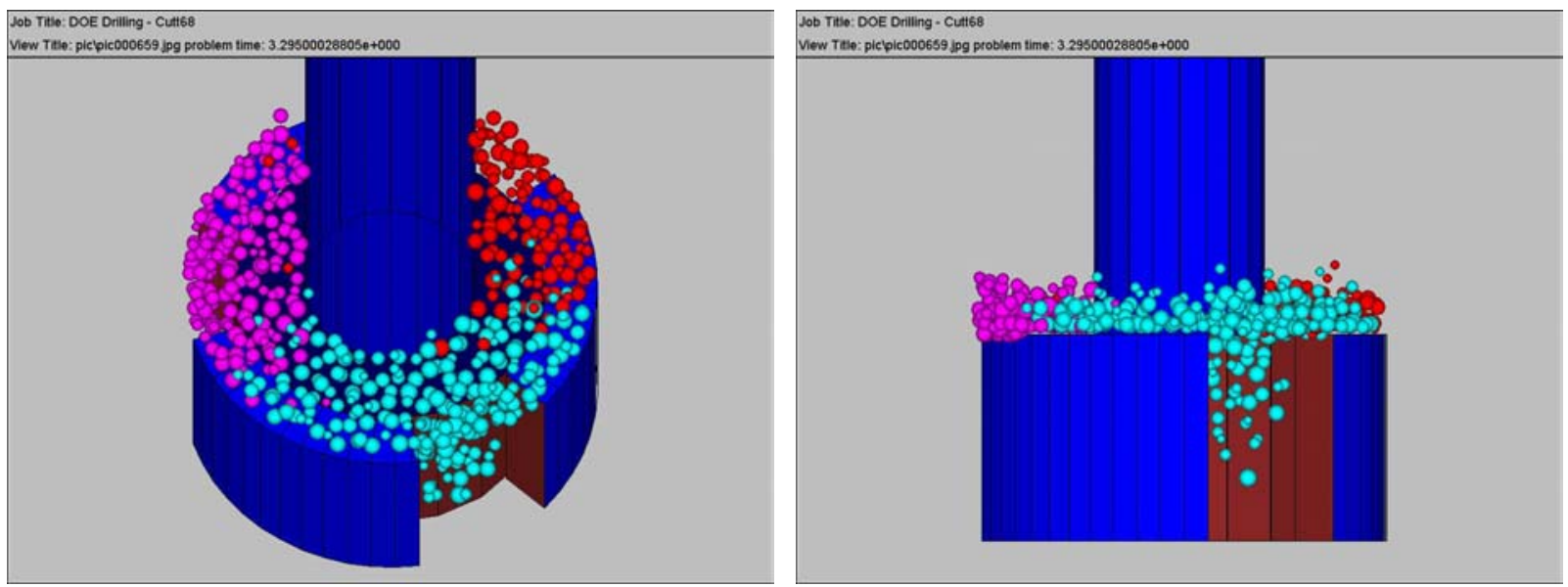

Figure 4-36. Particles behavior in the simulation cutt68 
Table 4-4. Data used in parameter-sensitivity analysis

\begin{tabular}{|c|c|c|c|c|c|c|c|c|}
\hline \multirow[b]{3}{*}{ GEOMETRY } & \multicolumn{4}{|c|}{ Cutt68 - vertical well bore, worst case \#1 } & \multicolumn{4}{|c|}{ Cutt71 - vertical well bore, worst case \#2 } \\
\hline & \multicolumn{2}{|c|}{$\begin{array}{c}\text { SI units } \\
\end{array}$} & \multicolumn{2}{|c|}{ Field units } & \multicolumn{2}{|c|}{ SI units } & \multicolumn{2}{|c|}{ Field units } \\
\hline & & & & & & & & \\
\hline well bore radius & 0.108 & $\mathrm{~m}$ & $4.25 \mathrm{i}$ & in & 0.108 & $\mathrm{~m}$ & 4.25 & in \\
\hline well bore height & 2.268 & $m$ & $7.44 \mathrm{f}$ & $\mathrm{ft}$ & 2.268 & $\mathrm{~m}$ & 7.44 & $\mathrm{ft}$ \\
\hline drill pipe radius & 0.04445 & $\mathrm{~m}$ & 1.75 & in & 0.04445 & $\mathrm{~m}$ & 1.75 & in \\
\hline drill bit height & 0.108 & $\mathrm{~m}$ & $4.25 \mathrm{i}$ & in & 0.108 & $\mathrm{~m}$ & 4.25 & in \\
\hline wall normal stiffness & $2.00 \mathrm{E}+08$ & $\mathrm{~N} / \mathrm{m}$ & $1.37 \mathrm{E}+07$ & $\mathrm{Ibf} / \mathrm{ft}$ & $2.00 \mathrm{E}+08$ & $\mathrm{~N} / \mathrm{m}$ & 1.37E+07 & Ibf/ft \\
\hline wall shear stiffness & $2.00 \mathrm{E}+08$ & $\mathrm{~N} / \mathrm{m}$ & $1.37 \mathrm{E}+07$ & $\mathrm{Ibf} / \mathrm{ft}$ & $2.00 \mathrm{E}+08$ & $\mathrm{~N} / \mathrm{m}$ & $1.37 \mathrm{E}+07$ & $\mathrm{lbf} / \mathrm{ft}$ \\
\hline wall friction & 0 & & 0 & & 0 & & 0 & \\
\hline number of slots & 3 & & 3 & & 3 & & 3 & \\
\hline slot opening angle & 40 & $\circ$ & 40 & $\circ$ & 40 & $\circ$ & 40 & ${ }^{\circ}$ \\
\hline inner slot radius & 0.081 & $\mathrm{~m}$ & $3.19 \mathrm{i}$ & in & 0.081 & $\mathrm{~m}$ & 3.19 & in \\
\hline well bore deviation & 0 & $\circ$ & 0 & $\circ$ & 0 & $\circ$ & 0 & o \\
\hline \multicolumn{9}{|l|}{ FLUID } \\
\hline density & 1497 & $\mathrm{~kg} / \mathrm{m}^{3}$ & 12.5 & Ib/gal & 1497 & $\mathrm{~kg} / \mathrm{m}^{3}$ & 12.5 & Ib/gal \\
\hline viscosity & 0.004 & $\mathrm{Pas}$ & & $\mathrm{cp}$ & 0.04 & $\mathrm{Pas}$ & 40 & $\mathrm{cp}$ \\
\hline rheology & \multicolumn{4}{|c|}{ Newtonian } & \multicolumn{4}{|c|}{ Newtonian } \\
\hline \multicolumn{9}{|l|}{ CUTTINGS/PARTICLES } \\
\hline density & 2650 & $\mathrm{~kg} / \mathrm{m}^{3}$ & 22.12 & Ib/gal & 2650 & $\mathrm{~kg} / \mathrm{m}^{3}$ & 22.12 & Ib/gal \\
\hline radius & $0.0025-0.005$ & $\mathrm{~m}$ & $0.098-0.197$ & in & $0.0025-0.005$ & $\mathrm{~m}$ & $0.098-0.197$ & in \\
\hline ball normal stiffness & $1.00 \mathrm{E}+08$ & $\mathrm{~N} / \mathrm{m}$ & $6.85 \mathrm{E}+06$ & $\mathrm{Ibf} / \mathrm{ft}$ & $1.00 \mathrm{E}+08$ & $\mathrm{~N} / \mathrm{m}$ & $6.85 \mathrm{E}+06$ & Ibf/ft \\
\hline ball shear stiffness & $1.00 \mathrm{E}+08$ & $\mathrm{~N} / \mathrm{m}$ & $6.85 \mathrm{E}+06$ & $\mathrm{Ibf} / \mathrm{ft}$ & $1.00 \mathrm{E}+08$ & $\mathrm{~N} / \mathrm{m}$ & $6.85 \mathrm{E}+06$ & $\mathrm{lbf} / \mathrm{ft}$ \\
\hline ball friction coefficient & 0 & & 0 & & 0 & & 0 & \\
\hline \multicolumn{9}{|l|}{ OPERATING CONDITIONS } \\
\hline pump rate & 0.0006333 & $\mathrm{~m}^{3} / \mathrm{s}$ & 0.1673 & gal/s & 0.006 & $\mathrm{~m}^{3} / \mathrm{s}$ & 1.5850 & gal/s \\
\hline average fluid velocity within annulus & 0.2054 & $\mathrm{~m} / \mathrm{s}$ & 0.6738 & in/s & 1.9456 & $\mathrm{~m} / \mathrm{s}$ & 6.3833 & $\mathrm{in} / \mathrm{s}$ \\
\hline Reynolds number & 4884 & & 4884 & & 4627 & & 4627 & \\
\hline assumed flow regime & \multicolumn{4}{|c|}{ laminar } & \multicolumn{4}{|c|}{ laminar } \\
\hline rate of penetration & 10 & $\mathrm{~m} / \mathrm{h}$ & $32.81 \mid f$ & $\mathrm{ft} / \mathrm{h}$ & 10 & $\mathrm{~m} / \mathrm{h}$ & 32.81 & $\mathrm{ft} / \mathrm{h}$ \\
\hline rotation rate & 1.047 & $\mathrm{rad} / \mathrm{s}$ & $10 \mathrm{r}$ & $\mathrm{rpm}$ & 1.047 & $\mathrm{rad} / \mathrm{s}$ & 10 & rpm \\
\hline
\end{tabular}




\section{Cases Studied}

Using the data input listed in Table 4-5, continuous cuttings generation has been achieved with PFC3D (Figure 4-37). Note that different colors in the figure represent different ages of drilling cuttings with bit progression.

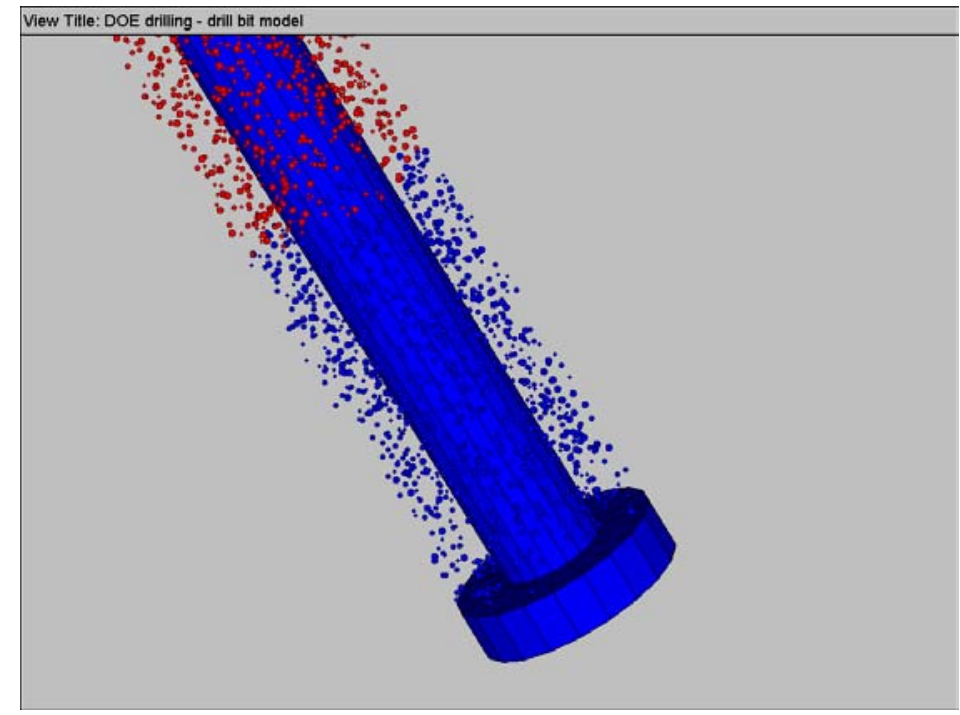

Figure 4-37. Modeling cuttings transport with PFC3D

Table 4-5. Data for PFC3D simulations on cuttings transportation

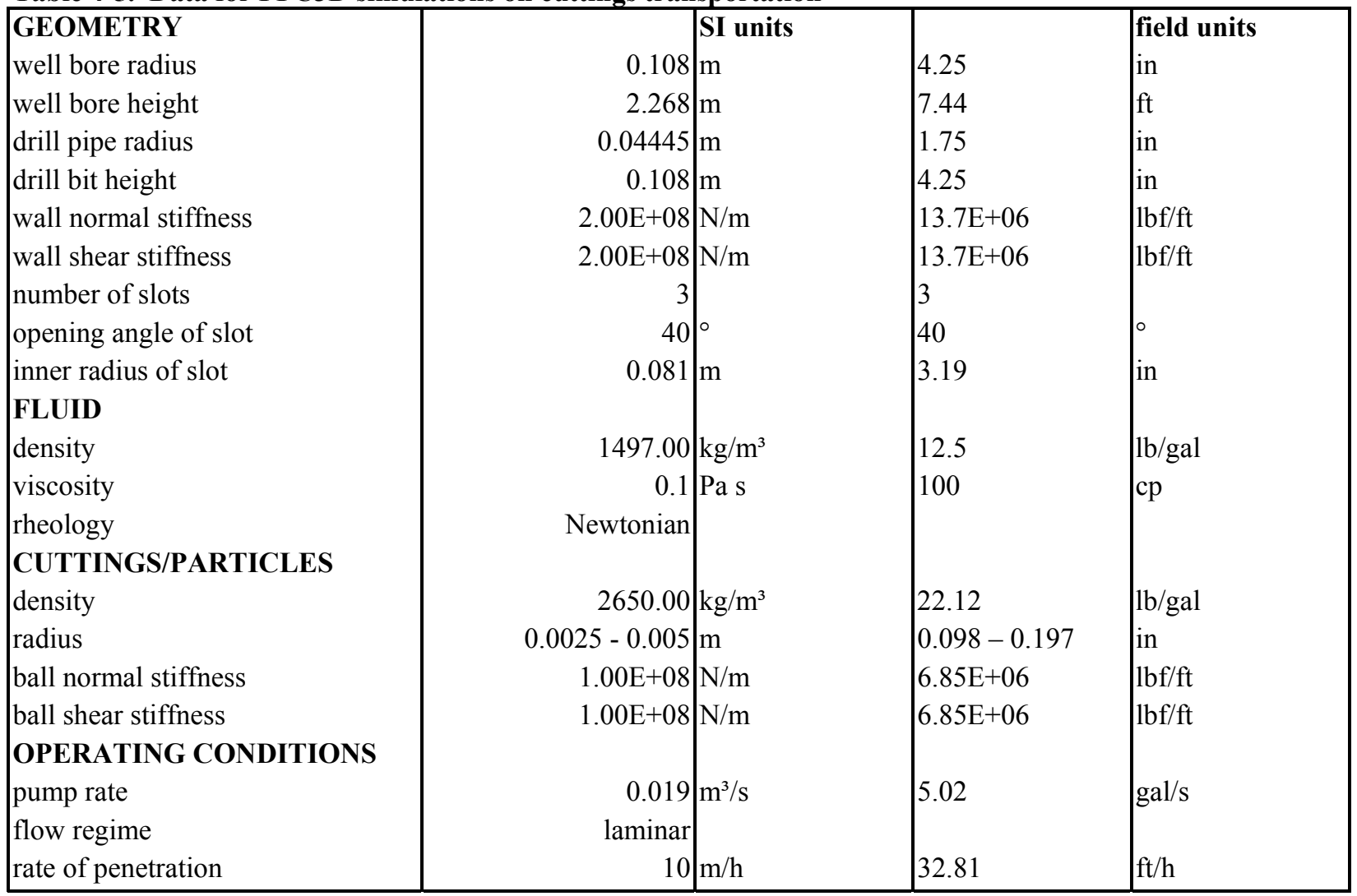


The efficiency of cuttings transport is directly visualized three-dimensionally and the effects of pipe rotation, particle entry speed, particle collisions, and mud circulation rate are investigated. First, cuttings transport in a vertical well with slow pipe rotation is studied (Figure 4-38). Compared to the situation where the pipe rotates much faster (Figure 4-39), the cuttings are less mixed and the axial flow is dominant in the slow pipe rotation case. This confirms that the rotation of the pipe mainly serves to mix the cuttings with mud into a homogenous fluid for efficient cuttings circulation. Without enough entry speed, i.e. mud circulation rate, as shown in Figure 4-40, most cuttings will fall down to the bottom of the annulus after a short lift, due to the effect of gravity. One big advantage of this simulation tool is to quantify, with the presence of pipe rotation, how efficient a mud circulation could be to remove drilling cuttings, and therefore to setup operation guidelines for field engineers.

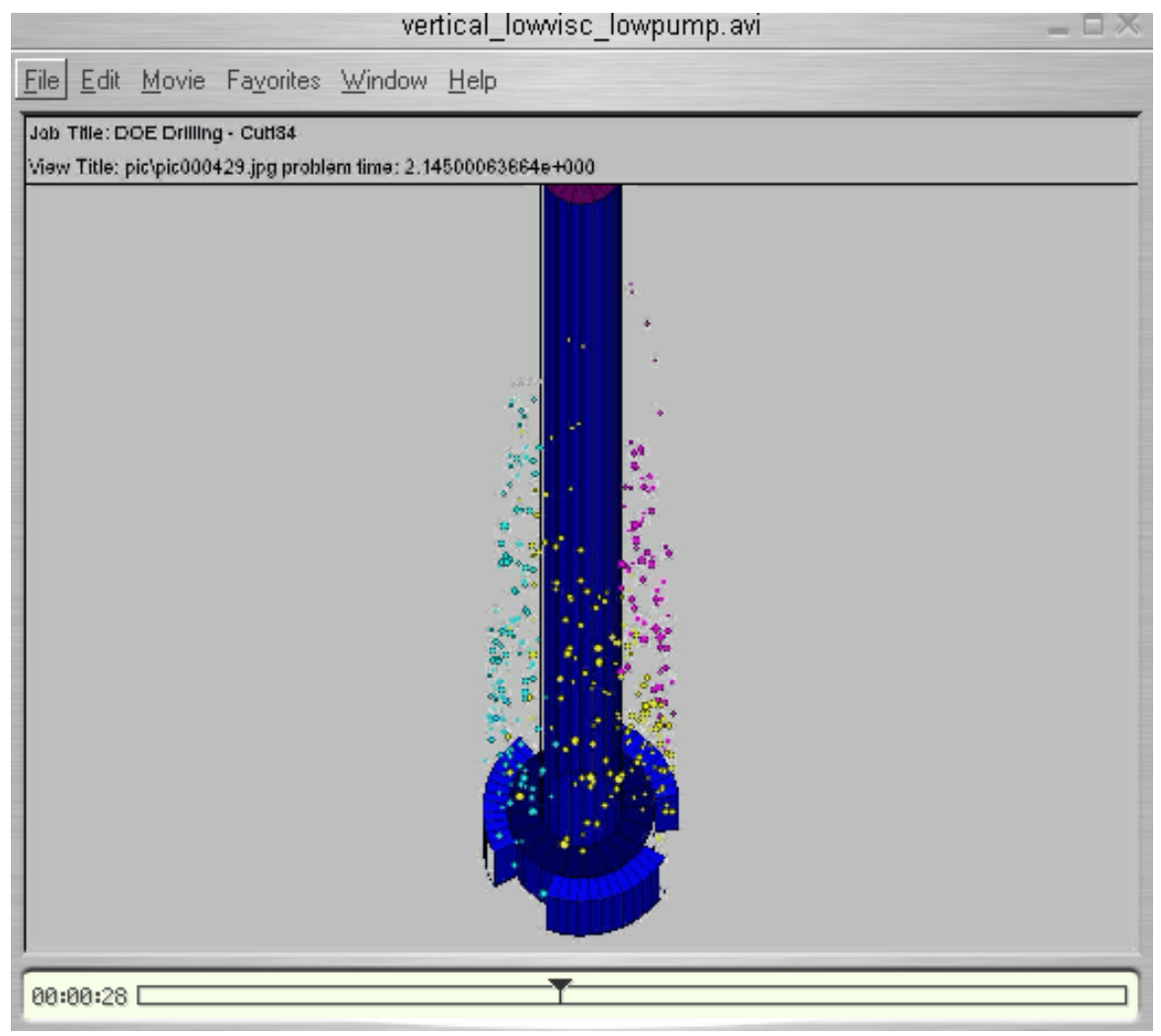

Figure 4-38. Cuttings transport in a vertical well with slow pipe rotation and mud circulation 


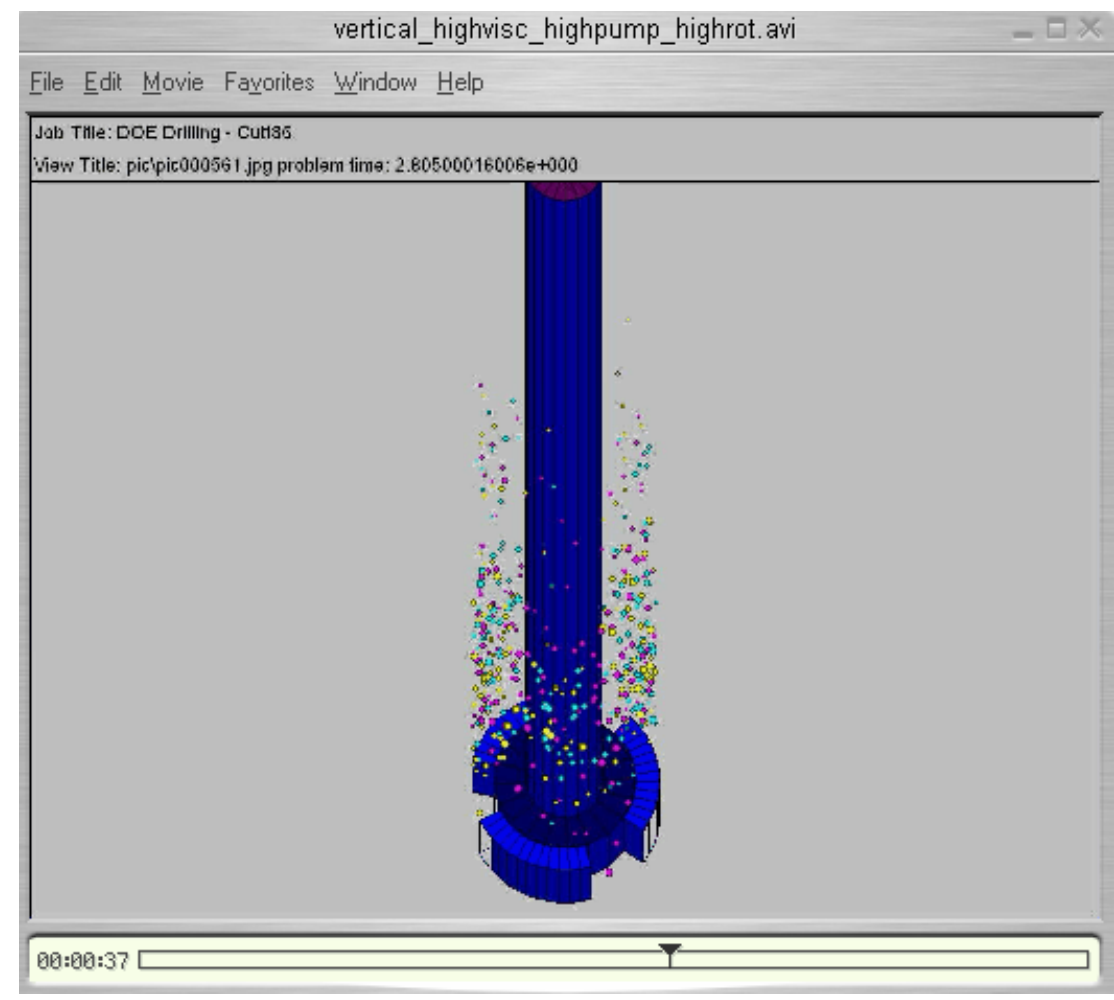

Figure 4-39. Cuttings transport in a vertical well with fast pipe rotation and mud circulation

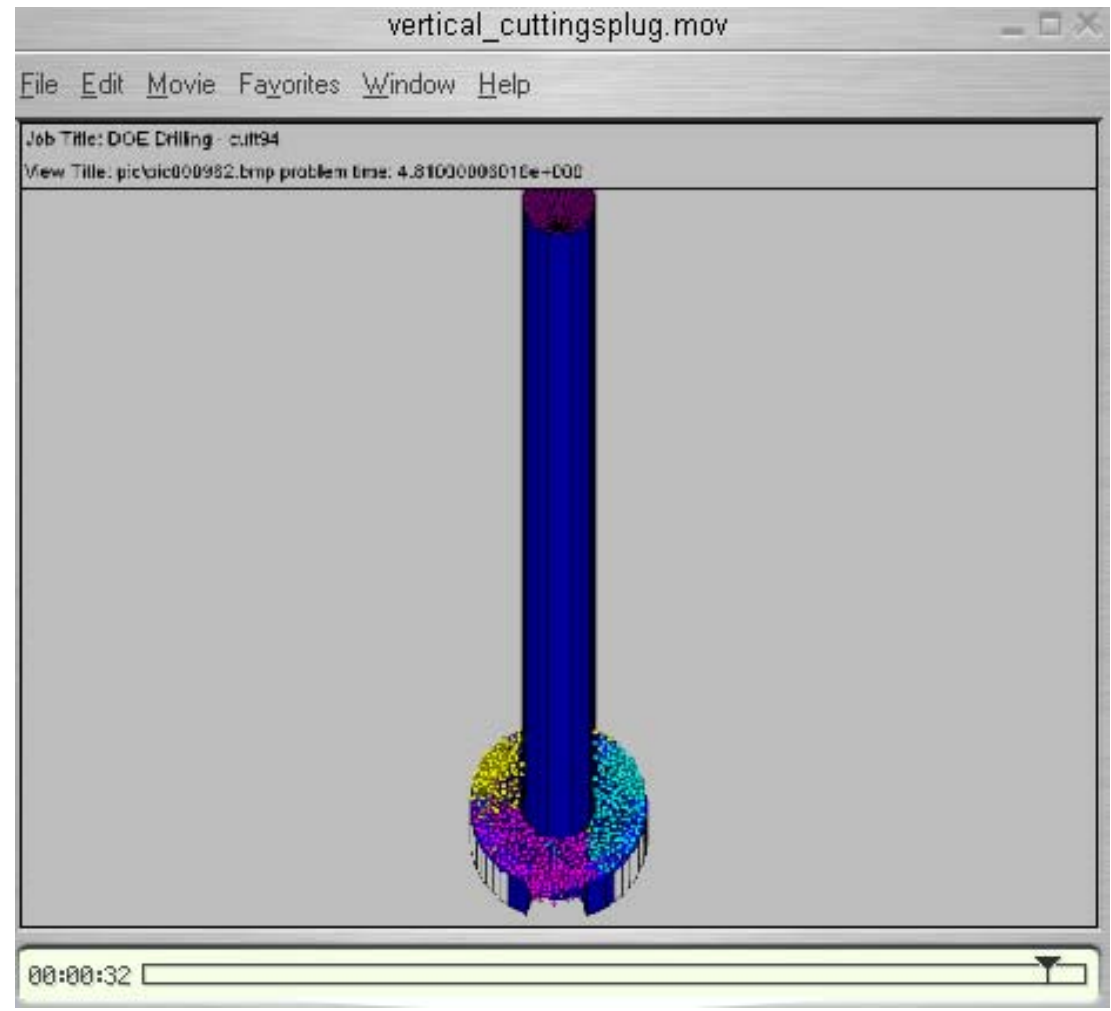

Figure 4-40. Inefficient cuttings transport due to slow mud circulation 


\section{FULL SCALE LAB TESTS}

The details of full scale lab tests can be found in the report 41999R07.doc. In summary, the tests can be divided into two categories: single impact tests with single indentor and full-scale fluid hammer tests under field conditions.

\subsection{Rock Property Determinations}

Both Berea sandstone and Mancos shale are used as samples. Their mechanical properties, including moduli, Poisson's ratio, cohesive strength, friction angle, tensile strength, etc., are first determined from confined triaxial tests and Brazilian tests.

\subsection{Single Impact Tests}

While the samples in the impact tests are $12.7 \mathrm{~cm}$ (diameter) by $10 \mathrm{~cm}$ (depth), those in the hammer tests are $39.4 \mathrm{~cm}$ (diameter) by $91.4 \mathrm{~cm}$ (length). For each impact test, three impacts are sequentially loaded at the same rock location to investigate rock response to repetitive loadings. After each impact, crater depth and width are measured and rock debris is washed out to leave a clean rock surface for the next impact. Meanwhile, the displacement and force in the rod, as well as the force in the rock are recorded at high frequency levels of about $100 \mathrm{KHz}$. Various pressure differences across the rockindentor interface (i.e. bore pressure minus pore pressure) are implemented to investigate the pressure effect on rock penetration.

\subsection{Full Scale Drilling Tests}

For hammer drilling tests, an industrial fluid hammer is used to drill both Berea sandstone and Mancos shale under both underbalanced and overbalanced conditions. The bottom hole pressure varies from 3.4MPa to $20.7 \mathrm{MPa}$ while pore pressure is controlled separately, varying from $0 \mathrm{psi}$ to $24.2 \mathrm{MPa}$. Water-based mud of $1.2 \mathrm{~g} / \mathrm{cm}^{3}$ density circulates fast enough to clear failed rocks at the hole bottom. During the tests, Rate of Penetration is recorded continuously from one pressure condition to another. Cuttings are collected and analyzed after the tests. 


\section{MODEL VALIDATIONS}

\subsection{Rock Property Determinations}

The material parameters for Berea sandstone used in the FLAC model are summarized in Table 6-1, including wave speed, impedance and constraint modulus, in both SI and field units. This information is used to build the Berea sandstone model for the numerical simulation described in this section. Table 6-2 summarizes the elastic material parameters of the impacting steel anvil.

The constraint modulus is defined as the stiffness, which determines the wave speed for uniaxial wave propagation. It is given by

$$
M=\frac{1-v}{(1+v)(1-2 v)} E
$$

where $v$ is the Poisson ratio and $E$ is the Young's modulus of the material. The specific impedance of the material is defined as the product of the density and wave speed. The transfer of energy at a material interface depends only on the ratio of the specific impedances of the two materials, i.e. the ratio of the specific impedances of the two materials on either side of the interface $\left(\rho_{2} \mathrm{v}_{2} / \rho_{1} \mathrm{v}_{1}\right)$. For an incident wave propagating from a stiffer to a softer material the impedance ratio is less than one. In our specific case this value is equal to 0.12 . For a wave approaching a stiffer material, the impedance ratio is greater than one. Again in our case, this value is equal to 8.33.

We denote by $A_{r}, A_{i}, A_{t}$ the displacement amplitudes of the reflected, incident and transmitted waves. It can be shown that the following relations are satisfied:

$$
\begin{aligned}
& A_{r}=\frac{1-\alpha_{z}}{1+\alpha_{z}} A_{i} \\
& A_{t}=\frac{2}{1+\alpha_{z}} A_{i}
\end{aligned}
$$

where $\alpha_{z}=\rho_{2} \mathrm{~V}_{2} / \rho_{1} \mathrm{~V}_{1}$. These relations are shown in Figure 6-1. For very large impedance ratio's, the reflected displacement wave has the same amplitude as the incoming wave, 
but changes sign. For interfaces with very large impedance ratios, no energy is transmitted.

Table 6-1. Material Parameters of Berea Sandstone

\begin{tabular}{|l|rl|rl|}
\hline & \multicolumn{2}{|c|}{ SI Units } & \multicolumn{2}{c|}{ Field Units } \\
\hline Bulk modulus & $8.75 \mathrm{E}+03$ & $\mathrm{MPa}$ & $1.27 \mathrm{E}+06 \quad$ Psi \\
\hline Shear modulus & $4.28 \mathrm{E}+03$ & $\mathrm{MPa}$ & $6.21 \mathrm{E}+05 \quad$ Psi \\
\hline Young's modulus & $1.10 \mathrm{E}+4$ & $\mathrm{MPa}$ & $1.60 \mathrm{E}+06 \quad$ Psi \\
\hline Poisson ratio & 0.29 & & 0.29 & \\
\hline Density & $2.11 \mathrm{E}+03$ & $\mathrm{~kg} / \mathrm{m}^{3}$ & 0.00232 & $\mathrm{slug} / \mathrm{inch}^{3}$ \\
\hline Constraint modulus & $1.45 \mathrm{E}+4$ & $\mathrm{MPa}$ & $2.10 \mathrm{E}+06$ & Psi \\
\hline Cohesive Strength & 10.5 & $\mathrm{MPa}$ & 1535 & Psi \\
\hline Friction Angle & 43 & $\mathrm{degree}$ & $43 \quad$ Degree \\
\hline Wave speed & 2617.5 & $\mathrm{~m} / \mathrm{sec}^{2}$ & 103,051 & inch $/ \mathrm{sec}^{2}$ \\
\hline Impedance & $5.52 \mathrm{E}+06$ & $\mathrm{~kg} / \mathrm{m}^{2} \mathrm{sec}$ & $239 \quad \mathrm{slug} / \mathrm{inch}^{2} \mathrm{sec}$ \\
\hline
\end{tabular}

Table 6-2: Material Parameters of Impacting Steel Anvil

\begin{tabular}{|l|ll|ll|}
\hline & SI Units & Field Units \\
\hline Bulk modulus & $1.67 \mathrm{E}+5$ & $\mathrm{MPa}$ & $24.2 \mathrm{E}+06 \quad \mathrm{Psi}$ \\
\hline Shear modulus & $7.26 \mathrm{E}+4$ & $\mathrm{MPa}$ & $10.5 \mathrm{E}+06 \quad \mathrm{Psi}$ \\
\hline Young's modulus & $1.90 \mathrm{E}+5$ & $\mathrm{MPa}$ & $27.6 \mathrm{E}+06 \quad \mathrm{Psi}$ \\
\hline Poisson ratio & 0.31 & & 0.31 & \\
\hline Density & $8.03 \mathrm{E}+03$ & $\mathrm{~kg} / \mathrm{m}^{\wedge} 3$ & $8.83 \mathrm{E}-03$ & $\mathrm{slug} / \mathrm{inch}^{\wedge} 3$ \\
\hline Constraint modulus & $2.64 \mathrm{E}+5$ & $\mathrm{MPa}$ & $38.3 \mathrm{E}+06$ & $\mathrm{Psi}$ \\
\hline Wave speed & 5731.6 & $\mathrm{~m} / \mathrm{sec}$ & $225,653.1$ & $\mathrm{inch} / \mathrm{sec}$ \\
\hline Impedance & $4.60 \mathrm{E}+07$ & $\mathrm{~kg} / \mathrm{m}^{\wedge} 2 \mathrm{sec}$ & 1990 & $\mathrm{slug} / \mathrm{inch}^{\wedge} 2 \mathrm{sec}$ \\
\hline
\end{tabular}




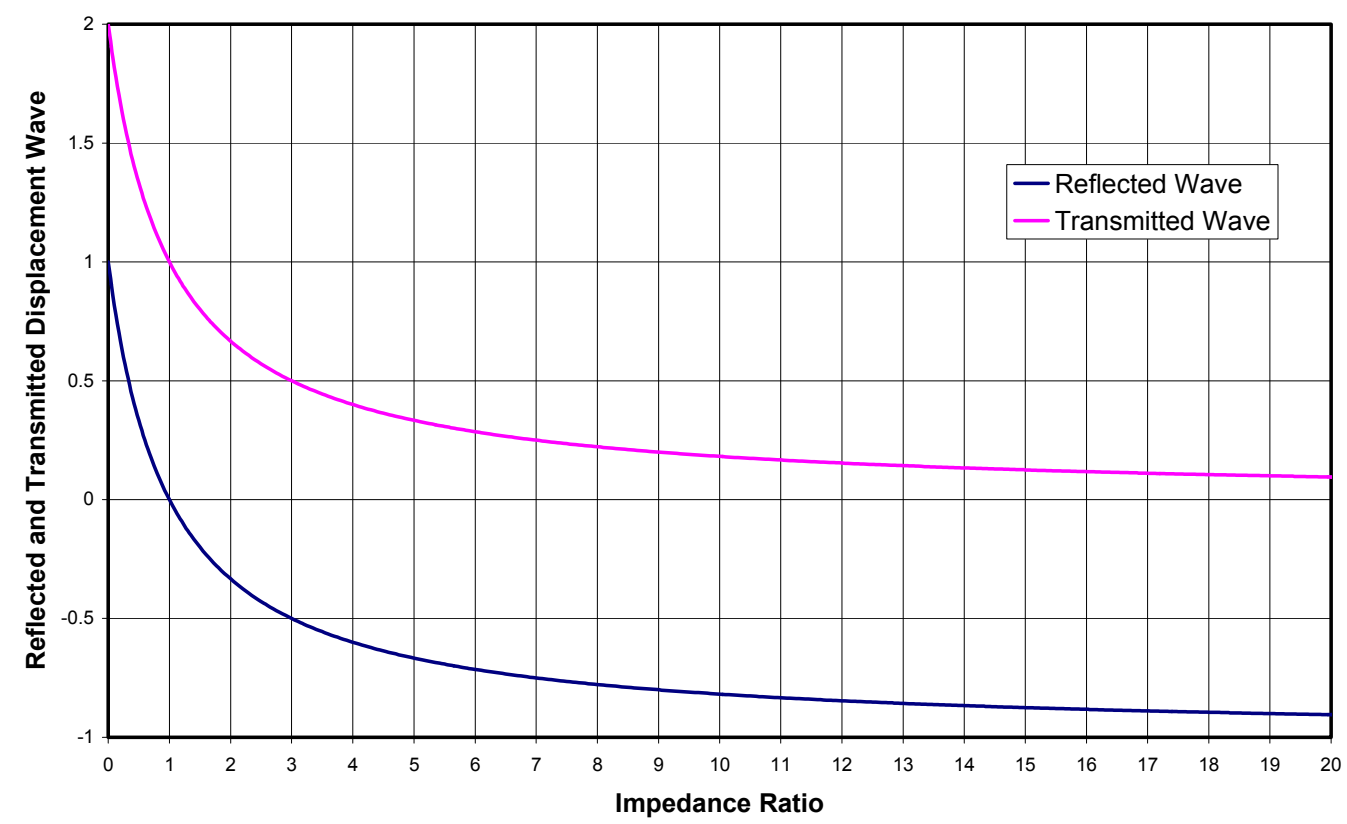

Figure 6-1. Reflected and transmitted displacement waves in a layered elastic medium

Similarly, for the stress amplitudes we have the relations correlating incident, transmitted and reflected stress waves given by

$$
\sigma_{r}=\frac{\alpha_{z}-1}{1+\alpha_{z}} \sigma_{i}
$$

and

$$
\sigma_{t}=\frac{2 \alpha_{z}}{1+\alpha_{z}} \sigma_{i}
$$

where $\alpha_{z}$ denotes the impedance ratio. These dependences are shown in Figure 6-2.

For the layered elastic medium with material parameters shown in Table 6-1 and Table $6-2$, the following values are obtained:

Impedance ratio from stiff to soft material: $\quad 0.120$

Displacement amplitude ratio of reflected to incident wave: $\quad 0.786$

Displacement amplitude ratio of transmitted to incident wave: $\quad 1.790$ 
Stress amplitude ratio of reflected to incident wave:

Stress amplitude ratio of transmitted to incident wave:

Impedance ratio from soft to stiff material:

Displacement amplitude ratio of reflected to incident wave:

Displacement amplitude ratio of transmitted to incident wave:

Stress amplitude ratio of reflected to incident wave:

Stress amplitude ratio of transmitted to incident wave:

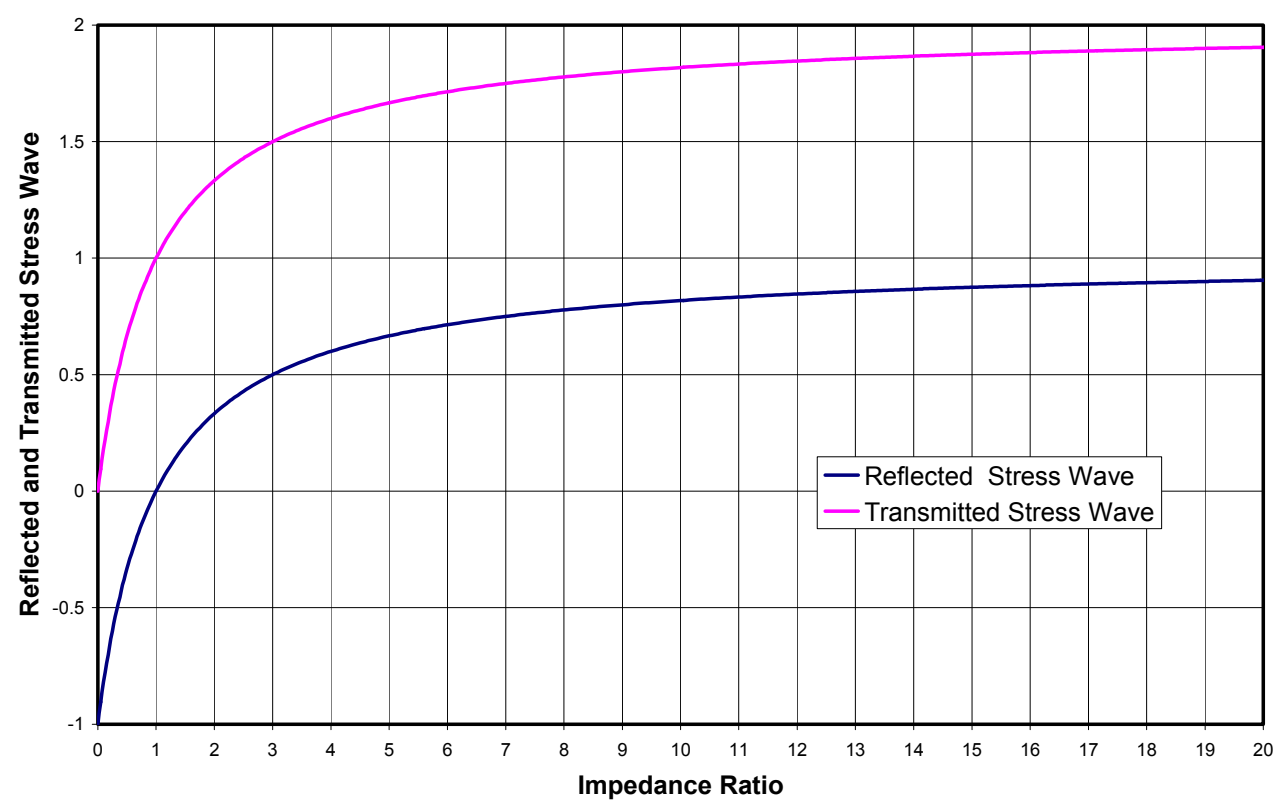

Figure 6-2. Reflected and transmitted stress waves in a layered elastic medium

\section{$\underline{\text { Sandstone Plasticity and Failure }}$}

Berea sandstone is described by an elastoplastic material model and an accumulated plastic strain dependent failure criteria when loaded in triaxial compression. During tensile loading, a critical tensile strength is implemented. The corresponding values for Berea sandstone are a critical tensile strength of $2.1 \mathrm{MPa}(304.5 \mathrm{psi})$, cohesion of $10 \mathrm{MPa}$ (1450 psi) and angle of friction equal to 43 degrees. 
To validate the model we use the triaxial compression data experimentally and compare them to our numerical results. In particular, the numerical simulations use, in addition to an unconfined compression test, a lateral confinement of $10.34 \mathrm{MPa}$ (1500 psi) and 20.68 $\mathrm{MPa}$ (3000 psi). Similar to the experimental process, we first apply the confinement and subsequently increase the axial compression until the material fails in shear. Finally, a uniaxial tensile test is performed to verify the specified tensile strength.

Figure 6-3 shows the principal stress differences versus the axial strains. The three graphs represent the unconfined compression and the two triaxial compression tests with lateral confinements of $10.34 \mathrm{MPa}$ (1500 psi) and $20.68 \mathrm{MPa}$ (3000 psi). This figure shows the increase in maximum and residual strengths with an increase in confinement pressure. The deformation accumulated during initial hydrostatic compression is not included, i.e. the measure of the axial strain is activated after completion of the initial hydrostatic compression.

Figure 6-4 shows the principal stress differences versus volume changes for the same triaxial compression tests. Initially the material compacts; after the maximum strength is reached, the material fails and starts to dilate. Again, the volume change is measured after initial compaction during hydrostatic compression is completed.

In Figure 6-5, the results of the triaxial tensile test are shown. The material reaches the imposed ultimate strength of $2.1 \mathrm{MPa}(304.5 \mathrm{psi})$. Note that in tension the ultimate strength is reached, but no failure is available. The material keeps the maximum tensile strength no matter how much tensile load is actually applied. 


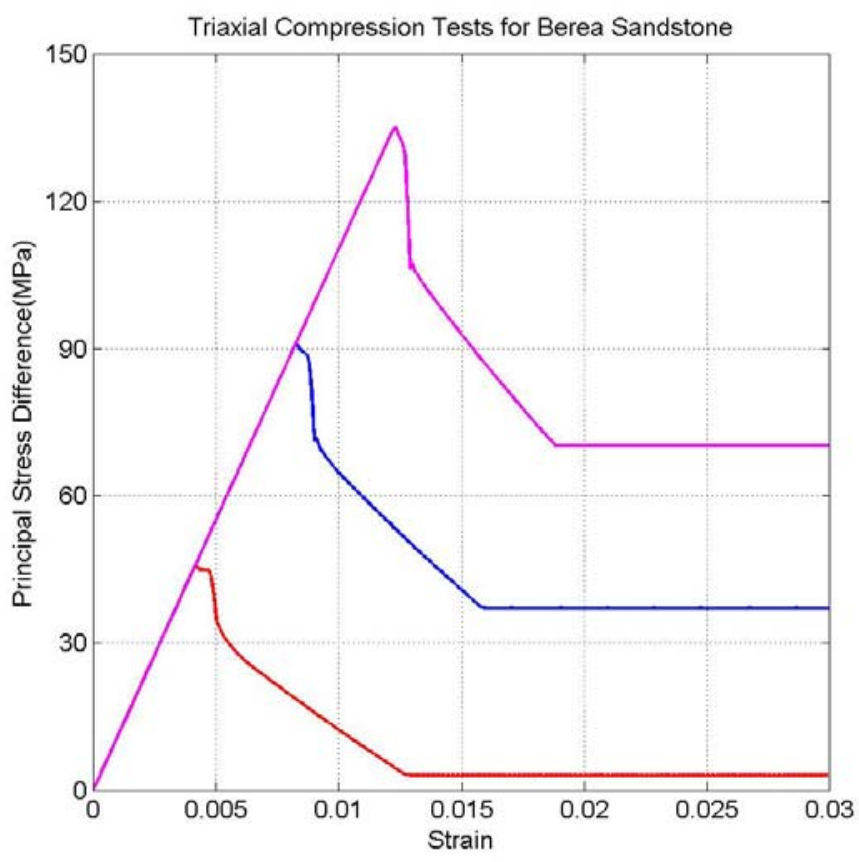

Figure 6-3. Principal stress differences of Berea sandstone under different confinements.

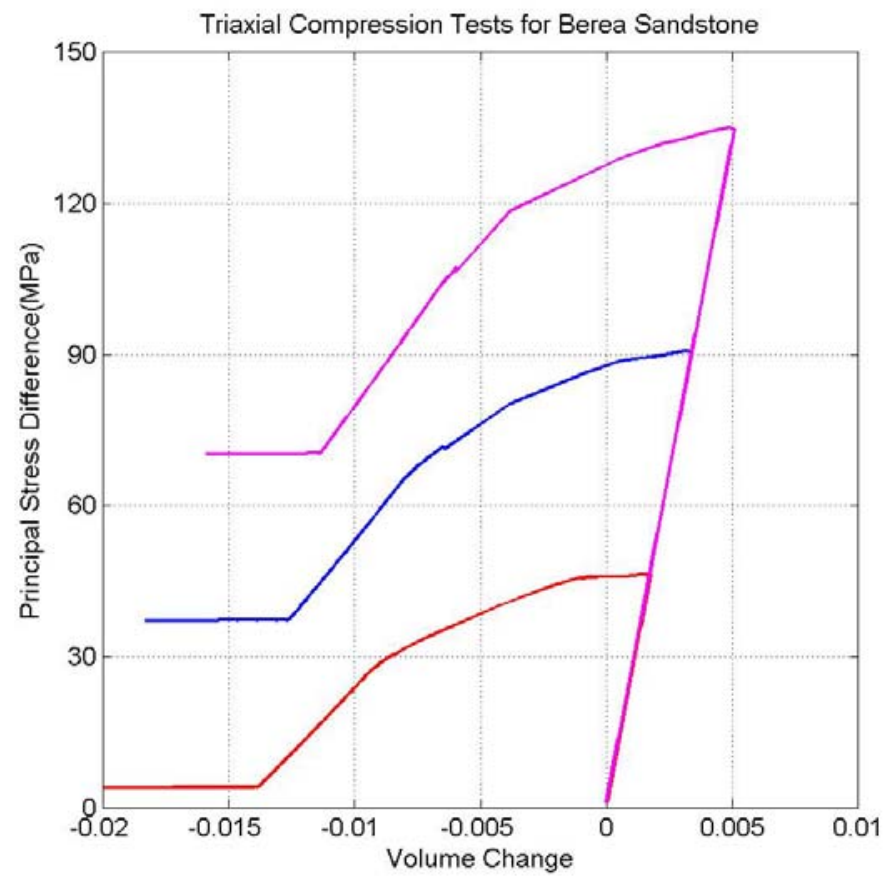

Figure 6-4. Principal stress differences versus volume changes for three triaxial compression tests. 


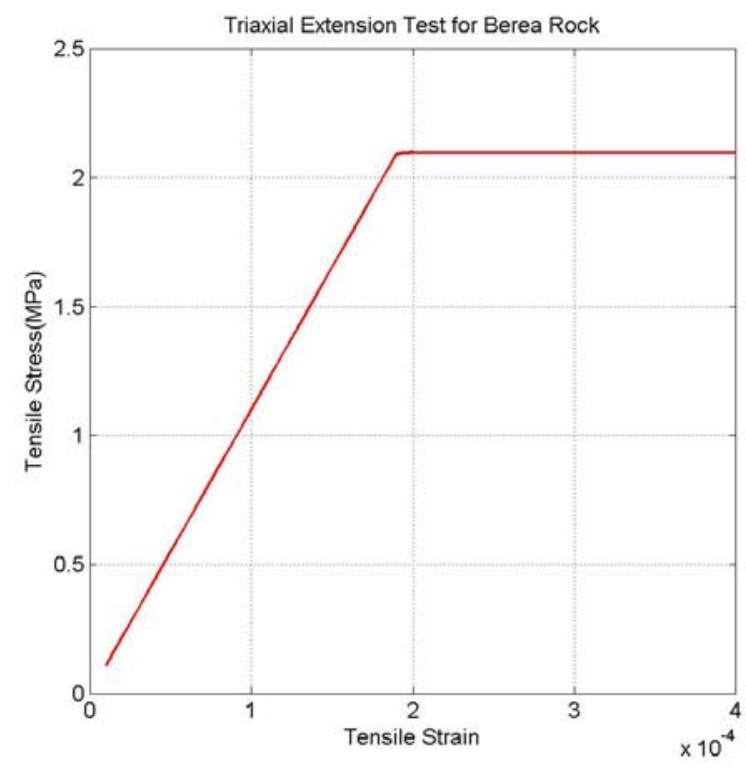

Figure 6-5. Tensile stress versus tensile strain for Berea sandstone.

\subsection{Single Impact Simulation}

\subsubsection{Experimental Layout}

The experimental impact tests were on rock samples $0.1334 \mathrm{~m}$ (5.25 inches) in diameter by $0.0921 \mathrm{~m}$ (3.625 inches) in height with the impact occurring at a distance of $0.0333 \mathrm{~m}$ (1.3125 inches) from the center of the rock ,see Figure 6-6.

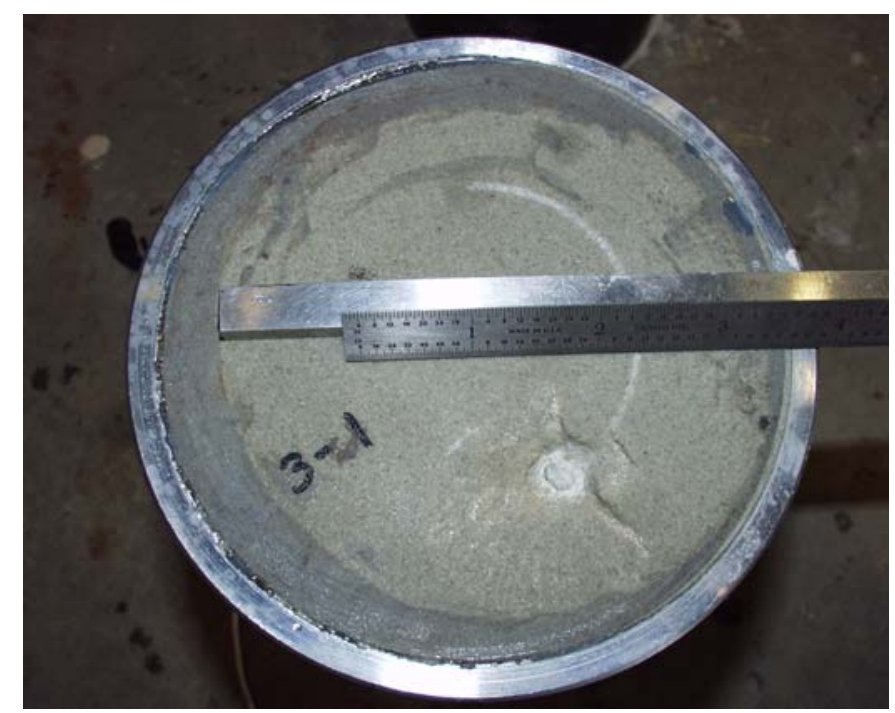

Figure 6-6. Top view of impacted Berea sandstone specimen 
After a careful evaluation and verification phase we assume for the numerical model, for simplicity, that the impact load can be applied to the center of the specimen. The experimental equipment setup is shown schematically in Figure 6-7. The gap between the bottom of the gas piston and lower cylinder top is 7.62E-4 $\mathrm{m}$ (0.03 inches). The nitrogen gas pressure is held constant at $3.1 \mathrm{MPa}(450 \mathrm{psi})$ before exhausting the bottom part of the gas cylinder to atmosphere through a $0.0254 \mathrm{~m}(1 \mathrm{inch})$ diameter orifice. The piston distance traveled before striking the rod anvil is $0.0127 \mathrm{~m}$ ( 0.50 inches) resulting in a calculated piston velocity of $12.32 \mathrm{~m} / \mathrm{sec}(495 \mathrm{inch} / \mathrm{sec})$ at contact with the anvil.
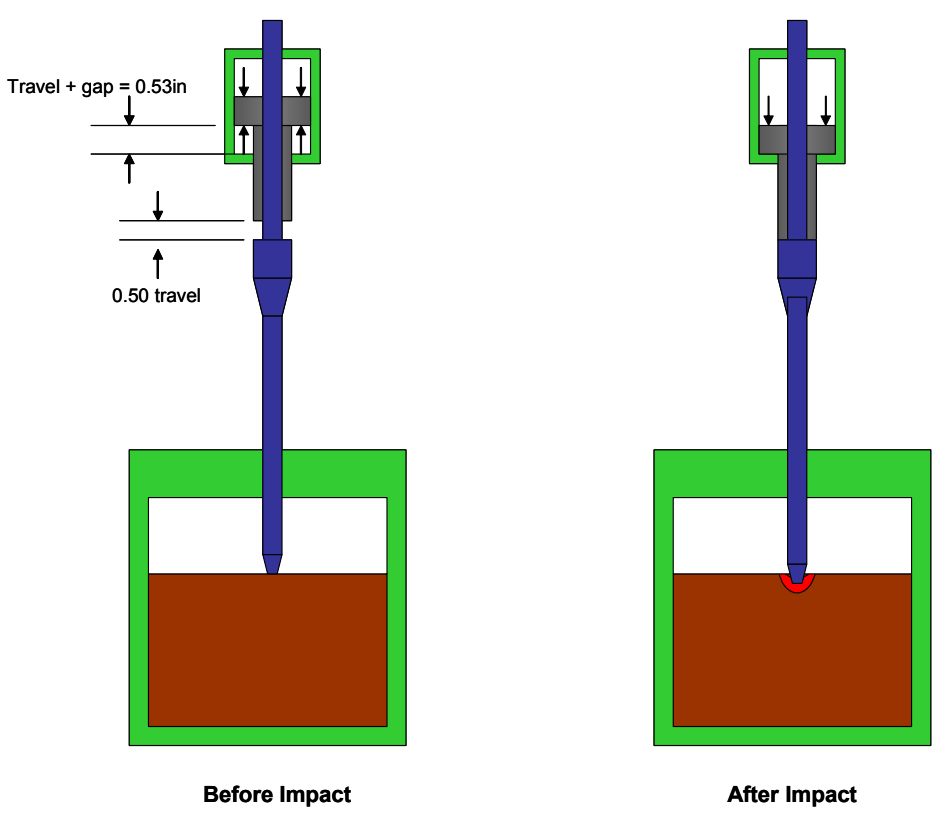

Figure 6-7. Schematic representation of test setup for impact on Berea sandstone

\subsubsection{Loading Patterns}

To simplify the simulation we do not attempt to model the physical impact mechanism in its entirety, but instead prefer to apply a sinusoidal shaped impact stress wave to the top surface of the striking cylindrical anvil. In the numerical model, shown schematically in Figure 6-8, diameter and length of the impacting rod are $0.0254 \mathrm{~m}(1 \mathrm{inch})$ and $0.4648 \mathrm{~m}$ (18.3 inches), respectively. The rock sample, enclosed in a cylindrical steel jacket, has a diameter of $0.1334 \mathrm{~m}$ (5.25 inches) and height of $0.0921 \mathrm{~m}$ (3.625 inches). The front end of the anvil is shaped like a cylindrical cone. 


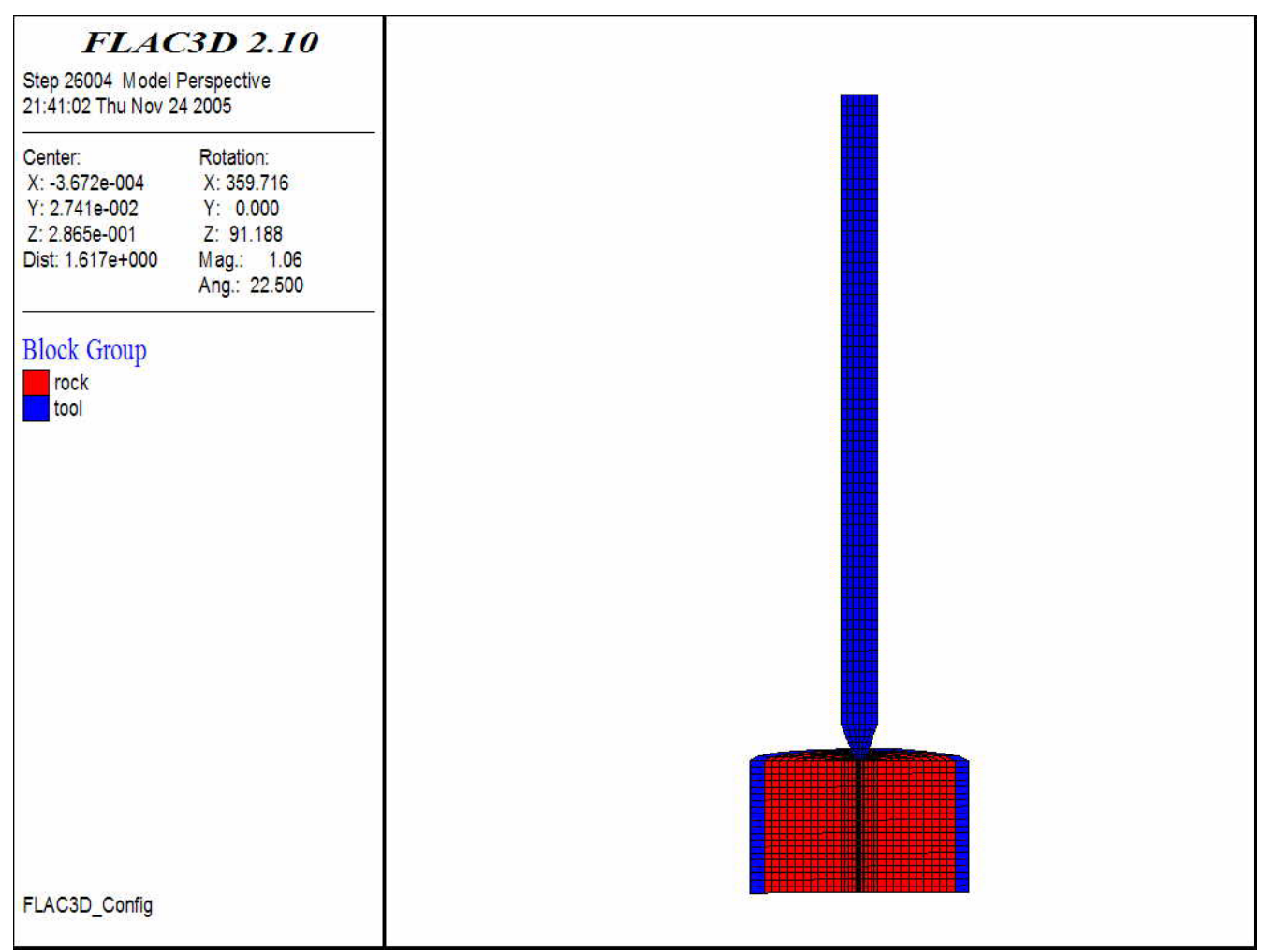

Figure 6-8. Geometric layout of numerical model with symmetry taken into consideration

We specify an applied stress history through the superposition of two half sine waves to best simulate the experimental impact wave measured by a sensor mounted on the steel anvil located $0.127 \mathrm{~m}$ (5 inches) below the impacted surface. Figure 6-9 shows the compression and tensile waves, which are combined to provide the equivalent applied load in Figure 6-10. These results are shown as loads for better comparison with experimental data. The justification for combining two wave forms is that in addition to the principal applied pressure wave a secondary high frequency wave is generated in the anvil during impact loading. The experimental setup shown in Figure 6-7 also indicates that the pressure is maintained in the upper half of the pressure chamber. This implies that a residual pressure is maintained on the impacting anvil, which we assume to be 51.8 $\mathrm{MPa}(7500 \mathrm{psi})$ and is shown in Figure 6-10 as a corresponding permanent load. 


\subsubsection{Numerical Models}

For the numerical model we assume a diameter of $0.0254 \mathrm{~m}$ ( 1 inch) for the striking anvil. We note that the physical anvil in the experiments does not have a constant diameter, about 70 percent of its length the diameter is $(0.028575 \mathrm{~m}) 1.125$ inches. The diameter increases when approaching the top surface, while the impacting cone itself does have a semi-spherical surface, see Figure 6-7. The lengths of the modeled and physical impacting rod correspond and are equal to $0.4648 \mathrm{~m}$ ( 18.3 inches), measured from the bottom of the anvil to the top impacted surface. In the experiments, the local axial strain is measured $0.127 \mathrm{~m}$ ( 5 inches) below the impacted surface and, assuming linear elastic behavior and homogenous deformation (constant strain over the entire cross-section), is converted into axial stresses and ultimately into an equivalent axial load.

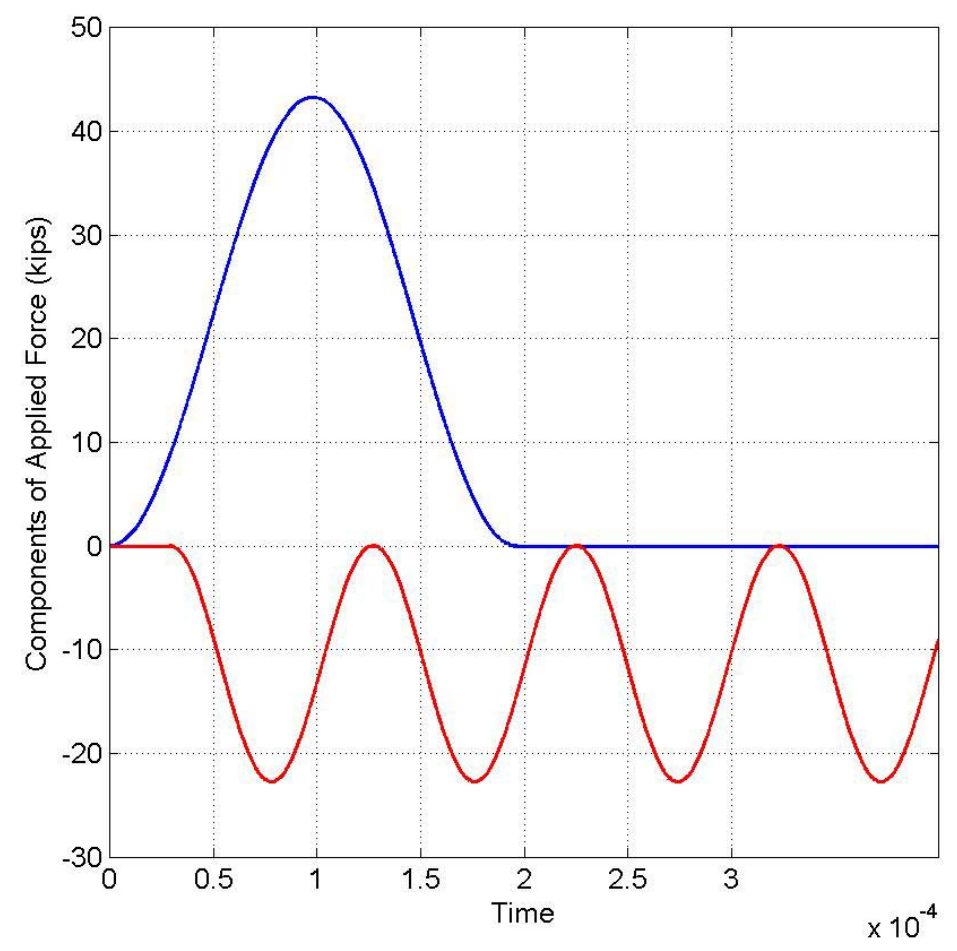

Figure 6-9. Compression and tensile waves applied to top surface of impacting rod 


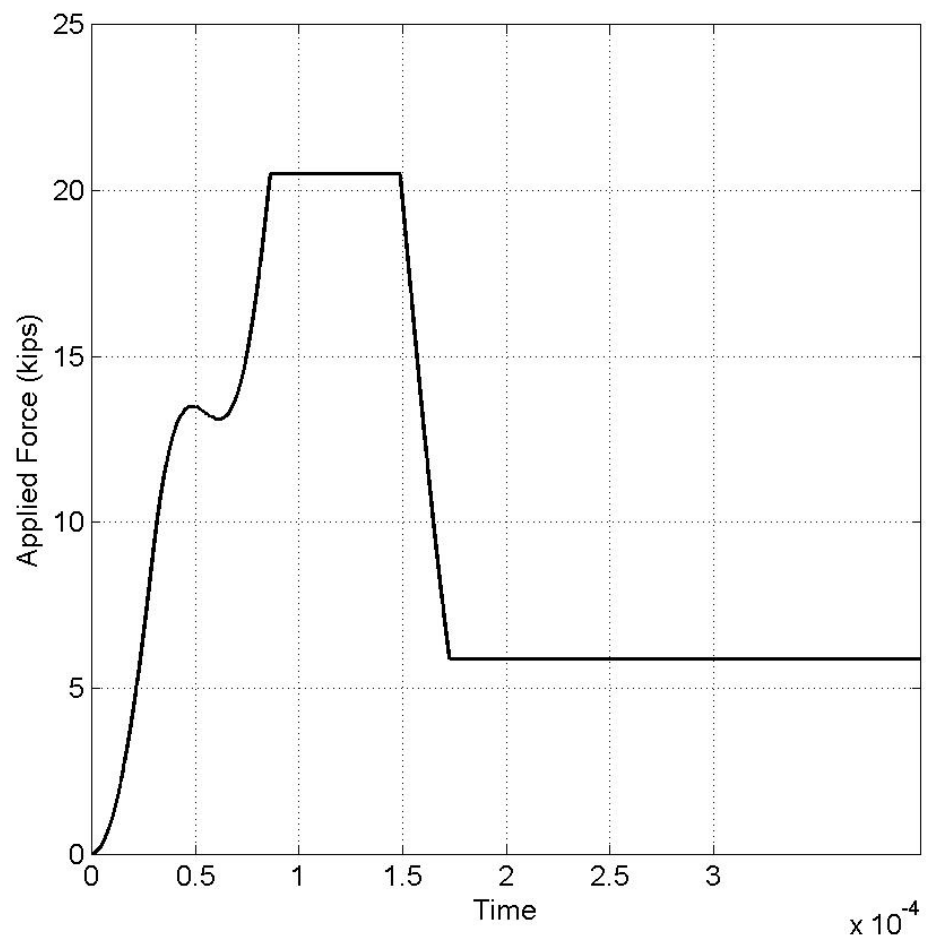

Figure 6-10. Resultant applied load obtained from superposition of compressive and tensile waves

\section{Reduced Model}

To optimize running time during the material model validation phase, a geometrically reduced model was developed. In this model, the rock sample has the same diameter as the impacting rod $0.0254 \mathrm{~m}$ ( 1 inch) and a total height of $0.092 \mathrm{~m}$ (3.625 inches). The total length of the impacting rod is $0.4648 \mathrm{~m}$ (18.3 inches). The bottom surface is fixed and no symmetry is used, i.e. the entire circular cylinder is modeled, as shown in Figure 6-11. Note that the stress waves travel down the steel rod and upon arrival at the steelrock interface will be in part reflected and in part transmitted. The transmitted wave propagates downward through the rock to be reflected at the bottom surface. Similarly, the wave reflected at the steel-rock interface will travel upward to be reflected at the now free top surface of the anvil. Therefore, it is evident, that at all times, a large number of waves travel up and down the structure, overlap and may amplify or reduce the amplitude. 
The surface where the stress impulse is applied is free to move and can therefore be described by zero impedance ratio. The fixed surface, on the other hand, corresponds to an interface with infinite impedance ratio. No stress can be transmitted across an interface with a zero impedance ratio. It can be shown that the displacement of the boundary must be twice the displacement amplitude of the incident wave. The reflected stress wave has the same amplitude as the incident wave, but changes sign. If the incident wave is a compression wave, the transmitted wave will be tensile and vice versa.

The boundary where all displacement components are fixed corresponds to an infinite impedance ratio. This implies that the stress at the boundary is twice the magnitude of the incident wave. The reflected wave has the same amplitude and sign as the incident wave. Obviously, all displacement components vanish.

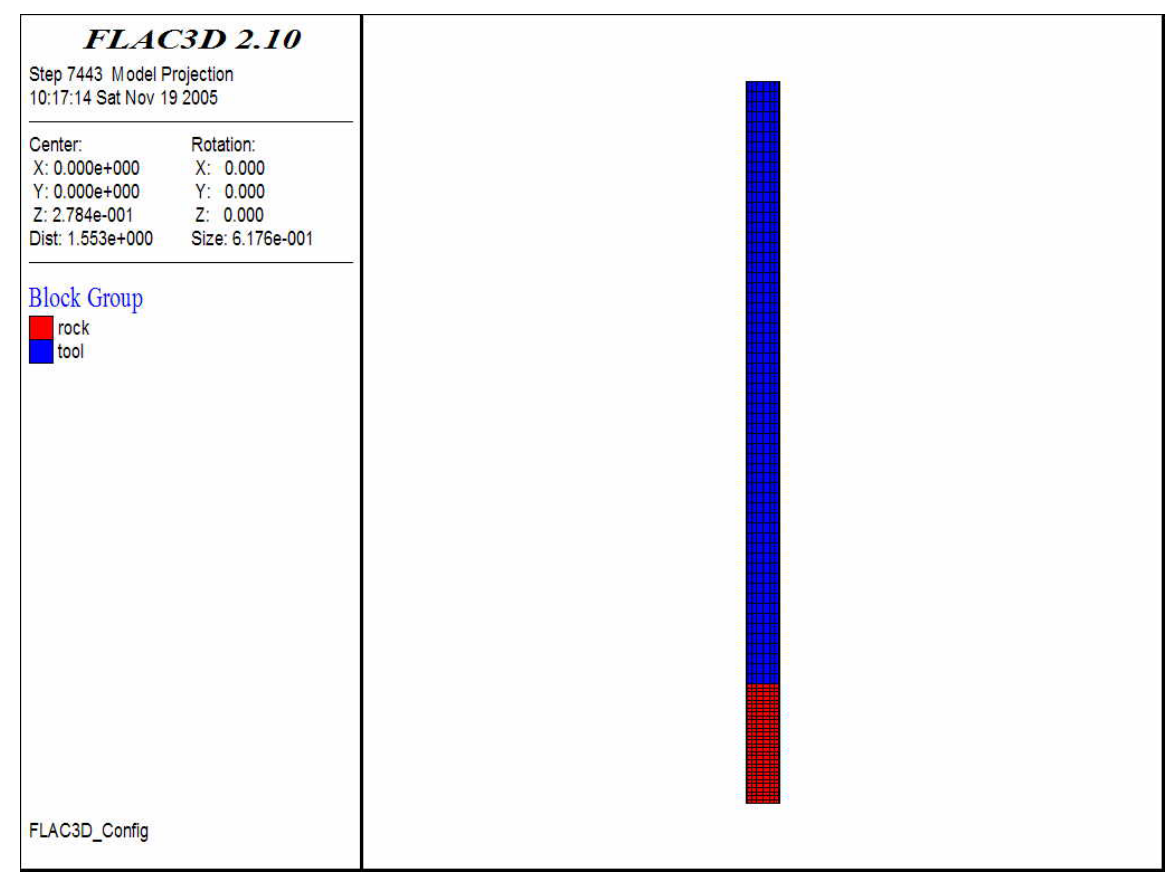

Figure 6-11. Geometric layout of reduced model

\section{Complete Model}

After the main material model parameters are determined and verified using the model in Figure 6-11, the model is modified to include the actual size of the impacted rock specimen. The dimensions of the rock sample in the physical test and in the numerical 
simulation are a diameter of $0.1334 \mathrm{~m}(5.25$ inches $)$ and a height of $0.0921 \mathrm{~m}(3.625$ inches), see Figure 6-8. Consistent with the boundary conditions in the experimental setup, the rock sample is enclosed by a steel cylinder. Also, the vertical displacement of the bottom rock surface is fixed. To optimize the running time, symmetry conditions are taken into consideration and only half of the physical specimen is modeled.

The length of the impacting rod is $0.4648 \mathrm{~m}$ ( 18.3 inches), and the diameter is $0.0254 \mathrm{~m}$ ( 1 inch). In the experiments, the axial strain is measured $0.127 \mathrm{~m}$ (5 inches) below the impacted (top) surface of the striking anvil. Assuming linear elastic behavior and homogenous deformation (constant strain over the entire cross-section), the strain is converted into axial stress and ultimately into an equivalent axial load. This value for the axial force is used and compared to the numerical data.

The effect of a tapered end cone on the impacting rod is investigated and the corresponding results summarized. In the selected geometry, the diameter of the impacting anvil reduces from the original $0.0254 \mathrm{~m}$ ( 1 inch) to $0.00635 \mathrm{~m}$ ( 0.25 inches) at the front end of the cone.

We again specify the applied load through the superposition of two half sine stress waves to best simulate the experimental impact wave as measured by the strain gage sensor located on the impacting anvil. The elastic and plastic material model parameters are unchanged and have been given before.

Figure 6-12 compares the time histories of the experimental data (red line) and the numerical results (blue line) for the axial load recorded $0.0127 \mathrm{~m}$ (5 inches) below the impacted surface of the anvil. Figure 6-13 shows the time history of the incoming wave at the bottom of the rock specimen. For convenience, the stress has been converted into incoming force and is compared to the experimental data. Finally, in Figure 6-14, the axial displacements of the top surface of the anvil and at the strain gage location are shown. After about six msec, the displacements levels off, as show in Figure 6-15. Finally, Figure 6-16 shows the amount of damage induced in the rock sample. The front 
cone of impacting anvil has an aspect ratio of 1:4. The diameter of the impacting cone is $0.00635 \mathrm{~m}$ (0.25 inches). The shape and extension of the fractured volume agree fairly well with the experiments, see Figure 6-6.

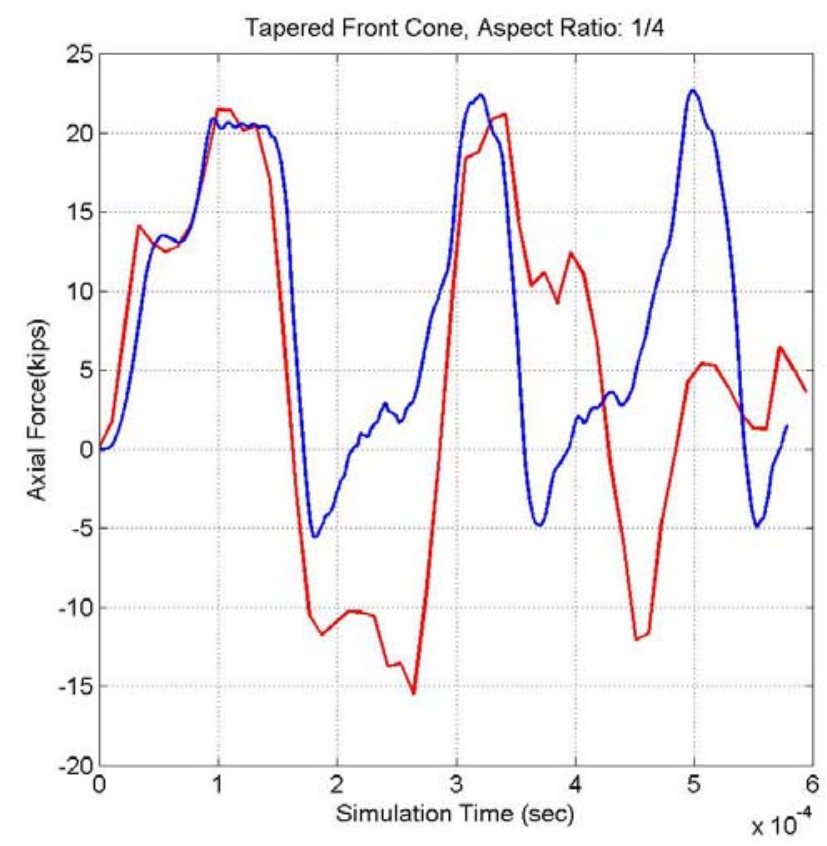

Figure 6-12. Comparison of experimental (red) and numerical values (blue) of axial impact force at measurement location

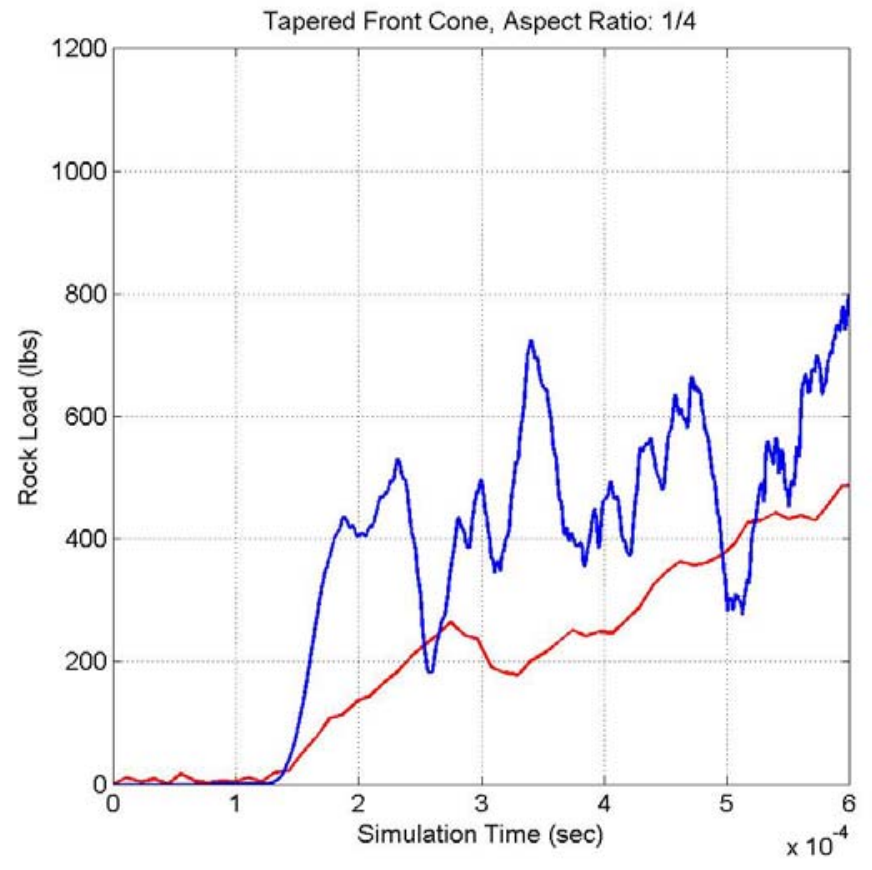

Figure 6-13. Time history of incoming force recorded at the bottom of the rock specimen 


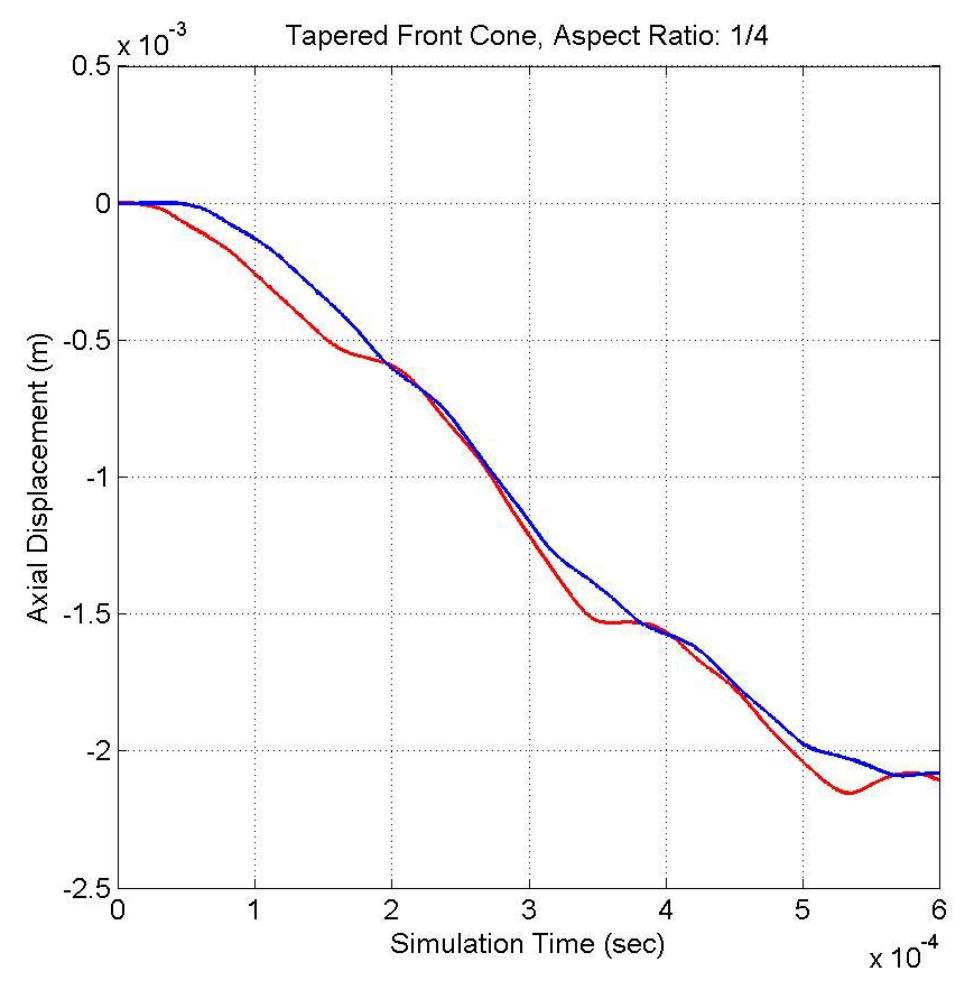

Figure 6-14. Time history of the axial displacements of the anvil recorded at the top surface (red line) and at the strain gage location (blue line)

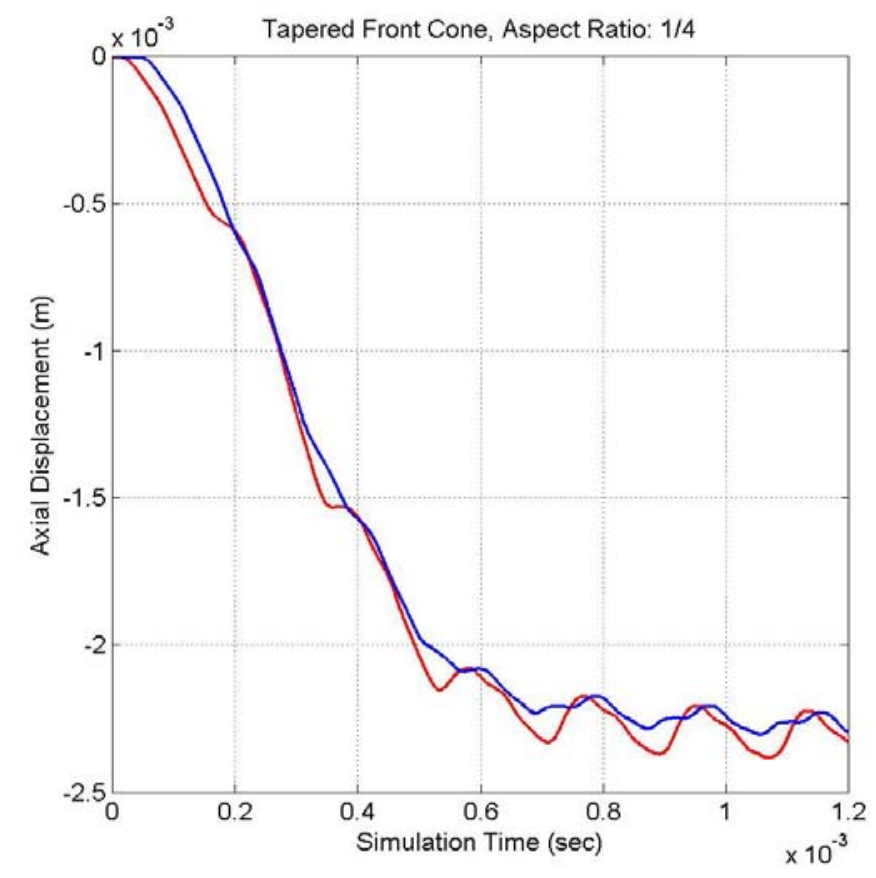

Figure 6-15. Axial displacement of top surface and at the strain gage location of the impacting anvil 


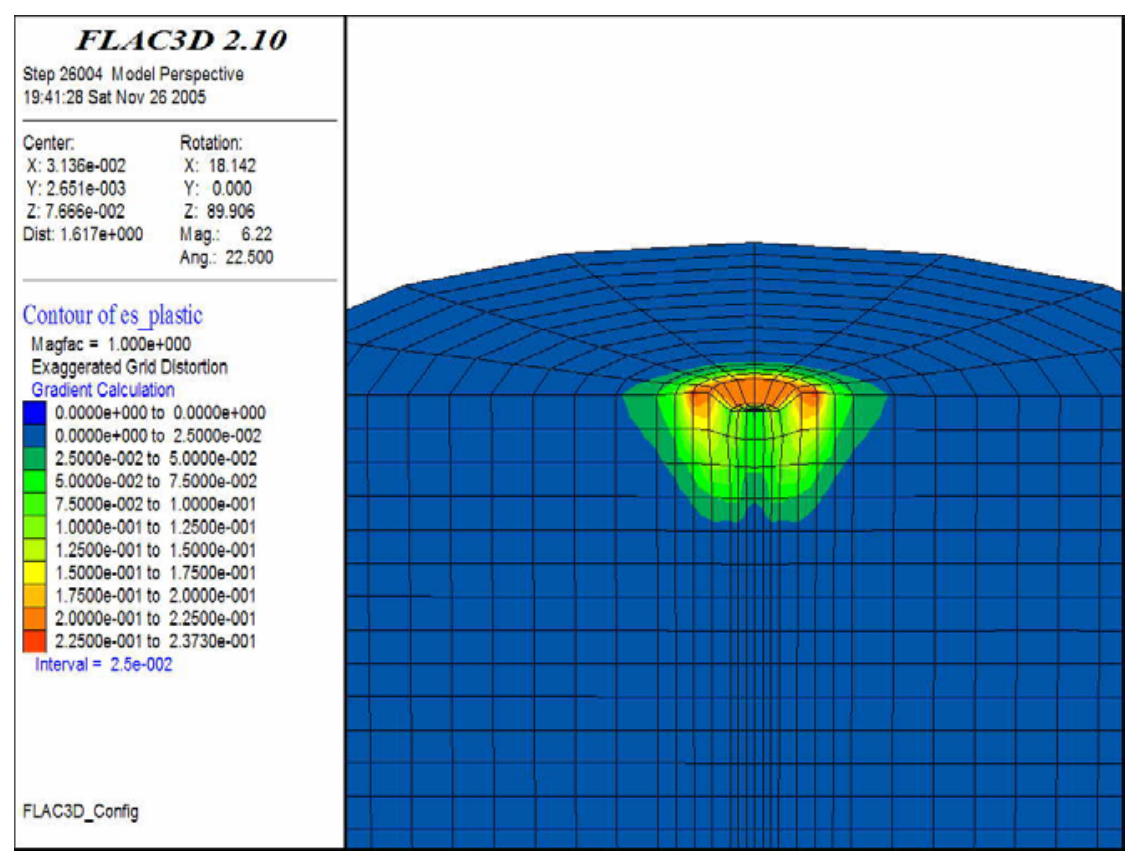

Figure 6-16. Contour plot of the plastic strain distribution in Berea sandstone

\subsection{Full Scale Drilling simulation}

In this simulation, a cyclic impacting force with constant maximum amplitude is applied to the bottom surface of the borehole and the accumulation of damage monitored. The impacting force has a sinusoidal shape, i.e. it starts at zero, increases to the maximum level and returns to zero. The maximum amplitude and impact duration are flexible and to be given as input parameters. Following the application and removal of the impacting force, a user defined time interval is inserted before the next impact occurs. During cyclic loading the rock is subjected to fatigue, which induces a reduction of the initial strength properties. Therefore, cyclic loading softens the material until a condition is reached whereby the impacting force becomes equal to the strength properties of the rock. At this point plastic damage accumulates and, upon reaching a critical level, the material fails in shear or by reaching the tensile strength.

\subsubsection{Geometry and Boundary Conditions}

The geometry of the model is a vertical cylinder with circular cross section. The total height of the numerical model is three meters, the outside radius equal to 0.3937 meters and the radius of the borehole at its center is 0.1079 meters. The cylindrical vertical 
borehole at the center of the rock sample has an initial depth of 0.1 meters. The applied boundary conditions are a constant lateral confinement, and overburden pressure equal to 24.138 MPa and fixed displacement degrees of freedom on the bottom surface. The fluid pressure inside the borehole is equal to $8 \mathrm{MPa}$; the pressure at the bottom surface, including the weight of the drill bit is $15.7 \mathrm{MPa}$. The initial geometry, the boundary conditions and the deformation during loading maintain cylindrical symmetry. Therefore, to reduce computational time, we reduce the model to a $10^{\circ}$ wedge, as shown in Figure 6-17 and Figure 6-18.

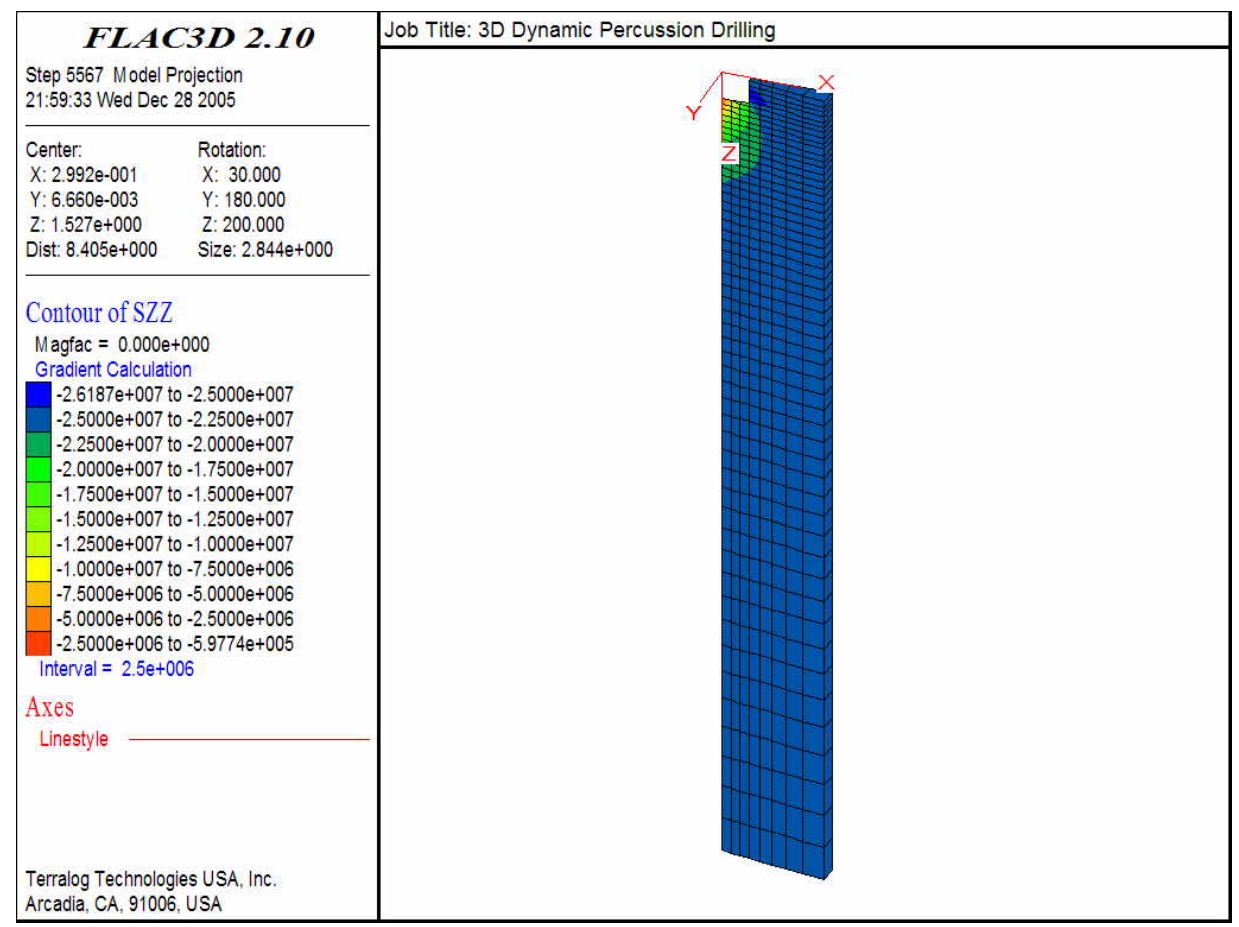

Figure 6-17: Geometric layout, and initial vertical stress distribution of the 3-D drilling simulation. 


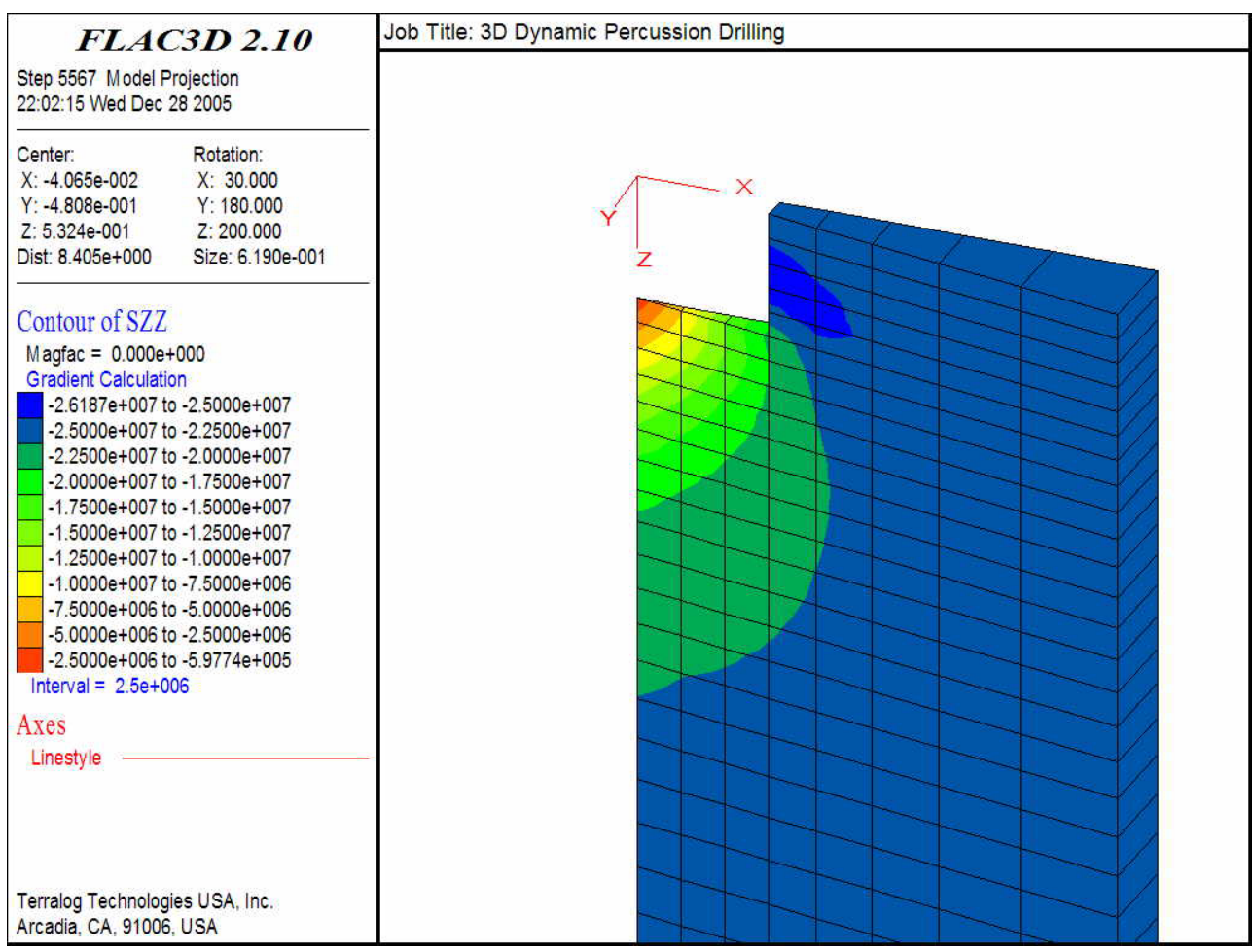

Figure 6-18: Detailed view of impact area and borehole.

\subsubsection{Loading and Failure}

A cyclic impacting force with constant maximum amplitude is applied to the bottom surface of the borehole and the accumulation of damage monitored. The impacting force has a sinusoidal shape, i.e. it starts at zero, increases to the maximum level and returns to zero. The maximum amplitude and impact duration are flexible and given as input parameters. During cyclic loading the rock is subjected to fatigue, which induces a reduction of the initial strength properties. Therefore, cyclic loading softens the material until a condition is reached whereby the impacting force becomes equal to the strength properties of the rock. At this point, plastic damage accumulates and, upon reaching a critical level, the material fails in shear or by reaching the tensile strength.

Each impacting impulse has a duration of 0.025 seconds, which is followed by a separation time to the next impact of 0.025 seconds. This corresponds to a loading frequency of $20 \mathrm{~Hz}$. The cyclic loading pattern is then characterized by a period of 0.05 seconds; the first two cycles are shown in Figure 6-19. 


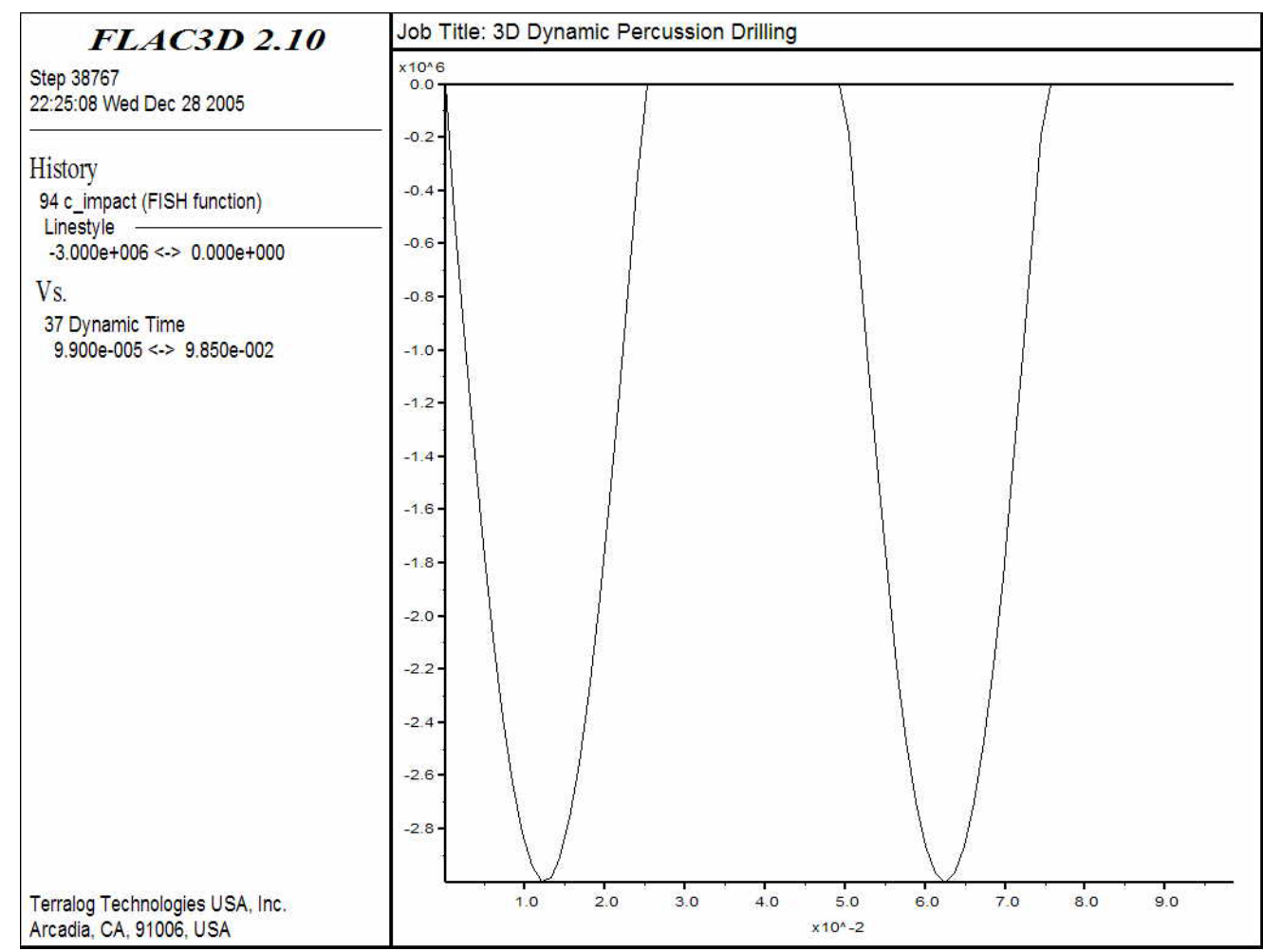

Figure 6-19: Applied load as a function of time applied to the bottom surface of the borehole, duration of impact and separation time.

The loading is designed to induce damage in the material and to reach one of the limiting criteria for failure. Three failure modes are possible:

1. The total strain reaches the critical value of 0.05 .

2. The stress paths hit the yield surface, plastic strain accumulates and there again, a critical value of 0.05 induces failure.

3. The last failure criterion, which the code verifies, is failure in tension.

When the material reaches the ultimate tensile stress of $1.2 \mathrm{MPa}$, it fails.

Failure of the material element implies removal of the element. Thus, whenever one of the three criteria listed above is satisfied, the uppermost layer in the borehole will be deleted and the drill advances. This determines the rate of penetration, i.e. the depth of the borehole as a function of drill time. We point out that in this particular example the tensile failure surface has been deactivated to improve interpretation of numerical results. Thus, only the first two failure criteria are active. 


\subsubsection{Results and Discussions}

Figure 6-20 and Figure 6-21 show the reduction in the material cohesion and friction angle due to fatigue immediately below the impacted surface and before the damaged layers are removed at 30.83 seconds (corresponding to 617 impacts). In particular, the top layers fail because the critical plastic strain in shear of 5 percent is reached, see Figure 6-22.

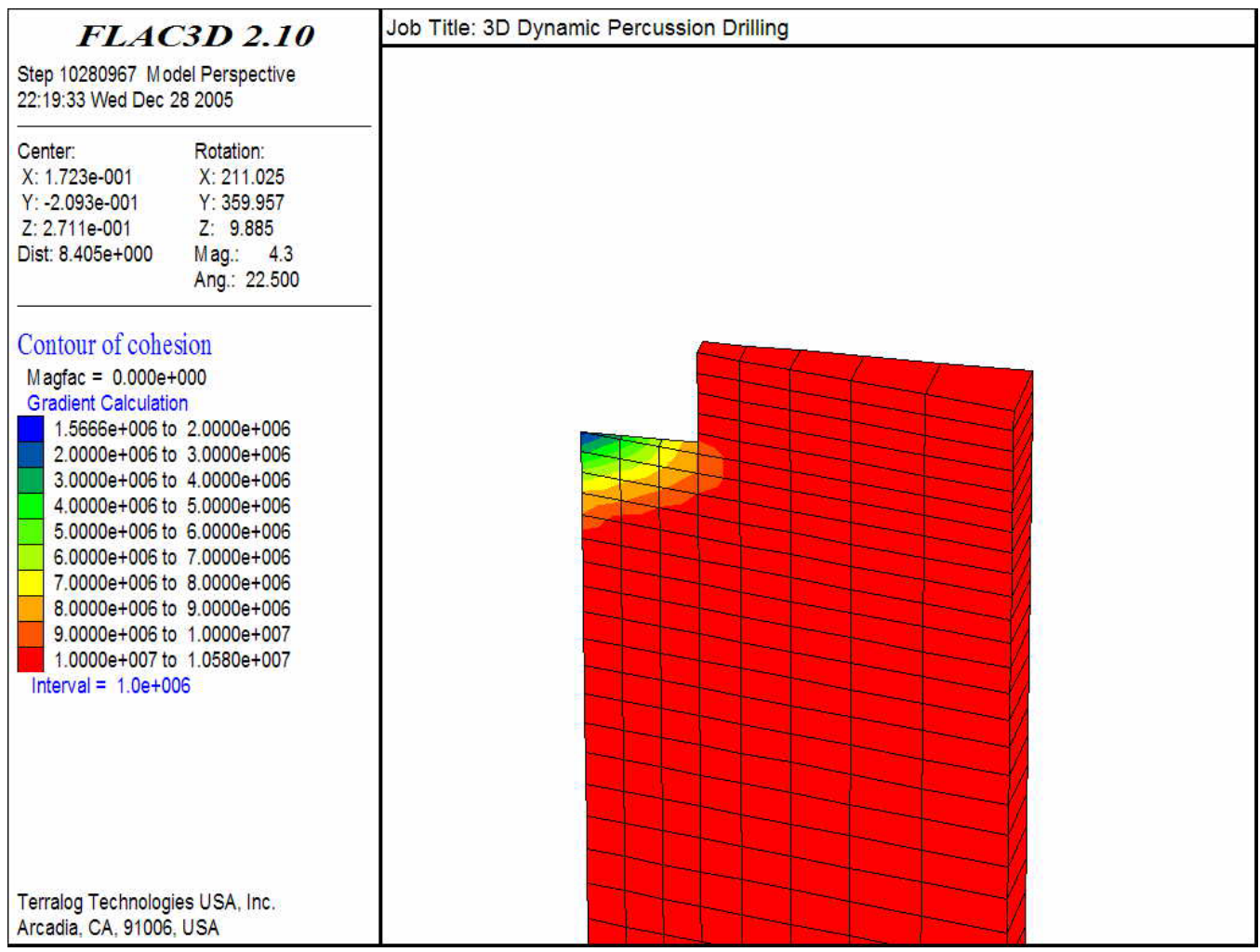

Figure 6-20: Change in cohesion $(\mathrm{Pa})$ below the borehole due to fatigue damage at 30.83 seconds after initiation of drilling. 


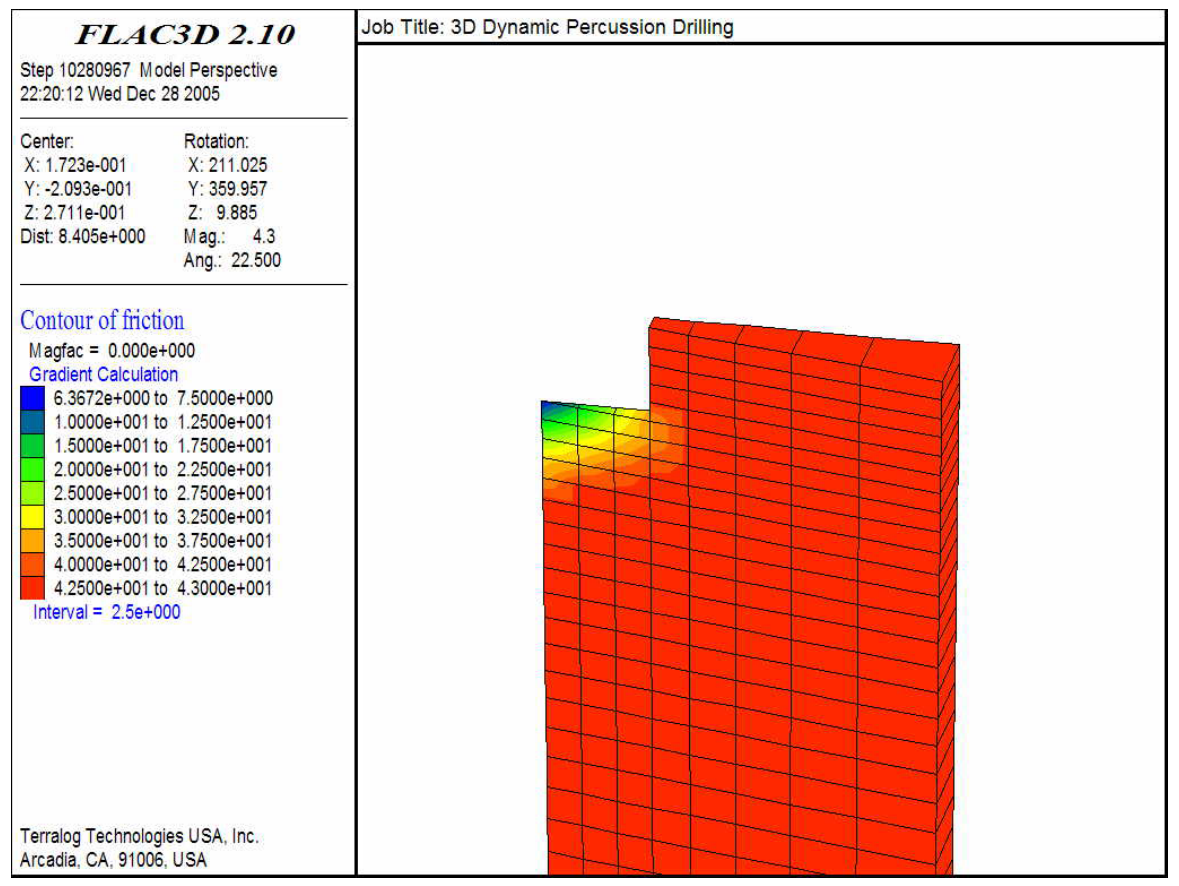

Figure 6-21: Change in the angle of friction below the borehole due to fatigue damage at 30.83 seconds after initiation of drilling.

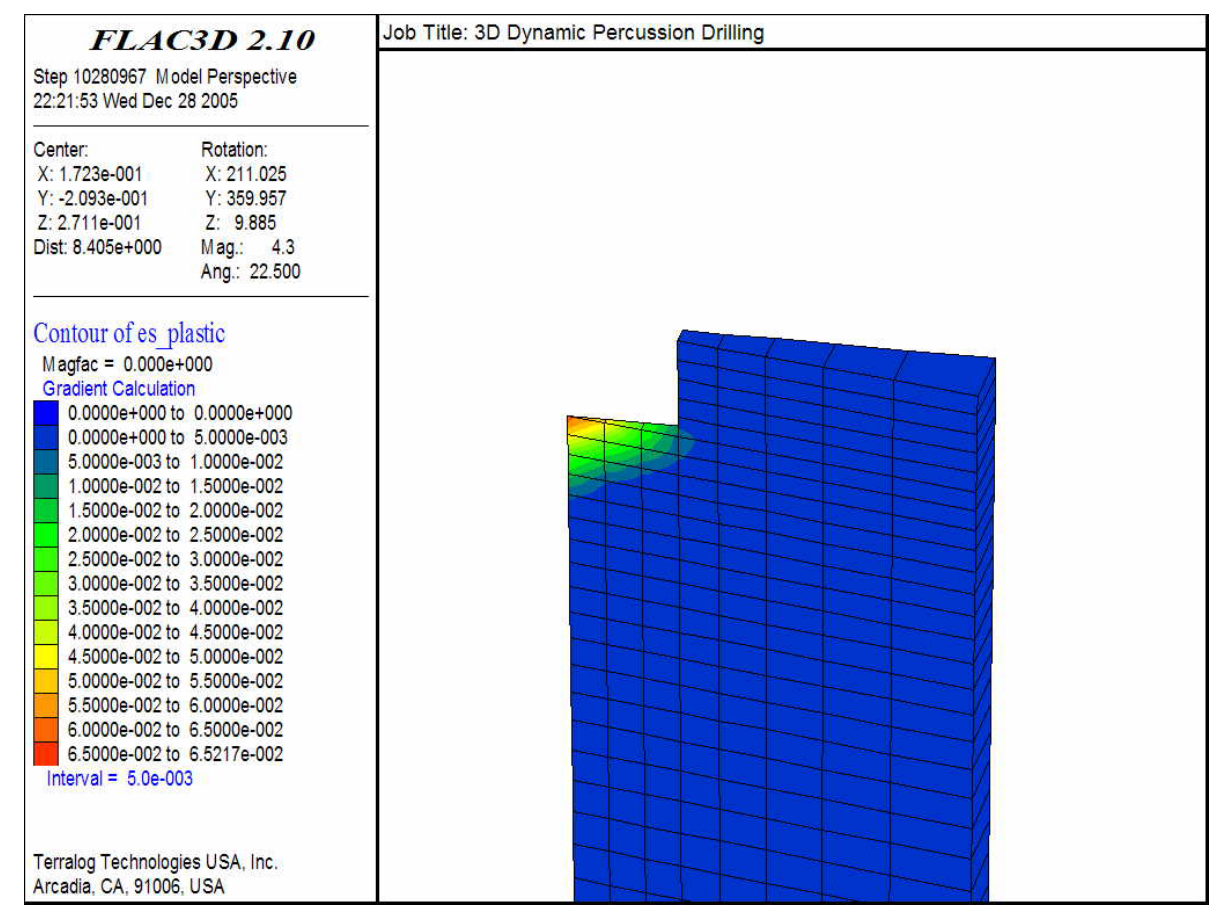

Figure 6-22: Contour plot of plastic strain distribution below the borehole due to fatigue damage at 30.83 seconds after initiation of drilling. The limit of $5 \%$ is reached in one element and the layer is about to fail. 
Figure 6-23 shows the plastic strain distribution immediately after the top three layers have been removed following 617 impacts. Note that the damaged expressed in terms of plastic strain is obviously much smaller now. After a total of 1097 impacts, corresponding to 54.88 seconds after initiation of drilling, three additional layers are removed, as shown in Figure 6-24. Finally, Figure 6-25 shows the state of the rock sample after 1674 impacts at 83.71 seconds after initiation of drilling. Three additional layers have been removed. Figure 6-26 shows the rate of penetration for this simulation. The total duration of the drilling simulation is 83.71 seconds, which corresponds to 1674 impacts. The depth of the borehole increased from the original 0.1 meter to 0.3148 meter. This corresponds to a rate of penetration of $0.0026 \mathrm{~m} / \mathrm{sec}$. The calculated rate of penetration is higher (by a factor of 4.5) compared to the one determined from experiments $(0.00057 \mathrm{~m} / \mathrm{sec})$.

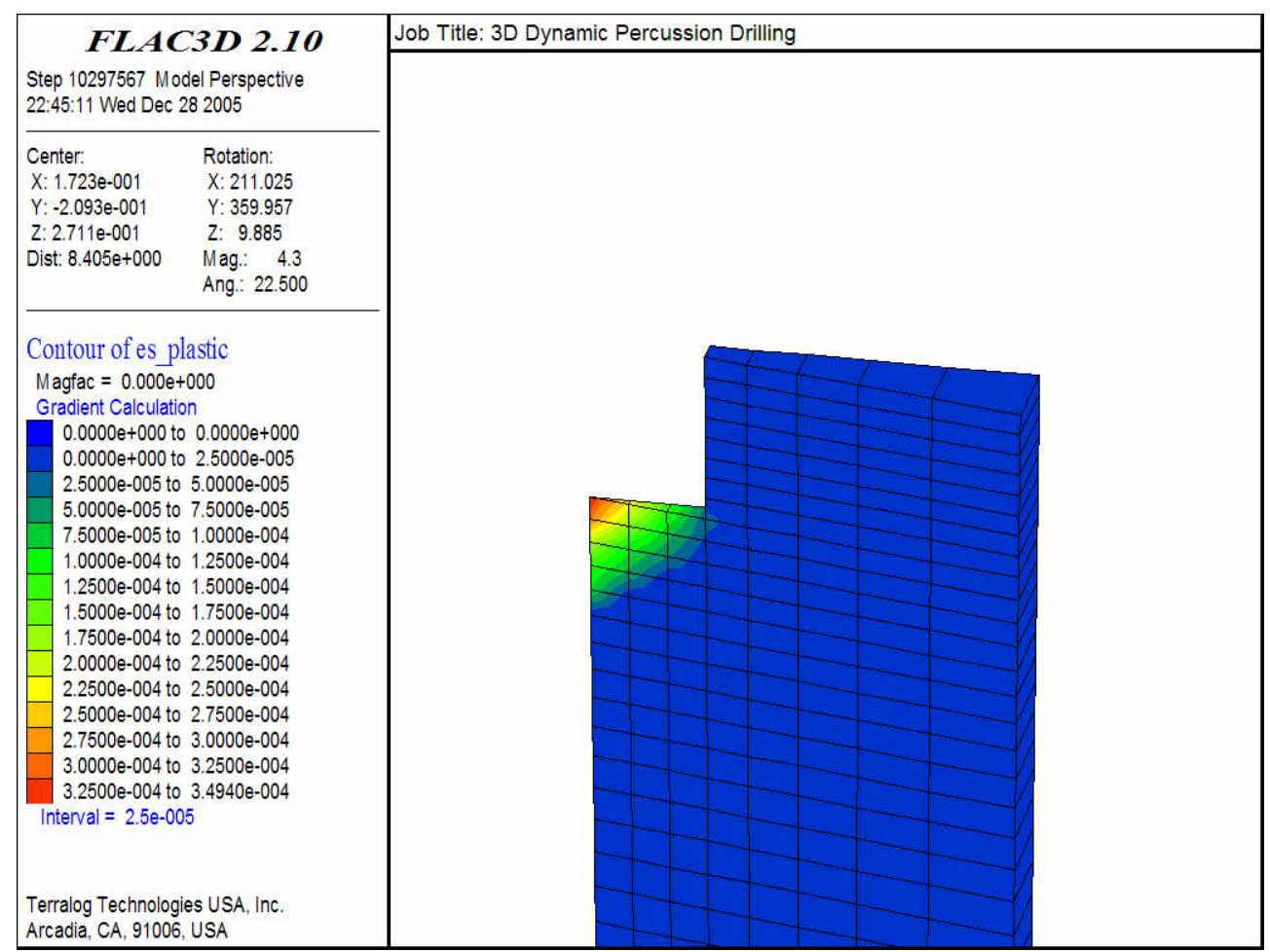

Figure 6-23: Contour plot of plastic strain distribution below the borehole after removal of top three layers. Time is $\mathbf{3 0 . 8 7}$ seconds after initiation of drilling. 


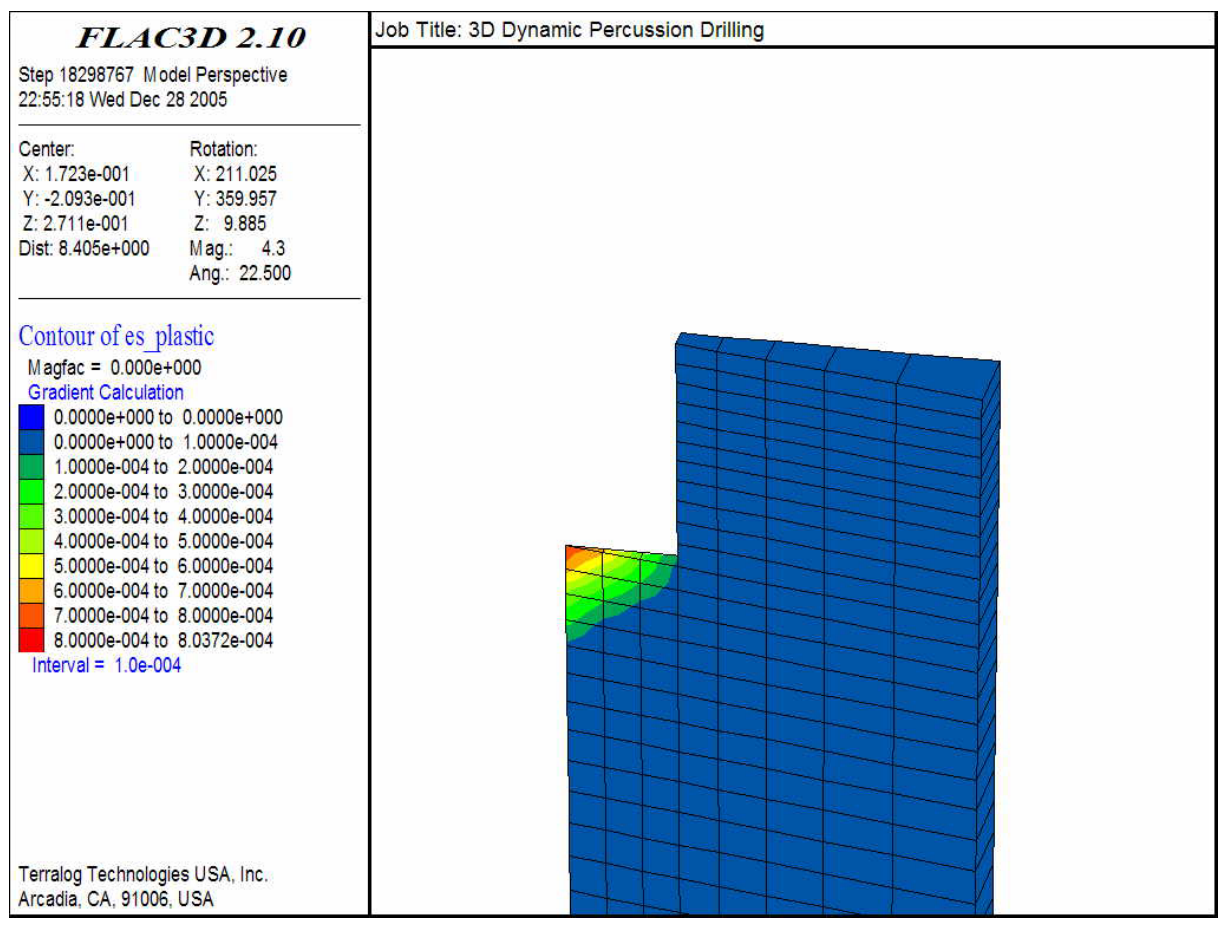

Figure 6-24: Contour plot of plastic strain distribution below the borehole after removal of additional three layers. Time is $\mathbf{5 4 . 8 8}$ seconds after initiation of drilling (1097 impacts).

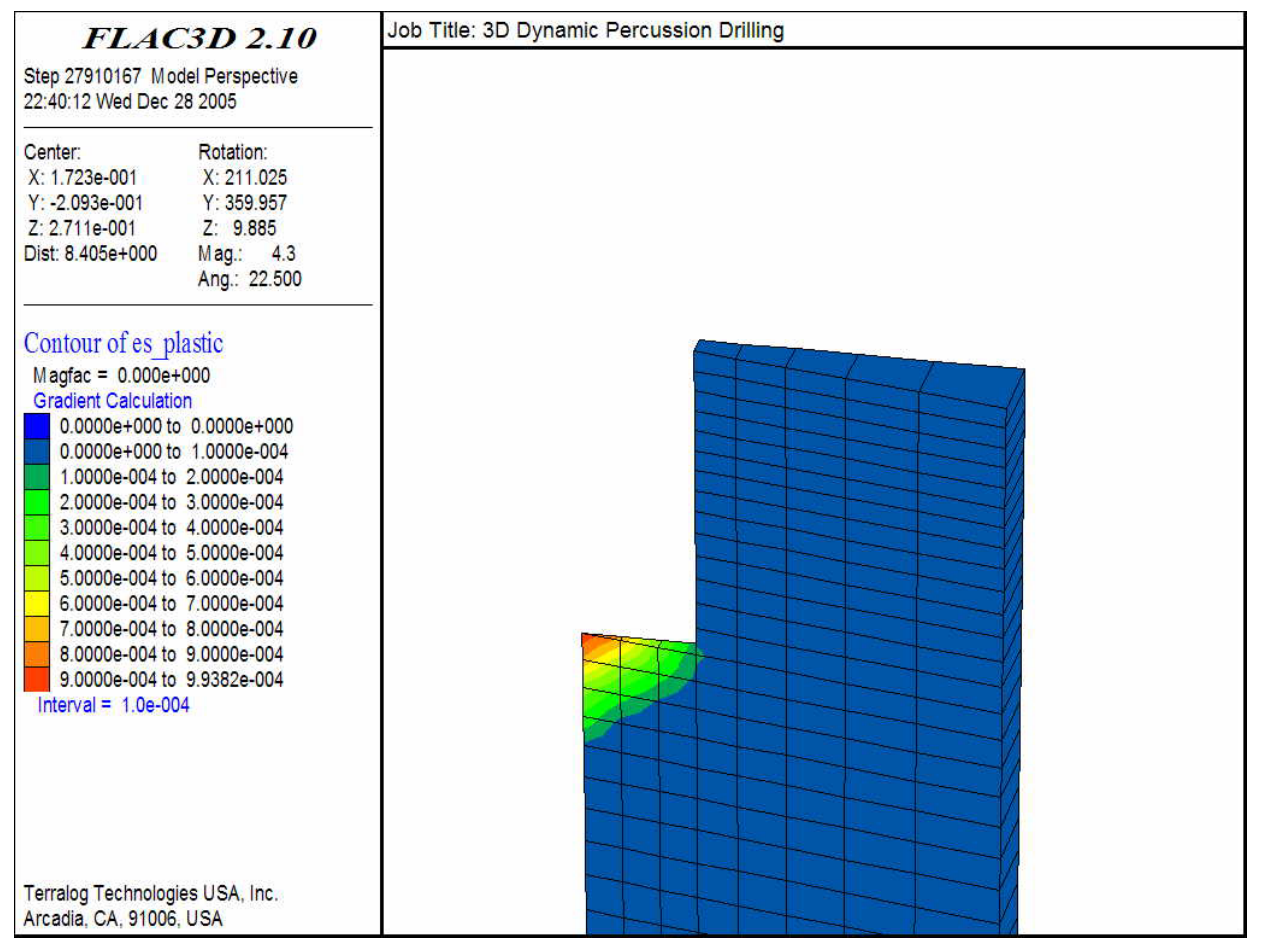

Figure 6-25: Contour plot of plastic strain distribution below the borehole at 83.71 seconds after initiation of drilling (1674 impacts). A total of nine layers have been removed since start of drilling. 


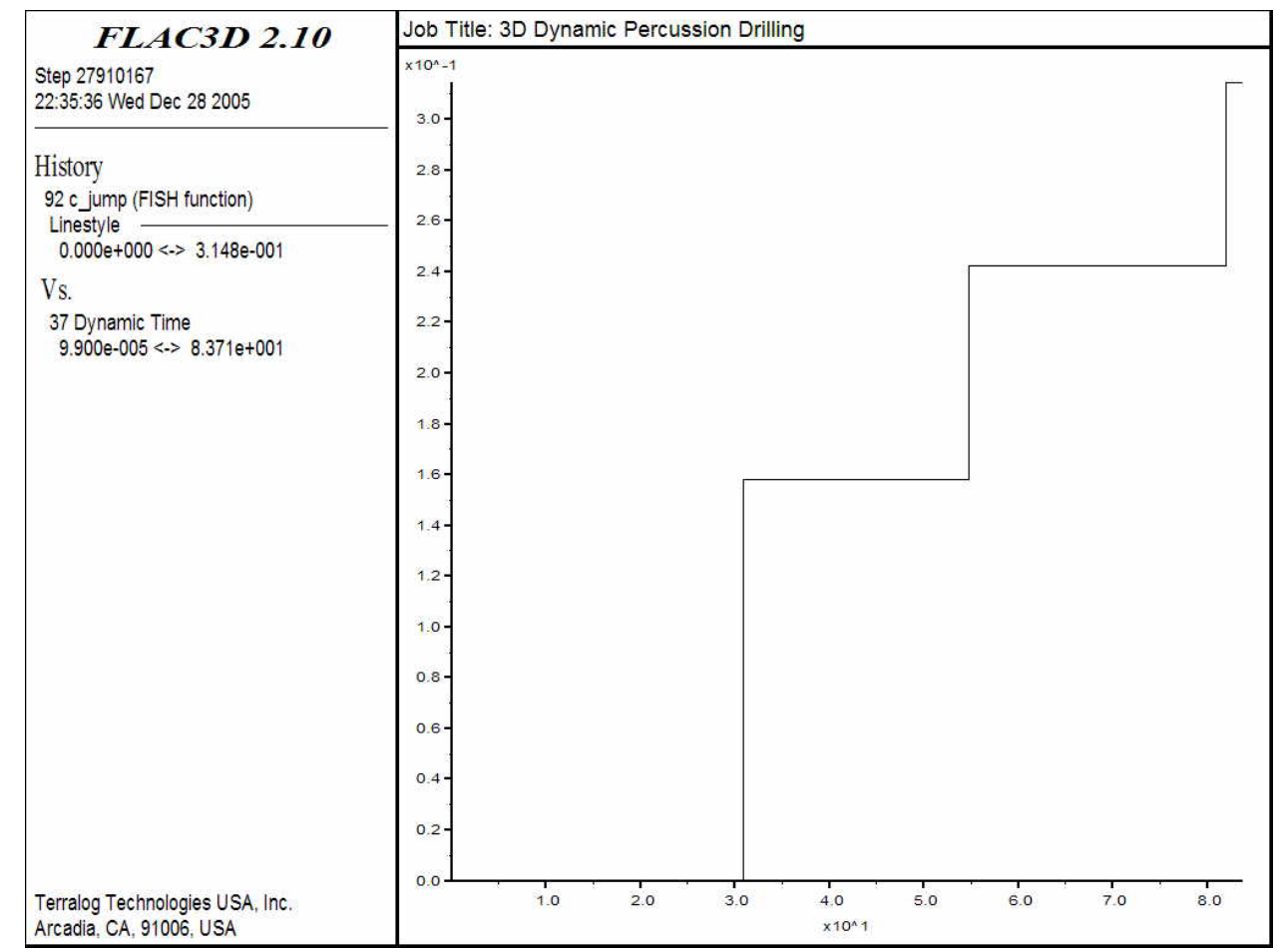

Figure 6-26: The increase of depth of the borehole as a function of time. The total time of the simulation is 83.71 seconds (1674 impacts). This corresponds to a $R O P$ of $0.0026 \mathrm{~m} / \mathrm{sec}$.

\subsection{Model Limitations}

For the single impact programs, the inputs have to be two superposed waves, i.e. one tensile wave and one compressive wave, in order to match the test results. We think this is an appropriate wave form, comparing to the reality where the reflected compressive wave will be slower to reach the strain gauge location than the tensile wave generated after the hammer impact wave reaches the rod end.

The great challenge to the full scale percussion drilling simulation lies in the running time required to complete the simulation. In order to speed up the simulation, we propose a single column edge model rather than a 3D cylindrical model. The target ROP from one hammer drilling test is $5.6727 \mathrm{E}-4 \mathrm{~m} / \mathrm{sec}(6.7 \mathrm{ft} /$ hour$)$. The frequency of impact is $20 \mathrm{~Hz}$, which corresponds to a period of $0.05 \mathrm{sec}$. The height of each element in the simulation model is $0.0125 \mathrm{~m}$. For this geometry, the maximum time step is about 3.5E-6, beyond which the solution becomes unstable. However, with such small timestep, the simulation 
takes about 36.7257 hours for the first layer to be eliminated. The computational requirements are substantial and simulations shown here easily run over several days.

The stability of FLAC3D poses a significant challenge, being that the model becomes unstable after the simulation timesteps reach certain limits. Extreme carefulness is needed to reach the balance between the model stability and running time.

\section{SUMMARY OF FINDINGS AND DELIVERIES}

Instead of compiling the information contained in previous quarterly or technical reports, this report focuses more on the descriptions of tasks, findings, and conclusions, as well as the efforts on promoting percussion drilling technologies to industries including site visits, presentations, and publications. As a part of the final deliveries, the 3D numerical model for rock mechanics is also attached.

After intensive reviews of rock drilling in different industries, a concept drilling model is proposed for numerical simulations. Three main processes involved in percussion drilling are summarized, including drillbit penetration with compression, rotation and percussion, rock response with stress propagation, damage accumulation and failure, and debris transportation inside the annulus after disintegrated from rock.

\subsection{Rock Penetration in Percussion Drilling}

After receiving impacts, rock may be damaged or failed in three ways: rock crushing by compressive bit load, rock fracturing by both shearing and tensile forces, and rock fatigue by repetitive compression-tension type of loading. Possible theoretical candidates, including stress wave theory, damage mechanics, elastoplastic continuum stress theory, are proposed for theoretical development of rock defragmentation, along with some empirical correlations. Based on a numerical tool, FLAC3D, percussion drilling is simulated. The main features include a Strain Softening (SS) material model to describe rock constitutive behaviors, various failure criteria to determine when, where, and how rock fails after post-yield state, such as strain-based failure criteria (critical strain criteria, critical shear plastic strain criteria) and tensile criteria, a Rayleigh damping feature to 
dissipate excessive oscillation energy, and a fatigue/damage algorithm to update rock properties due to cyclic loading.

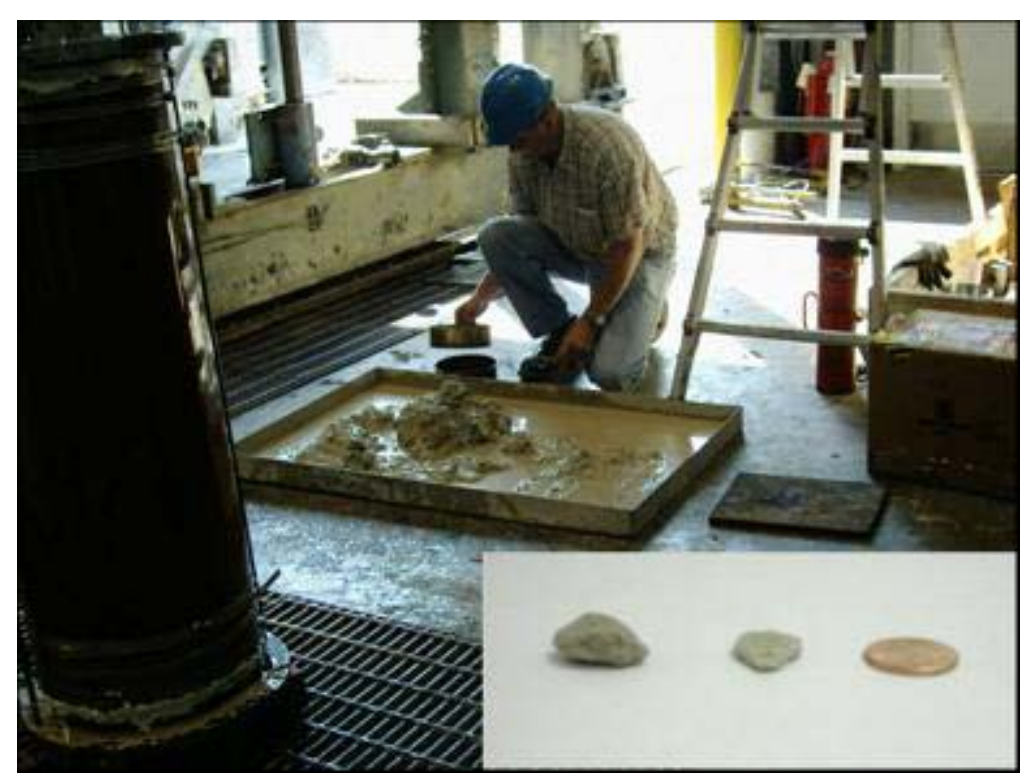

Figure 7-1. Cuttings from drilling tests (Left: roller cone; Middle: hammer underbalance; Right: penny coin)

Model simulation indicates that compressive failure due to high impact force may be dominant rock failure during bit-rock contact, while rock may fail in tension if there is not enough bottom hole pressure acting on the exposed rock surface. Because rock tensile strength is usually $1 / 5$ to $1 / 10$ of rock compressive strength, it may fail more easily in tension if conditions permit. For instance, tensile failure can account for up to 90 percent of rock penetration when there is no pressure acting on top of the rock at the hole bottom. To achieve the maximum drilling efficiency, encouraging rock deforming in tension is recommended. Lab tests also confirm the significance of tensile failure when BHP is low. For example, when drilling underbalance, ROP can be as high as $36.6 \mathrm{~m} / \mathrm{hr}$ (120ft/hr), more than 10 times higher than the ROP under 6.89MPa (1000psi) overbalanced conditions. When analyzing the difference between the cuttings generated from a traditional roller-cone drill bit and an under-balanced percussion hammer, as shown in the Figure 7-1, significant difference can be found. The cuttings generated by the roller-cone bit (left in the picture) is bulky with round edges, which means they are 
created by shear due to bit rotation. In comparison, the cuttings from hammer bit is flat and thin, indicating that tensile failure may be dominant since the hammer cutters are spherical without any sharp edge.

Another interesting finding from the single impact lab tests is how rock penetration responds to repetitive loadings. Three impacts are loaded on the same location on top of the rock surface. After each impact, the debris is cleaned and rinsed with water, and the depth and width of craters are measured. Plotting the penetration depth against the number of loadings in Figure 7-2, we can clearly see a different trend of penetration performance between Mancos shale and Berea sandstone. For Berea sandstone, the crater depth after each impact increases with number of impacts (except the third one at 0 psi fluid pressure, which may be an abnormal test point). This is in agreement with the model assumption that rock becomes weaker (fatigue) due to cyclic loading. However, for Mancos shale (dash lines in Figure 7-2), the crater depth decreases with number of impacts. Since the energy level of each impact is constant, this indicates the rock, instead of being weakened by repetitive loadings, is actually stronger than its original state. We believe the discrepancy results from the rock structures. Berea sandstone is a porous (porosity is 20.5 percent) and medium strength rock (UCS is $45.9 \mathrm{MPa}$ ), whose particles more easily move upon loading. Micro-fissures are easily introduced while particles shift and loading force increases. Mancos shale is a compacted (porosity is 7.9 percent), highly layered rock with higher strength (UCS is $55.7 \mathrm{MPa}$ ). When hammer impacts the shale, the shale particles are more likely crushed into smaller particles instead of moving to a porous space. Crushed particles, as a new material, have more strength and higher density than their original combinations, which explains why rock becomes stronger after each loading. 


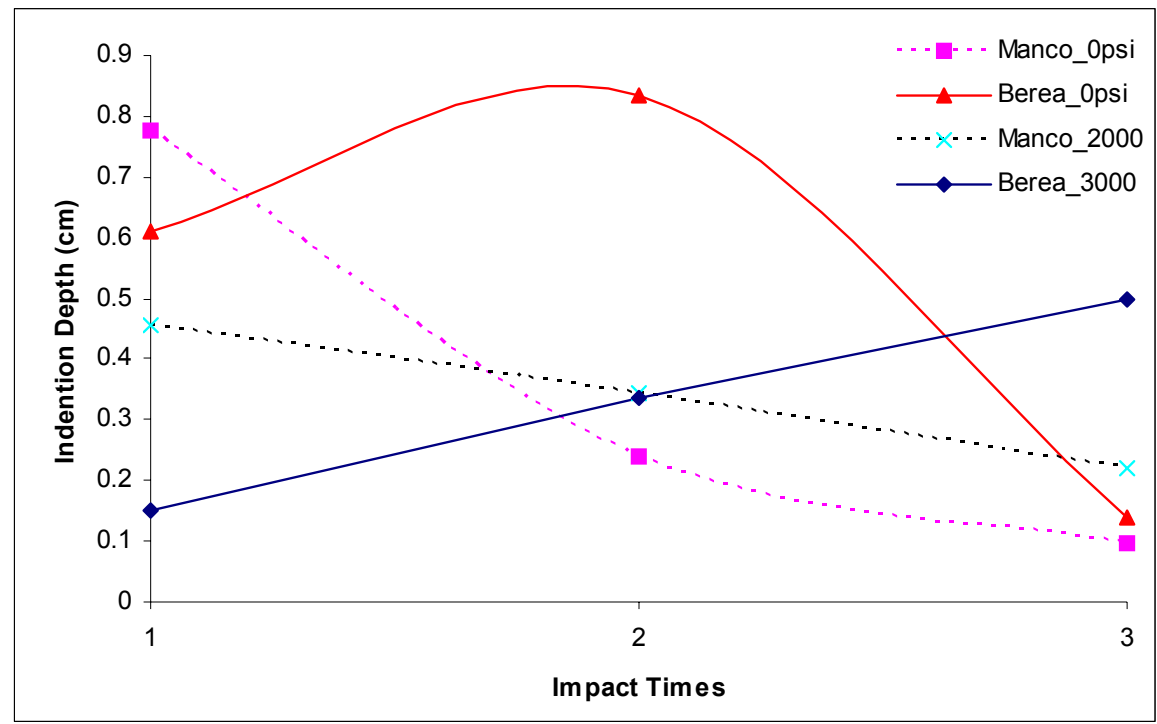

Figure 7-2. Rock penetration vs. repetitive loadings

Also it should be noted that the indentations created by the first impact in Mancos shale are higher than those in Berea sandstone. This is mainly because layered structure of the shale facilitates rock tensile failure even though it is stronger than Berea sandstone in compression. The chips can more easily detach from the rock matrix due to the low cohesion between layers. To avoid crushing particles and encourage rock tensile failure, bit needs to rotate to help cutters find next fresh rock surface. Too slow or too fast rotation may limit hammer performance in the shale because of the compacting effect discussed above.

These findings are one of many examples that demonstrate the complexity of percussion drilling. Hammer performance is not only related to the percussive energy level that the hammer creates, but also the cutter and bit design, the rock strength and moduli, and also closely to the rock structure. Different types of rocks may have the same strength and moduli, but hammer may perform quite differently because of the difference in rock structures. In our case, even though Mancos shale is more competent and stronger than Berea sandstone, the hammer performs better in the drilling simulator (Figure 7-3). 


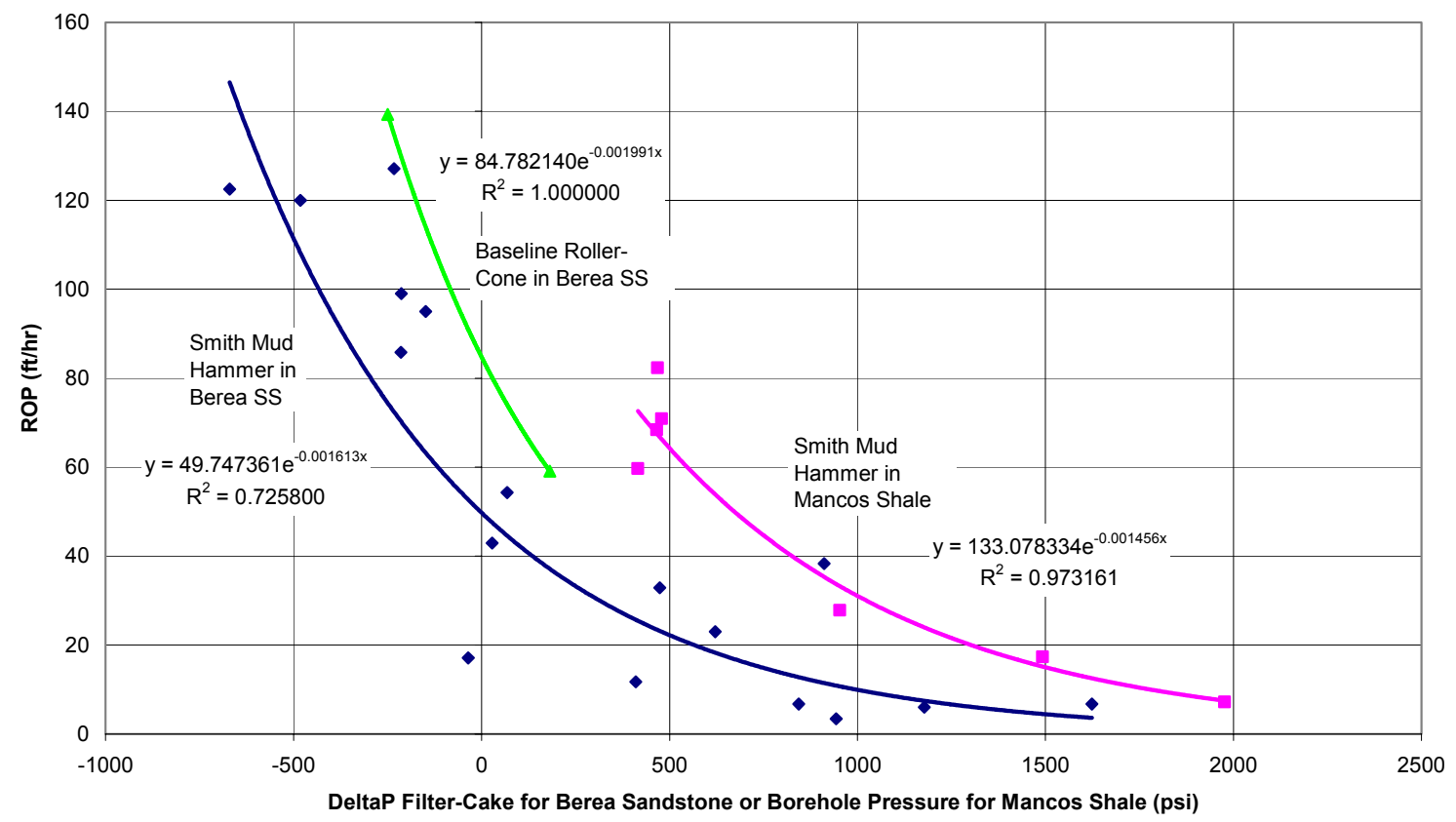

Figure 7-3. ROP data for a hammer drilling in Berea Sandstone and Mancos Shale, and for a baseline roller-cone Bit in Berea Sandstone

\subsection{Cuttings Transport and Mud Circulation}

With fluid dynamics coupled with particle mechanics, cuttings transport is investigated both at macroscopic and microscopic levels. Fluid dynamics is coupled with particle mechanics so that not only macroscopic fluid behavior but the effect of solid particles on mud flow at microscopic level can be described either as a Newtonian or non-Newtonian, laminar or turbulent flow.

There are numerous factors related to cuttings transport such as pump rate, fluid viscosity (currently Newtonian rheology active), density, particle shape and mass, rotation rate, penetration rate, type of flow regime, etc. It is well known that an increase of mud circulation rate and/or increased mud viscosity can lead to improvement of cuttings transport efficiency. However, the effect of pipe rotation is also important. The rotation of the pipe is mainly found to mix the cuttings with mud into a homogenous fluid for efficient cuttings circulation. Without enough entry speed, i.e. mud circulation rate, most cuttings will fall down to the bottom of the annulus after a short lift, due to the effect of 
gravity. One big advantage of this simulation tool is to three-dimensionally visualize and quantify, with the presence of pipe rotation, how efficient mud circulation could be to remove drilling cuttings, and therefore to setup operation guidelines for field engineers.

\subsection{Recommendations for Future Research}

The developments documented above significantly advance the fundamental understandings of the physical mechanisms involved in percussive-rotary drilling, and thereby may facilitate more efficient and lower cost drilling and exploration of hard-rock reservoirs.

Realizing the complexity of percussion drilling, however, we recommend to further study the following issues that are critical to the drilling simulations.

\section{For Simulation Work}

First, investigate rock compaction phenomenon due to cyclic loading on the same location. A rock strength/modulus enhancement model needs to develop based on lab data, along with rock weakening model for porous rock.

Secondly, develop a more complete constitutive equation for rock failure to include rotation of principal axis during impact.

Lastly, include a real 3D hammer tool module with manufacture specifications of hammer pressure and operations. The tool module is expected to couple with the rock module in a way that it provides impact velocity/force for rock module input and receives resistance to slow down the impact. The operation specifications and hammer internal structure have to be specified in order to carry out the modeling efforts.

\section{$\underline{\text { For Lab Test }}$}

Mancos shale used in the tests is strong but friable, which exhibits little ductile behavior that typical shale usually does. Because of friable layers, the shale is more easily failed in tension, which has been confirmed by cuttings collected after the tests. This may partially explain why mud hammer performs better in Mancos 
shale than in Berea sandstone. For future research, typical ductile shale is recommended to investigate hammer performance and explain why, in reality, mud hammer generally performs poorly in shale formations.

Besides choosing more typical shale as testing material, we recommend to further investigate the effect of pore pressure in the shale. To saturate low permeability shale, weeks or even months are needed. Due to the time constraints on saturating the shale samples, the pore pressure in Mancos shale has not been elevated to the insitu conditions. When hammer impacts the rock, the pore space is squeezed so that the fluid pressure may increase. This is particularly the case around the bitrock contacts. The increased pressure may reduce the impact force and help to push the rock into the wellbore, facilitating the rock tensile failure to a great extent when the bit retreats.

Currently, the load measurement is at the bit tip while the displacement is at the top (two feet away). Due to the complex geometry of the rod, it is very challenging to relate displacement with load so that the energy level, defined by the load-displacement curve, can be determined. Therefore we recommend load and displacement (or stress and strain) should be measured at the same location in the future single impact tests.

As a promising drilling technology, percussion drilling has been demonstrated in mining and other industries to be capable of drilling fast and efficiently, especially in hard rocks. In oil and gas industries, however, it still faces a lot of challenges even though tremendous improvements and innovations have been achieved within the past two decades. This is mainly because the unique environment hammer is expected to operate, including versatile rock types (e.g. ductile shale), deep depth, high pressure environment, and the existence of mud and fluid. With increasing demand of oil and gas and drilling deep for wells, more efforts and devotions are needed to improve the current hammer capacity and meet the challenges. 


\subsection{Site Visit, Presentations and Publications}

During the course of the project, Terralog has consistently pursued the exposure of the technologies and collaborations with industries, through site visits, presentations at conferences, and publications. The detailed lists are:

1. On Feb. 12, 2004, Dr. Mike Bruno presented at National Energy Technology Lab of Department of Energy in Pittsburgh, PA.

2. In April 2004, TTI received a visit from Prof. Marian Wiercigroch at the University of Aberdeen (UK) to critically review the theoretical development and exchange info in the research.

3. From April 25th to the 27th, 2004, Dr. Gang Han visited TerraTek at Salt Lake City, where Smith Bits carried out a series of full-scale hammer tests. He closely observed two sets of hammer tests with different mud densities and BHPs, gathered laboratory data for PD applications, such as hammer frequency, WOB, RPM, torque on pipe, mud flow rate, etc. He collected cuttings samples from a sandstone and photographed the hammered rock after the tests.

4. On April $27^{\text {th }}, 2004$, Dr. Gang Han attended a 2-hour conference with Mr. Shantanu Swadi and Mr. Justin Scott at Smith Bits; Mr. Sidney Green, Dr. Arnis Judzis, Mr. Alan Black of TerraTek; and Dr. David Pixton at NovaTek. He discussed technical details of and experimental challenges during PD, and presented some TTI simulation results with positive and useful feedbacks.

5. On June $7^{\text {th }}, 2004$, Dr. Mike Bruno visited and presented at Smith Bits in Houston.

6. From June $28^{\text {th }}$ to Sept. 30, 2004, TTI received a visit from a PhD student, Mr. Joe Emans, from the University of Aberdeen (UK), for working on dynamic modeling of percussion drilling.

7. On Oct 14, 2004, Dr. Mike Bruno visited and presented at National Energy Technology Lab of Department of Energy in Morgantown, WVa.

8. Nov. 17, 2004, Dr. Mike Bruno and Dr. Arnis Judzis (of TerraTek) convened a colloquium on percussion drilling and single cutter impact tests in Houston 
with invited guests from industry asked to provide observations and suggetions on the projects and industry's interests in the project.

9. In Dec. 2004, Dr. Mike Bruno published a paper, Advanced Simulation Technology for Combined Percussion and Rotary Drilling and Cuttings Transport, at GasTips. The full reference is: Bruno, M., Han, G.,and Honeger, C., Winter 2004. Advanced Simulation Technology for Combined Percussion and Rotary Drilling and Cuttings Transport, GasTips, 11(1): 5-8.

10. On Feb. $16^{\text {th }}$, 2005, Dr. Gang Han visited TerraTek, gathered the single impact data from previous tests on Carthage Marble and Crab Orchard sandstones. Discussions with Mr. Sidney Green, Dr. Arnis Judzis, and Mr. Alan Black helped to start the single impact simulations.

11. In April 2005, Dr. Gang Han presented a paper, Percussion Drilling in Oil Industry: Review and Rock Failure Modeling, at 2005 AADE National Technical Conference \& Exhibition in Houston, Texas. The full reference of the paper is: Han, G., Bruno, M., and Lao, K., April 2005. Percussion drilling in oil industry: review and rock failure modeling, AADE-05-NTCE-59, 2005 AADE National Technical Conference \& Exhibition, Houston, TX.

12. In June 2005, Dr. Gang Han presented a paper, Dynamically Modelling Rock Failure in Percussion Drilling, at the annual symposium of American Rock Mechanics Association in Anchorage, Alaska. The full reference is: Han, G., Bruno, M., and Dusseault, M.B., Jun 25-29, 2005. Dynamically modelling rock failure in percussion drilling, ARMA/USRMS 05-819, The 40th US Rock Mechanics Symposium, Anchorage, Alaska, USA.

13. From Jul. $17^{\text {th }}$ to $22^{\text {nd }}$, Dr. Gang Han visited TerraTek and witnessed the full scale hammer drilling tests and part of the single impact tests. He met with Mr. Tim Grant at Department of Energy; Mr. Lance Underwood and Mr. Shantanu Swadi at SmithBits; and Mr. Sidney Green, Dr. Arnis Judzis, and Mr. Alan Black from TerraTek.

14. From Aug. $22^{\text {nd }}$ to Aug. $23^{\text {rd }}$, Dr. Gang Han visited TerraTek and witnessed the remaining single impact tests, along with Dr. William Thomas, Dr. Rao Bangaru, and Dr. Michael Luton from ExxonMobil. He also presented to the 
industry the current status and modeling efforts at a joint meeting following the tests.

15. On April 19, 2006, Dr. Gang Han presented the final report to Department of Energy at Morgantown, WV.

16. In June, 2006, Dr. Gang Han will present a technical paper, Lab Investigations of Percussion Drilling: from Single Impact to Full Scale Fluid Hammer, at 2006 ARMA, held at Colorado School of Mines. Paper \#ARMA962.

17. In Dec. 2006, Dr. Gang Han will present a technical paper, Percussion Drilling: from Lab Tests to Dynamic Modeling at the SPE International Oil \& Gas Conference and Exhibition in China, SPE 104178.

\subsection{The Deliveries}

Along the path of this project, TTI has delivered three types of reports to DOE based on the contract requirements: Quarterly Technical Reports, Project Status Reports (Form DOE F 4600.6), and Financial Status Report (Form 269A). More specifically,

\subsubsection{Quarterly Technical Reports}

Eight quarterly/monthly technical reports have been generated and submitted.

$\begin{array}{lll}\text { Title } & \text { Period } & \text { Pages } \\ \text { 41999R01.doc } & \text { Jan. 01, 2004 to Mar 31, 2004 } & 82 \\ \text { 41999R02.doc* } & \text { April 01, 2004 to April 31, 2004 } & 4 \\ \text { 41999R03.doc* } & \text { May 01, 2004 to May 31, 2004 } & 3 \\ \text { 41999R04.doc } & \text { July 01, 2004 to Sept 30, 2004 } & 57 \\ \text { 41999R05.doc } & \text { Oct 01, 2004 to Dec 31, 2004 } & 39 \\ \text { 41999R06.doc } & \text { Jan 01, 2005 to Mar 31, 2005 } & 23 \\ \text { 41999R07.doc } & \text { April 01, 2005 to Aug 31, 2005 } & 63 \\ \text { 41999R08.doc } & \text { Jan 01, 2004 to Sept 30, 2005 (this report) } & 101 \\ \text { *: Monthly updates } & & \end{array}$




\subsubsection{Project Status Reports}

Seven quarterly reports on project status have been generated and submitted.

Percussion_4600_6_033104.doc Jan 01, 2004 to Mar 31, 2004

Percussion_4600_6_063004.doc April 01, 2004 to June 30, 2004

Percussion_4600_6_093004.doc July 01, 2004 to Sept 30, 2004

Percussion_4600_6_123104.doc Oct 01, 2004 to Dec 31, 2004

Percussion_4600_6_033105.doc Jan 01, 2005 to Mar 31, 2005

Percussion_4600_6_063005.doc April 01, 2005 to June 31, 2005

Percussion_4600_6_093105.doc July 01, 2005 to Sept 31, 2005

\subsubsection{Financial Status Reports}

Eight financial status reports have been generated and submitted.

DOE269A123103.doc

DOE269A033104.doc

DOE269A063004.doc

DOE269A093004.doc

DOE269A123104.doc

DOE269A033105.doc

DOE269A063005.doc

DOE269A093005.doc
Oct 01, 2003 to Dec 31, 2003

Jan 01, 2004 to Mar 31, 2004

April 01, 2004 to June 30, 2004

July 01, 2004 to Sept 30, 2004

Oct 01, 2004 to Dec 31, 2004

Jan 01, 2005 to Mar 31, 2005

April 01, 2005 to June 30, 2005

July 01, 2005 to Sept 30, 2005

\subsubsection{Programs for rock mechanics simulations}

TTI also submitted the 3D numerical tools developed for rock simulation during percussion drilling processes. The package includes two zip folders:

Single_Impacts_3D.zip developed for single indentation simulations; and Hammer_Drilling_3D.zip developed for full scale percussion drilling simulations.

To run the single impact programs, the user needs to: 
1) Unzip all files in the Single_Impacts.zip into one folder. There are a total of 10 files, including three programs (Main.dat, Geom_Var.fish, Hist_Var.dat) and seven result files from the programs (Displ_Match.jpg; Force_Match.jpg; input_2waves.jpg; input_final_load.jpg; Rock_Penetration_3D.jpg; Stress_RockBottom.jpg; Results.sav).

2) Install FLAC3D with dynamic module

3) Open FLAC3D, type "ca Main.dat". It will generate meshes, define variables, apply appropriate boundaries, and execute hammer impacts. At the end of simulation, Results.sav file is generated and saved.

To run the full scale drilling tests, the user needs to:

1) Unzip all files in Drilling_Input.zip into one folder. There are a total of nine files (8 programs, 3D.dat; 3D_Geo_Cyl.dat; Failtest.fish; Fatigue.dat; hist_plot.dat; init_cyl.fish; Main_cyl.dat; numint.fish; and one save file, Geo3D_Cyl.sav)

2) Install FLAC3D with dynamic module

3) Open FLAC3D, type “ca 3D.dat". It will generate geometry, apply loading and boundary conditions, and carry out the simulations. The .sav files in Drilling_Output.zip are the results saved after certain stage of simulations. 


\section{LIST OF ACRONYMS AND ABBREVIATIONS}

$\begin{array}{ll}\text { AADE } & \text { American Association of Drilling Engineers } \\ \text { ARMA } & \text { American Rock Mechanics Association } \\ \text { BHP } & \text { Bottom Hole Pressure } \\ \text { DEM } & \text { Discrete Element Modelling } \\ \text { DOE } & \text { Department of Energy } \\ \text { FEM } & \text { Finite Element Modelling } \\ \text { PD } & \text { Percussion Drilling } \\ \text { PDC } & \text { Polycrystalline Diamond Composites } \\ \text { ROP } & \text { Rate of Penetration } \\ \text { RPM } & \text { Rotation per Minute } \\ \text { TTI } & \text { Terralog Technologies Inc (USA) } \\ \text { UCS } & \text { Uniaxial Compressive Strength } \\ \text { WOB } & \text { Weight on Bit }\end{array}$




\section{REFERENCES}

1. Achenbach, J.D., 1973. Wave propagation in elastic solids, Applied mathematics and mechanics, North-Holland, Amsterdam-London.

2. Akgun, F., Oct 2002. How to estimate the maximum achievable drilling rate without jeopardizing safety, SPE 78567, the $10^{\text {th }}$ Abu Dhabi International Petroleum Exhibition and Conference.

3. Aliabadi, M.H., 2001. Nonlinear Fracture and Damage Mechanics, WIT Press.

4. ANON, 1994. Percussion drilling: how to optimize drill system economy using energy efficiency concepts, Engineering \& Mining Journal, 195(4): 26-29; Oct. 1994, International Journal of Rock Mechanics and Mining Science \& Geomechanics Abstracts, 31(5): 243.

5. Austin, E.H., 1983. Drilling Engineering Handbook, International Human Resources Development Corporation, Boston, USA.

6. Bates, R.E., Oct 1964. Field results of percussion air drilling, SPE 886, the $39^{\text {th }}$ SPE Annual Fall Meeting, Houston, TX, USA.

7. Baumgartner, P., 1982. Rock Breaking and Mechanical Excavation, $14^{\text {th }}$ Canadian Rock Mechanics Symposium, Canadian Institute of Mining and Metallurgy, Vancouver, BC, Canada.

8. Beck, S.M., Haider, H., and Boucher, R.F., 1995. Transmission line modeling of simulated drill strings undergoing water-hammer, Proceedings of the Institution of Mechanical Engineers -C- Journal of Mechanical Engineering Manufacture, 209(6): 419-427.

9. Black, A.D., et al., Sept. 8- 22, 1977. Drillability of sandstone and dolomite at simulated depths, the ASME Petroleum Division Conference, Houston, TX, USA.

10. Boehler, J.P., 1993. Failure Criteria of Structured Media, A. A. Balkema, Rotterdam, the Netherlands.

11. Bourgoyne, A.T., Chenevert, M.E., Milheim, K.K., and Young Jr., F.S., 1991. Applied Drilling Engineering, SPE textbook series, vol 2.

12. Bridges, P.S., McGann, C., and Hall, D.J., Comparison of results from diamond and percussion drilling at Abu Marawat, Egypt, Trans Inst Min Metall (Sect A Min Ind) V99, May-Aug 1990, PA98-A104, International Journal of Rock Mechanics and Mining Science \& Geomechanics Abstracts, 28(2-3), May 1991, Page A100.

13. Bui, H., Apr 1995. Steerable percussion air drilling system, DOE contractor review meeting, Baton Rouge, USA.

14. Chakvetadze, G., and Stepin, A., 1999. On dynamical model of drilling wells, International Journal of Bifurcation and Chaos, 9(9): 1705-1718.

15. Cheatham, J.B. Jr., 1977. The state of knowledge of rock/bit tooth interactions under simulated deep drilling conditions, TerraTek report. 
16. Cheatham, J.B. Jr., Dec. 1963. Rock-bit tooth friction analysis, SPE 748. Society of Petroleum Engineering Journal, 327-333.

17. Cheng, H.B., 1994. Continuum damage theory for geomaterials and its application to coupling in transport processes, Ph.D thesis, University of Waterloo.

18. Chien, S., 1992. Settling velocity of irregularly shaped particles, SPE 26121.

19. Chilingarian, G.V., and Vorabutr, P., Drilling and Drilling Fluids, Development in Petroleum Science 11, Elsevier Scientific Publishing Company.

20. Cho, H., Shah, S.N., Osisanya, S.O., 2002. A three-segment hydraulic model for cuttings transport in horizontal and deviated drilling, Journal of Canadian Petroleum Technology, 41(6): 32-39.

21. Civan, F., and Engler T., 1994. Drilling mud filtrate invasion - improved model and solution, J Petro Sci \& Eng, 11: 183-193.

22. Clark, G.B., 1987. Principles of Rock Fragmentation, John Wiley \& Sons.

23. Cook, N.G.W., 1982. Wear on drag bits in hard rock, Rock Breaking and Mechanical Excavation, CIM (Canadian Institute of Mining and Metallurgy) Special volume 30, Vancouver, BC, Canada, 39-43.

24. Cornet, F.H., 1987. Results from Le Mayet de Montagne project, Geothermics, 16(4): 355-374.

25. Cunningham, R.A., and Eenink, J.G., Jan. 1959. Laboratory study of effect of overburden, formation, and mud column pressure on drilling rate of permeable formations, J. Pet. Tech. 9-17. Trans., AIME, 204.

26. Davis, J.L., 1988. Wave propagation in solids and fluids, Springer-Verlag New York Inc., New York, USA.

27. Deily, F.H., and Durelli, A.J., Oct. 5-8, 1958. Bottom hole stress in a well bore, SPE 1095. the SPE Annual Meeting, Houston, TX, USA.

28. Demou, S.G., Olson, R.C., and Wingquist, C.F., 1983. Determination of Bit Forces Encountered in Hard Rock Cutting for Application to Continuous Miner Design, Report of Investigations 8748, United States Department of the Interior and Bureau of Mines.

29. Dewan, J.T., and Chenevert, M.E., May-Jun 2001. A model for filtration of waterbased mud during drilling: determination of mudcake parameters, Petrophysics, 42(3): 237-250.

30. Ema, S., Fujii, H., and Marui, E., Nov 1988. Chatter vibration in drilling, Transactions of the ASME, Journal of Engineering for Industry, 110: 309-314.

31. Ema, S., Fujii, H., and Marui, E., 1988. Whirling vibration in drilling. Part 3: Vibration analysis in drilling workpiece with a pilot hole, Transactions of the ASME, Journal of Engineering for Industry, 110: 315-321.

32. Faihust, C., and Lacabanne, W.D., 1956. Some principles and developments in hard rock drilling techniques, Proc. $6^{\text {th }}$ Ann. Drilling and Blasting Symposium, Minnesota Uni., 15-25. 
33. Finger, J.T., Oct 1981. Investigation of percussion drills for geothermal applications, SPE 10238, the $56^{\text {th }}$ SPE Annual Fall Technical Conference and Exhibition, San Antonio, TX, USA.

34. Fish, B.G., Feb 1961. Research in rock drilling and tunneling, Min. Elect. Mech. Engr, 1-13.

35. Fish, B.G., and Barker, J.S., 1956. Studies in rotary drilling, National Coal Board, MRE Rep. No. 209.

36. Fujii, H., and Marui, E., Ema, S., Aug 1986. Whirling vibration in drilling. Part 1: Cause of vibration and role of chisel edge, Transactions of the ASME, Journal of Engineering for Industry, 108: 157-162.

37. Fujii, H., and Marui, E., Ema, S., Aug 1986. Whirling vibration in drilling. Part 2: Influence of drill geometries, particularly of the drill flank, on the initiation of vibration, Transactions of the ASME, Journal of Engineering for Industry, 108: 163168.

38. Furby, J., 1964. Strain wave behaviour in the percussive drilling process, Trans. Inst. Min. Metall., 73: 393-413.

39. Gatlin, C., 1960. Petroleum Engineering, Prentice-Hall, London, UK.

40. Giles, C.A., Seesahai, T., Brooks, J.W., and Johnatty, W., Mar 2001. Drilling efficiencies provided by hydraulic thrusting devices, the AADE 2001 National Drilling Conference, Houston, Texas, USA.

41. Gnirk, P.F., and Cheatham, J.B. Jr., Dec. 1969. A theoretical description of rotary drilling for idealized down-hole bit/rock conditions, SPE 2243, Society of Petroleum Engineering Journal, 443-451.

42. Gnirk, P.F., and Musselman, J.A., Sept. 1967. An experimental study of indexed dull bit-tooth penetration into dry rock under confining pressure. SPE 1712, Journal of Petroleum Technology.1225 - 1234.

43. Gnirk, P.F., and Cheatham, J.B. Jr., Jun. 1965. An experimental study of single bittooth penetration into dry rock at confining pressure 0 to 5,000psi. SPE 1051. Society of Petroleum Engineering Journal, 117-131.

44. Graf, L.E., and Kogan, D.I., 1972. Hydro-percussion machines and tools, Nedra, Moscow, Russia.

45. Green, S., Judzis, A., Curry, D., Black, A., and Prasad, U., and Rogers, J., Oct. 9-12, 2005. Single cutter impact tests investigate deep-well hammer-drilling performance. SPE 97173. the SPE Annual Technical Conference and Exhibition, Dallas, TX, USA.

46. Haimson, B.C., 1978. Effect of cyclic loading on rock, Dynamic Geotechnical Testing, ASTM STP 654, American Society for Testing and Materials, 228-245.

47. Harpst, W.E., and Davis, E.E., Mar 17, 1949. Rotary percussion drilling, Oil and Gas Journal, 182-187.

48. Hartman, H.L., 1959. Basic studies of percussion drilling, Trans. Am. Inst. Min. Engrs, 214: 68-75. 
49. Hartman, H.L., Jun 1963. The simulation of percussion drilling in the laboratory by indexed-blow studies, SPE 500, SPE Journal, 214-226.

50. Hartman, H.L., Nov 1966. The effectiveness of indexing in percussion and rotary drilling, International Journal of Rock Mechanics and Mining Science \& Geomechanics Abstracts, 3(4): 265-278.

51. Heisig, G., and Neubert, M., 1996. Mathematical description of the directional drilling process and simulation of directional control algorithm, ZAMM - Zeitschrift fur Angewandte Mathematik und Mechanik, 76(supp.5): 361-362.

52. Howarth, D.F., Aug 1987. The effect of pre-existing microcavities on mechanical rock performance in sedimentary and crystalline rocks, International Journal of Rock Mechanics and Mining Science \& Geomechanics Abstracts, 24(4): 223-233.

53. Hustrulid, W.A., and Fairhurst, C., Jul 1971. A theoretical and experimental study of the percussive drilling of rock part I--theory of percussive drilling, International Journal of Rock Mechanics and Mining Science \& Geomechanics Abstracts, 8(4): 311-333.

54. Hustrulid, W.A., and Fairhurst, C., May 1972. A theoretical and experimental study of the percussive drilling of rock Part IV--application of the model to actual percussion drilling, International Journal of Rock Mechanics and Mining Science \& Geomechanics Abstracts, 9(3): 431-442.

55. Jorden, J.R., and O.J. Shirley, 1966. Application of drilling performance data to overpressure detection, JPT: 1387-1394

56. Keith, S.E., Brammer, A.J., Jul 1994. Rock drill handle vibration: measurement and hazard estimation, Journal of Sound and Vibration, 174(4): 475-491.

57. Kolle, J.J., 1993. A model of dynamic confinement during drilling in pressurized boreholes, Int J Rock Mech Min Sci \& Geomech Abstr, 30(7): 1215-1218.

58. Kong, J., Marx, C., Palten, P.J ., 1996. Mathematical simulation of a spring-free hydraulic drilling hammer and verification of the results by experiment, Erdol Erdgas Kohle, 112(1): 19-25.

59. Krajcinovic, D., and Lemaitre, J.,1987. Continuum Damage Mechanics - Theory and Applications, Springer Verlag Wien - New York.

60. Larson, D.A., and Olson, R.C., Apr 1977. Design considerations of mechanical fragmentation systems for entry development in oil shale. Proc. $10^{\text {th }}$ Oil Shale Symp., Colorado School of Mines Press, Golden, CO, USA, 99-119.

61. Leighton, J.C., 1982. Predicting power factors from rotary drill performance for controlled blasting, Rock Breaking and Mechanical Excavation, CIM (Canadian Institute of Mining and Metallurgy) Special volume 30, Vancouver, BC, Canada, 1924.

62. Leonard, R., 2001, Features - groundwater development - tough down hole drilling demands expand bit options: Ralph Leonard of Numa explains drill bit options for down hole percussion drilling applications, Water and Wastewater International, $16(2): 17$. 
63. Iyoho, A.W., Horeth II, J.M., and Veenkant, R.L., Sept 1987. A computer model for hole cleaning analysis, SPE 16694, the SPE Annual Technical Conference, Dallas, TX, USA.

64. Maurer, W.C., Nov 1962. The "perfect-cleaning" theory of rotary drilling, J. Pet. Tech., 1270-1274, Trans. AIME, 225.

65. Maurer, W.C., Nov. 18, 1964. Shear failure of rock under compression. SPE 1054, SPE-U of Texas Conference on Drilling and Rock Mechanics.

66. Maurer, W.C., Dec. 1965. Bit tooth penetration under simulated borehole conditions, J. Pet. Tech., 1433-1442. Trans. AIME, 234.

67. McCarthy, D., 1982. Percussive drilling economics - a function of productivity and reliability, Rock Breaking and Mechanical Excavation, CIM (the Canadian Institute of Mining and Metallurgy) Special volume 30, Vancouver, BC, Canada, 44-50.

68. McGregor, K., 1967. The Drilling of Rock, CR Books Ltd., London.

69. McMillin, K., Nov 1999. Fluid hammer tool improves directional steering performance, Offshore 53

70. Meehan, R., Nutt, L., Dutta, N., Menzies, J., May 1998. Case histories show real-time information reduces uncertainty, Oil and Gas Journal: 55-59.

71. Melamed, Y., Kiselev, A., Gelfgat, M., Dreesen, D., and Blacic, J., 2000. Hydraulic hammer drilling technology: developments and capabilities, Journal of Energy Resources Technology, 122(1):1-8.

72. Minear, J.W., Heysse, D.R., Boonen, P.M., 1996. Initial results from an acoustic logging-while-drilling tool, SPE 36543.

73. Miller, T.W., and Cheatham, J.B. Jr., Jun. 1971. Rock/bit-tooth interaction for conical bit teeth, SPE 3031, Society of Petroleum Engineering Journal, 162-171.

74. Mody, F.K., and Hale, A.H., 1993. Borehole-stability model to couple the mechanics and chemistry of drilling-fluid/shale interactions, Journal of Petroleum Technology, 45(11): 1093-1101.

75. Muro, T., 1988. Drilling rate of rotary percussion drill bits and rock characteristics, Journal of Terramechanics, 25(3): 191-199.

76. Myers, G.M., and Gray, K.E., Jun. 1968. Rock failure during tooth impact and dynamic filtration, SPE 1862. SPE Journal, 163-74.

77. Ng, G.K.L., and Li, L., Jan 2003. Repeatability characteristics of laser percussion drilling of stainless-steel sheets, Optics and Lasers in Engineering, 39(1): 25-33.

78. Paul, B., and Gangal, M.D., 1969. Why compressive loads on drill bits produce tensile splitting in rock, SPE 2392.

79. Palmov, V, 1996. A mathematical model for dynamical simulation of deep drilling, ZAMM - Zeitschrift fur Angewandte Mathematik und Mechanik, 76(supp.5): 371372. 
80. Pariseau, W.G., and Fairhurst, C., Apr 1967. The force-penetration characteristic for wedge penetration into rock, International Journal of Rock Mechanics and Mining Science \& Geomechanics Abstracts, 4(2): 165-180.

81. Pérez-Téllez, C., Smith, J.R., and Edwards, J.K., Sept 2003. A new comprehensive mechanistic model for underbalanced drilling improves wellbore pressure predictions, SPE Drilling and Completion, 18(3): 199-208.

82. Pixton, D., and Hall, D., 1995. A new-generation mud-hammer drilling tool annual report, DOE project DE-FG03-95ER82042, Novateck Inc., Provo, UT, USA.

83. Pixton, D.S., and Hall, D.R., Feb 1998. A rotary percussive drilling engine, Proceedings of the 1998 ASME Energy Sources Technology Conference, Houston, TX, USA.

84. Pixton, D., and Hall, D., 2002. Advanced mud hammer systems, DOE project \#DEFC26-97FT34365, Novateck Inc., Provo, UT, USA.

85. Podio, A., and Gray, K.E., Sept. 1965. Single-blow bit-tooth impact tests on saturated rocks under confining pressure: I. zero pore pressure. SPE 1056. SPE Journal, 211-225.

86. Pratt, C.A., Mar 1987. Modifications to and experience with percussion air drilling, SPE/IADC 16166, the SPE/ IADC Drilling Conference, New Orleans, LA, USA.

87. Pratt, C.A., Dec 1989. Modifications to and experience with air-percussion drilling, SPE Drilling Engng, 4(4): 315-320; Aug. 1990, International Journal of Rock Mechanics and Mining Science \& Geomechanics Abstracts, 27(4): 231.

88. Pruitt, J., Goldman, W., and Claudey, E, 2002. Software program offers predictive capability to optimize drilling - A rock mechanics model has proven itself in test wells and in drilling of a target formation and hard limestone section in the North Sea's Oseberg field, World Oil, 223(4): 77-99.

89. Putot, C.J.M., Guesnon, J., and Perreau, P.J., Constantinescu, A., Jun 2000. Quantifying drilling efficiency and disruption: field data vs. Theoretical model, SPE Drilling and Completion, 15(2): 118-125.

90. Rabinowicz, E., 1965. Friction and Wear of Materials, New York, Wiley.

91. Ramirez, J., Geraud, M., Salazar, V., Algate, G., Mar. 25-28, 2001. Fluid percussion drilling in deep hard rock in Eastern Venezuela, SPE 69520, the SPE Latin American and Caribben Petroleum Engineering Conference, Buenos Aires, Argentina.

92. Reichmuth, D.R., 1963. Correlation of force-displacement data with physical properties of rock for percussive drilling systems. Proceedings of Fifth Symposium of Rock Mechanics, Ed. By Fairhurst, C., University of Minnesota, Pergamon, 33-61.

93. Reinsvold, C.H., Clement, J., Oliver, M., Witt, C., and Crockett, J., Feb. 28 - Mar. 2, 1988. Diamond-enhanced hammer bits reduce cost per foot in the Arkoma and Appalachian basins. IADC/SPE 17185, the IADC/SPE Drilling Conference, Dallas, TX, USA. 
94. Reichmuth, D.R., 1962. Correlation of force-displacement data with physical properties of rock for percussive drilling systems, Proc. of the Fifth Symposium on Rock Mechanics, U. of Minnesota, USA, 33-59.

95. Roberts, A., 1981. Applied Geotechnology - A Text for Students and Engineers on Rock Excavation and Related Topics, Pergamon Press.

96. Robinson, L.H., and Ramsey, M.S., Mar 2001. Are you drilling optimized or spinning your wheels? the AADE 2001 National Drilling Conference, Houston, Texas, USA.

97. Rossmanith, H.P., Knasmillner, R.E., Daehnke, A., Mishnaevsky Jr, L., 1996. Wave propagation, damage evolution, and dynamic fracture extension part I. percussion drilling, Materials Science, 32(3): 350-359.

98. Saada, A.S., 1974. Elasticity theory and applications, Pergamon Press Inc.,

99. Samuel, G.R., Mar 1996. Percussion drilling... is it a lost technique? a review., SPE 35240, the Permian Basin Oil \& Gas Recovery Conference, Mildland, TX, USA.

100. Sandvik Rock Tools, 1994. Percussion drilling - optimizing drill system economy using energy efficient concepts, Engineering and Mining Journal. 195(4): 26-32.

101. Sewell, M., and Billingsley, J., 2002. An effective approach to keeping the hole clean in high-angle wells - Basic application of weighted sweeps, design model applications and effects of viscosity, rotation speed and drillstring sliding in high-angle wells, World Oil, 223(10): 35-39.

102. Simon, R., Dec. 1963. Energy balance in rock drilling, Soc. Pet. Eng. J., 298-306; Trans. AIME, 228.

103. Simon, R., 1964. Transfer of stress wave energy in the drill steel of a percussive drill to the rock, Journal of Rock Mechanics and Mining Science.

104. Singleton, D., and Correll, T., 1994. Percussion hammer method of drilling, Water Well Journal. 48(10): 71-73.

105. Smellie, J.A.T., Wikberg, P., Aug 1991. Hydrochemical investigations at Finnsjön, Sweden, Journal of Hydrology, 126(1-2): 129-158.

106. Smith, F.W., and Kopczynksi, W., Nov 1961. Oilfield percussion drilling, SPE 222, the $32^{\text {nd }}$ Annual California Regional Meeting of SPE, Bakerfield, CA, USA.

107. Somerton, W.H., Timur, A., and Gray, D.H., Oct. 8-11, 1961. Stress behavior of rock under drilling loading conditions. SPE 166, the $36^{\text {th }}$ SPE Annual Fall Meeting, Dallas, TX, USA.

108. Terekhov, V.M., and Kondratenko, L.A., 1999. On the mathematical model of deephole drilling, Journal of Machinery Manufacture and Reliability, No.1, 45-50.

109. Tibbitts, G.A., Long, R.C., Miller, B.E., Judzis A., and Black, A.D., Feb 2002. World's first benchmarking of drilling mud hammer performance at depth conditions, IADC/SPE 74540, the IADC/SPE Drilling Conference, Dallas, TX, USA.

110. Timoshenko, S., and Goodier, J.N., 1951. Theory of Elasticity, McGraw-Hill, NY, USA. 
111. Topanelian Jr., 1958. Effect of low frequency percussion in drilling hard rock, AIME - Petroleum Transaction, v213.

112. Treadway, C., 1997. Percussion and down-the-hole hammer drilling: yesterday and today, Water Well Journal, 51(7): 55-59.

113. Van Lingen, N.H., 1962. Bottom scavenging - a major factor governing penetration rates at depth, J. Pet. Tech., 187-196.

114. Wahl, H., Kantenwein, G., Schäfer. W., May-Jun 1961. Verschleiss beim gesteinsbohren (modell-versuche): wear in rock drilling (laboratory tests), Wear, 4(3): 234-245.

115. Walker, B.H., Black, A.D., Klauber, W.P., Little T., and Khodaverdian, M., 1986. Roller-bit penetration rate response as a function of rock properties and well depth, SPE 15620, the $61^{\text {st }}$ ATCE of SPE, New Orleans, USA.

116. Wanamaker, J.A., Sept 1951. Rotary percussion drilling in west texas, World Oil, 182-187.

117. Warren, T.M., and Smith, M.B., 1985. Bottomhole stress factor affecting drilling rate at depth. SPE 13381, J. Pet. Tech., 1523-1533.

118. Wells, M.R., 1989. Dynamics of rock chip removal by turbulent jetting, SPE Drilling Eng., 144-152.

119. Weller, T.F., Baum, G.A., and Muncy, W.H., Oct. 24-27, 1989. Diamond-enhanced hammer bits reduce costs-per-foot and directional problems in southwestern Pennsylvania Oriskany wells. SPE 19335. the SPE Eastern Regional Meeting, Morgantown, West Virginia, USA.

120. Wheeler, J.B., Hoersch, H.M., McGlinchey, E.J., and Mahy, H., 1978. Dynamic Geotechnical Testing, ASTM Special Technical Publication 654, American Society for Testing and Materials.

121. White, C.G., April 1969. A Rock Drillability Index, Quarterly of the Colorado School of Mines, v.61, No.2.

122. Whiteley, M.C., England, W.P., Oct 1986. Air drilling operations improved by percussion-bit/hammer-tool tandem, SPE 13429, SPE Drilling Engineering: 377-382.

123. Williams, C.E., Jr., and Bruce, G.H., 1951. Carrying capacity of drilling fluids, Trans. Soc. Pet. Eng. AIME, 192(3026): 111-120.

124. Wilson, C.C., 2001. Computational rheology for pipeline and annular flow, Butterworth-Heinemann.

125. Yasov, V.G., 1977. The theory and calculations of the hydraulic machines operational processes, Nedra, Moscow, Russia.

126. Yang, J.H., and Gray, K.E., Dec. 1967. Single-blow bit-tooth impact tests on saturated rocks under confining pressure: II. elevated pore pressure. SPE 1702, Society of Petroleum Engineering Journal, 389-409.

127. Zhang, L., Wang, L., and Liu, X., 2001. A mechanical model for predicting critical thrust forces in drilling composite Laminates, Proceedings of the Institution of 
Mechanical Engineers -C- Journal of Mechanical Engineering Manufacture, 215(2): $135-146$.

128. McMillin, K., 1999. Hammer tool improves directional steering - Fluid hammer gives drillstring an extra motion and reduces drill bit tripping in difficult geology, Offshore, 59(11): 53-56. 


\section{APPENDIX A: NUMERICAL PROGRAM FOR SINGLE IMPACT}

(Attached separately) 


\section{APPENDIX B: NUMERICAL PROGRAM FOR HAMMER DRILLING}

(Attached separately) 